\title{
Phylogenetic Relationships in the Lizard Family \\ Pygopodidae: an Evaluation of Theory, Methods and Data
}

By

Arnold G. Kluge

Ann Arbor

MUSEUM OF ZOOLOGY, UNIVERSITY OF MICHIGAN

December 10, 1976 


\title{
MISCELLANEOUS PUBLICATIONS MUSEUM OF ZOOLOGY, UNIVERSITY OF MICHIGAN
}

\author{
FRANCIS C. EVANS, EDITOR
}

The publications of the Museum of Zoology, University of Michigan, consist of two series-the Occasional Papers and the Miscellaneous Publications. Both series were founded by Dr. Bryant Walker, Mr. Bradshaw H. Swales, and Dr. W. W. Newcomb.

The Occasional Papers, publication of which was begun in 1913, serve as a medium for original studies based principally upon the collections in the Museum. They are issued separately. When a sufficient number of pages has been printed to make a volume, a title page, table of contents, and an index are supplied to libraries and individuals on the mailing list for the series.

The Miscellaneous Publications, which include papers on field and museum techniques, monographic studies, and other contributions not within the scope of the Occasional Papers, are published separately. It is not intended that they be grouped into volumes. Each number has a title page and, when necessary, a table of contents.

A complete list of publications on Birds, Fishes, Insects, Mammals, Mollusks, and Reptiles and Amphibians is available. Address inquiries to the Director, Museum of Zoology, Ann Arbor, Michigan 48109. 
Phylogenetic Relationships in the Lizard Family

\section{Pygopodidae: an Evaluation of Theory, Methods and Data}

By

Arnold G. Kluge

Ann Arbor

MUSEUM OF ZOOLOGY, UNIVERSITY OF MICHIGAN

December 10, 1976 



\section{CONTENTS}

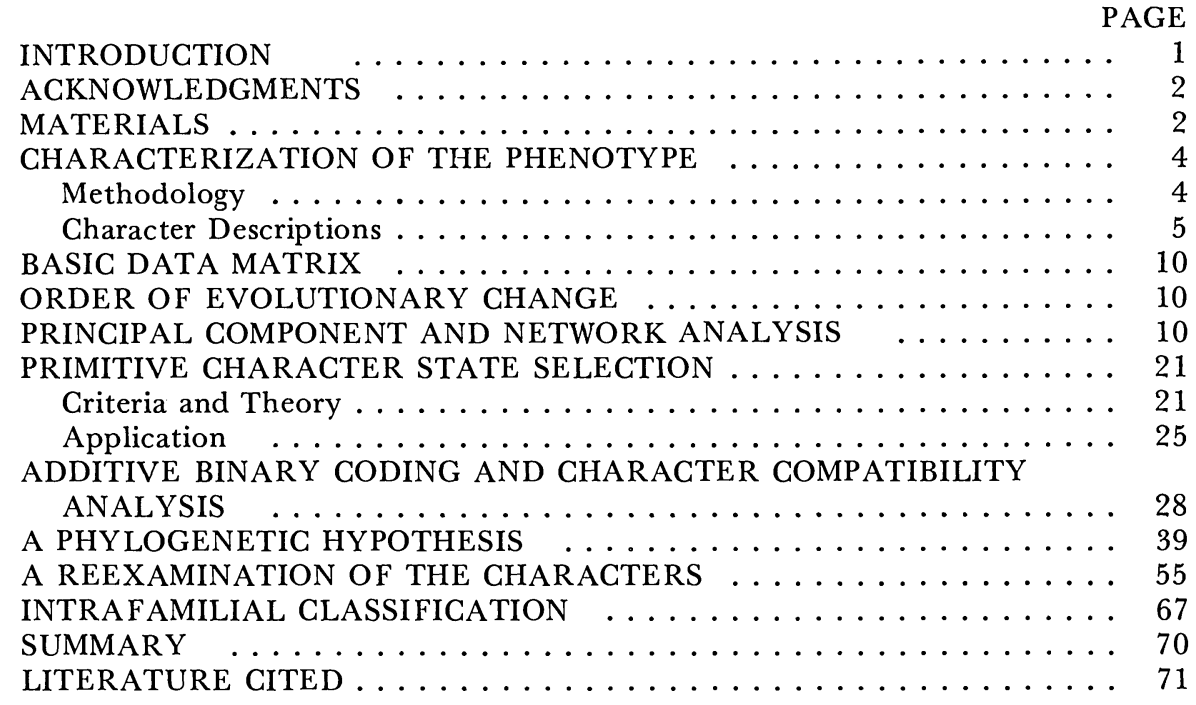




\section{ILLUSTRATIONS}

FIGURE

PAGE

1. Principal component I plotted against II and III $\ldots \ldots \ldots \ldots 17$

2. Principal component I plotted against IV and V . . . . . . 17

3. Prim network cluster analysis of pygopodids

described by osteological characters ............ 20

4. Wagner network cluster analysis of pygopodids described by osteological characters ............ 20

5. Hypothetical phylogenetic history of three groups

of evolutionary species $\ldots \ldots \ldots \ldots \ldots \ldots \ldots$

6. Hypothesis of cladistic ancestry of the Pygopodidae . . . . . . . 24

7. Minimum length trees based on largest cliques in

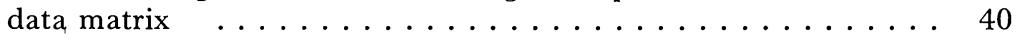

8. Phylogenetic hypothesis of pygopodid species based

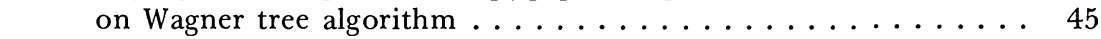

9. Phylogenetic hypothesis of pygopodid species with

distortion of patristic estimate

10. Ventral views of pectoral girdle in selected

pygopodids $\ldots \ldots \ldots \ldots \ldots \ldots \ldots \ldots \ldots \ldots$

11. Three possible hierarchic classifications of pygopodids 


\section{INTRODUCTION}

The lizard family Pygopodidae is endemic to Australia and New Guinea and according to the usually accepted classification it is the only family of lower tetrapods restricted to the Australian Region. Savage's (1973) reclassification of anuran amphibians might provide two exceptions to this zoogeographic generalization, but his proposal is not widely accepted (O. Sokal, 1975). Pygopodids are known throughout mainland Australia and on many of its offshore islands. Members of the family do not occur on Tasmania and they appear to be absent from elevations above $1200 \mathrm{~m}$ in the Great Dividing Range. Pygopodids are probably widely distributed in New Guinea although known localities are few in West Irian. The highest record in New Guinea is about $1500 \mathrm{~m}$ and they have been collected as far west as the Vogelkop Peninsula. Pygopodids probably occur on New Britain as well. Several species are abundant in the most arid deserts of Australia, enviroments receiving less than $12.7-25.4 \mathrm{~cm}$ mean annual rainfall, and at least one species is common in the habitat classified as rain forest, which receives about $254 \mathrm{~cm}$ mean annual rainfall. A few species are predominately fossorial; the majority live on the surface of the ground or in low shrubs and grass tussocks of the genus Triodia. Almost all species are crepuscular to nocturnal but one appears to be active at any time of the day and night. Inactive individuals are found in spider burrows and natural cracks in the ground, particularly beneath rocks and among plant roots. Most species feed on a wide variety of arthropods although some are restricted to ants. Two species are lizard-eating specialists, and they apparently prefer small slender skinks. Many pygopodids emit low buzzing and rattle-like sounds when disturbed. All species appear to lay two elongate leathery eggs per clutch.

Pygopodids are serpentine in appearance, and they are often mistaken for elapid snakes. The remnants of the forelimb, if present at all, never protrude beyond the external body surface. The hindlimbs are well-developed paddle-like appendages in some species, but they are reduced externally to a single scale in others. Males have slightly longer tails and shorter snout-vent lengths than females. Tail length varies among pygopodid species from 0.5 to 4.3 times the snout-vent length. External ear openings may be absent, and the head scalation exhibits considerable interspecific variation. Body scales are large, cycloid and imbricate; they are smooth or possess either single or double keels. Earth colors predominate on the head and body; the extremes in life are lemon yellow and gray-black. Head bands and body stripes are common in the family, and the tail may be brightly colored, although it usually tends to be reddish. Considerable ontogenetic change in color pattern has been observed. 
Pygopodids appear to be more closely related to gekkonid lizards than to any other known saurian family. Unlike pygopodids, gekkonids invariably have well-developed limbs and, with few exceptions, small, juxtaposed body scales. Thirty species and seven genera of pygopodids are currently recognized (Kluge, 1974). Most species are easily identified by their external scalation, proportions and color pattern but very little is known of intraspecific geographic variation and inter- and intrageneric relationships. The primary purpose of this paper is to identify objectively groups of species based on a large number of characters. The second purpose is to discover the most probable phylogenetic relationships among the groups and use these as the basis of a higher classification. The nature of the data analyzed has required a critical review of some phylogenetic theory and methods of inference.

\section{ACKNOWLEDGMENTS}

Many people and institutions have provided me with invaluable advice, companionship in the field, and the use of material in their care during my several years of study of the Pygopodidae. I particularly appreciate the gift and loan of skeletons used in the present study. These were provided by G. Foley and R. Zweifel of the American Museum of Natural History, New York; H. Cogger of the Australian Museum, Sydney; H. Marx of the Field Museum of Natural History, Chicago; A. Coventry and J. M. Dixon of the National Museum of Victoria, Melbourne; E. Pianka of the University of Texas, Austin; J. Savage of the University of Southern California, Los Angeles; G. Zug and the late J. Peters of the United States National Museum, Washington. I also wish to thank J. S. Farris of State University of New York, Stony Brook for his advice on quantitative phylogenetic methods and for computer programming assistance.

My research on pygopodid lizards has been supported financially by the National Science Foundation (GB-8209), John Simon Guggenheim Memorial Foundation (1971-2), American Philosophical Society (4902), and University of Michigan.

\section{MATERIALS}

The species identifications are those of Kluge (1974). The following is a list of the cleared and stained and dermestid beetle-prepared skeletons used in this study. The specimens are listed according to university catalog number and, where known, the snout-vent length in millimeters and sex are given in parentheses. Those numbers followed by an asterisk are paratypes. 
Aprasia

aurita-UMMZ 131224* (107.0, female).

parapulchella-UMMZ 131157* (106.5, male), 131193* (122.0, female).

pulchella-UMMZ 131235 (88.5, female).

pseudopulchella-UMMZ 131208* (111.2, female), 131210* (102.0, male).

repens-UMMZ 129978-9, 137573.

striolata-UMMZ 131176 (125.5, female), 131180 (102.0, male).

Delma

australis-UMMZ 84309 (59.5, male).

fraseri-FM 11348; JMS 671 (107.0, female), 676-7, 682 (96.8);

UMMZ 137576.

impar-UMMZ 129982-3, uncat.

inornata-UMMZ 131155*, (124.3, female), 131161* (77.0, male).

molleri-AMNH 24850, 24852

nasuta-UMMZ 130001 (54.7, female), 131206* (73.5, female). tincta-UMMZ 131237 (82.0, male).

\section{Lialis}

burtonis-AMNH 20883; JMS 670 (136.0), 674-5, 680, 684, 686; UMMZ S-2822, 131149-51, 131154, 131190, uncat. jicari-UMMZ 131189 (265.0, female).

\section{Pletholax}

gracilis-UMMZ 131215 (72.0, female), 131232 (60.5, male).

Pygopus

lepidopodus-UMMZ 129981, 137575; USNM 56234.

nigriceps-AMNH 32851; UMMZ 129980, 129984-5, 137574.

Over 2000 pygopodids were x-rayed and these were used to confirm and expand the limits of the variation observed in the cleared and stained and dermestid beetle-prepared skeletons. All x-ray plates, except those of Ophidiocephalus taeniatus, which are in the National Museum of Victoria, Melbourne, are housed in the Museum of Zoology, University of Michigan. Numerous detailed monoscopic and stereoscopic x-rays of the following individuals were made, and these were the primary source of the osteologic data recorded for those species.

Aclys

concinna-WAM R17312, R41156. 


\section{Ophidiocephalus \\ taeniatus-NMV D11761}

\section{Paradelma \\ orientalis-AM R3463; CAS 77652; QM J14400.}

The meaning of the museum abbreviations and the locality data for the above specimens can be found in Kluge (1974), with the exception of those labled JMS. The JMS material is part of the private osteological collection of Jay M. Savage, University of Southern California, and almost all of his pygopodids are without precise locality data.

\section{CHARACTERIZATION OF THE PHENOTYPE}

\section{Methodology}

I have chosen 86 binary and multistate osteological characters as the data base for my study of pygopodid relationships. These variables were finally selected from a much larger number, well over 100 , because they were the easiest to observe and define, and because of the greater likelihood that their states are homologous. The 86 characters represent all of the major structural regions of the skeletal system. The skeletal system was chosen as the raw data source because it provides numerous relatively conservative characters and because most of the comparable studies of other lizard groups have employed this system. The general descriptions of the characters and the definitions of their states are summarized below. Each character is numbered and this index is used as a standard reference throughout the text and tables. The anatomical terms are defined and exemplified by Kluge (1962) and Stephenson (1962).

A character is a set of phenotypic expressions which are hypothesized to be homologous (Kluge, 1971). Almost all of the 86 characters used in this study are qualitative. The continuous phenotypic variation of the few quantitatively scored characters is transformed to fewer subjectively delimited states to make the span and number of states of all characters more nearly equal. This practice attempts to reduce the differential effect that characters with more numerous states and greater spans have on the measures of similarity between species. The number and size of the intervals is approximately proportionate to the span of the originally observed continuous phenotypic variation.

The numerical value that identifies each state in all characters is one of a continuous array of whole numbers that begins with zero. The basis for the rank order of the states is discussed below (p. 10). The continuous array of whole numbers reflects the hypothesized 
order of evolutionary change. It is impossible to argue that the phenotypic differences, unit character state changes, recognized within and between qualitatively defined characters are equal, or that they are exactly proportionate to the character state numbers (Kluge and Kerfoot, 1973). I can only assume that they are good approximations. The PRIMITIVE CHARACTER STATE SELECTION and the application of ADDITIVE BINARY CODING to these basic data are discussed separately under those subheadings (pp. 21-28, 28-39).

\section{Character Descriptions}

1. Humerus present (0), or absent (1).

2. Midclavicle bone absent (0), or present (1). The midclavicle is the interclavicle of Stephenson (1962).

3. Maximum number of ribs attached to sternum (per side) one or two (0), none (1), or sternum absent (2).

4. Epicoracoids not fused on midline (0), or fused together on midline (1).

5. Coracoid portion of scapulocoracoid wide and emarginate medially, rarely only notched, (0), moderately wide and not emarginate medially (1), or narrow and not emarginate medially (2).

6. Coracoid fenestra present (0), or absent (1).

7. Clavicles articulate on midline, deep and usually with one fenestra (0), articulate on midline and emarginate posteriorly, only part of shelf present (1), articulate on midline and rod-like in appearance (2), do not articulate on midline and rod-like in appearance (3), or absent (4).

8. Number of cloacal bones (per side) in adult males one (0), or two (1).

9. Distal two-thirds of ilium rod-like in profile $(0)$, or strongly blade-like (1).

10. Ischiopubic fenestra large (0), or absent or small, narrow and/or shallow (1).

11. Ischium wider than pubis $(0)$, or equal to or narrower than pubis (1).

12. Internal trochanter of femur strongly developed (0), or weakly developed or absent (1).

13. Tibia present (0), or absent (1).

14. Cuboid and/or tibiofibulare present (0), or absent (1).

15. Second phalangeal series: phalangeal element(s) and metatarsal present (0), phalangeal element(s) absent, metatarsal present (1), or both phalangeal and metatarsal elements absent. The first series of phalangeal elements is believed to be absent in all pygopodids. 
16. Third phalangeal series: phalangeal element(s) and metatarsal present (0), phalangeal element(s) absent, metatarsal present (1), or both phalangeal and metatarsal elements absent (2).

17. Fourth phalangeal series: phalangeal element(s) and metatarsal present (0), phalangeal element(s) absent, metatarsal present (1), or both phalangeal and metatarsal elements absent (2).

18. Fifth metatarsal present (0), or absent (1).

19. Posterior-most trunk vertebra possesses no ribs (0), or ribs present (1).

20. Rib (diapophysis) fused to centrum of sacral vertebra (0), or does not fuse to centrum (1).

21. Anterior-most completely formed chevron bone articulates with second, third, fourth or fifth postsacral vertebra (0), or first postsacral vertebra (1). A completely formed chevron bone is one in which the bony arcade is continuous.

22. Anterior-most autotomic septum absent (0), present in fourth, fifth or sixth caudal vertebra (1), or seventh or eighth caudal vertebra (2).

23. Diapophyses of anterior-most caudal vertebrae large (0), or very small or absent (1).

24. Lateral profile of dorsal margin of neural arch of a midbody vertebra inclined diagonally, may be slightly curved, (0), or horizontal (1).

25. Dorsal profile of posterior end of neural spine of a midbody vertebra knob-like or only slightly notched posteriorly (0), or conspicuously expanded laterally and deeply notched (1).

26. Number of ribless cervical vertebrae, including atlas and axis, two (0), or three (1).

27. Modal number of scleral ossicles per eyeball 11 (0), 12 (1), 13 (2), 14 (3), 15 (4), 17 (5), or 19 (6).

28. Maximum number of teeth per mandible 0-9 (0), 10-19 (1), 20-29 (2), 30-39 (3), 40-49 (4), 50-59 (5), or 60-69 (6). State 4 was observed in an individual burtonis but it does not appear as a modal state for any species in Table 1.

29. Maximum number of teeth per maxilla 0-4 (0), 5-9 (1), 10-14 (2), 15-19 (3), 20-24 (4), 25-29 (5), 30-34 (6), or 35-39 (7).

30. Maximum number of premaxilla teeth 13-12 (0), 11-10 (1), 9-8 (2), 7-6 (3), 5-4 (4), 3-2 (5), or 1-0 (6). Spaces approximately a tooth in width within the continous series of mandibular, maxillary and premaxillary teeth were also counted. 
31. First visceral arch continuous, large hypohyal present (0), discontinuous, large hypohyal present (1), discontinuous, small hypohyal present (2), or discontinuous and hypohyal absent (3).

32. Both footplate and columella portions of stapes large (0), footplate large and columella reduced in size or absent $1(1)$, or both footplate and columella absent or reduced to a small undifferentiated piece of bone (2).

33. Splenial present (0), or absent (1).

34. Viewed laterally, coronoid elevated markedly above general profile of lower jaw (0), moderately above profile (1), or slightly above profile (2).

35. Retroarticular process long (0), or very short and nearly absent (1).

36. Viewed dorsally, posteromedial process of surangular large and rounded (0), moderately large and pointed (1), or absent (2).

37. Margins of posterior one-third of nasal process of premaxilla do not obviously converge towards midline (0), gradually converge (1), very abruptly converge (2).

38. Nasal process of premaxilla separates and/or overlaps nasals and contacts frontal (0), separates nasals throughout approximately one-half their length (1), approximately one-fourth their length (2), or does not separate nasals and may project noticeably anteriorly beyond general profile of snout (3).

39. Subnareal region of premaxilla toothed $(0)$, or toothless (1).

40. Labial margin of premaxilla forms anterior-most edge of snout (0), or curves posteriorly and does not form anteriormost edge of snout (1).

41. Posteromedial margin of premaxillary shelf indented or even in profile (0), or projects posteriorly (1).

42. Premaxillary shelf present (0), or absent (1).

43. Posteromedial extreme of premaxillary shelf present $(0)$, or absent (1).

44. Nasals paired (0), or fused together (1).

45. Nasal-maxilla contact extensive to moderate $(0)$, very slight, (1), or absent (2).

46. Nasal-prefrontal contact absent (0), slight (1), or extensive (2).

47. Posteriorly projecting dorsomedial process of prefrontal narrow and pointed (0), or relatively wide and blunt (1).

48. Anterolateral process of frontal dagger-shaped (0), or short and rounded or absent (1).

49. Posterolateral process of frontal absent (0), or large and 
projecting along lateral edge of parietal (1).

50. Postfrontal and prefrontal in contact or very slightly separated $(0)$, or widely separated (1).

51. Postfrontal foramina present (0), or absent (1).

52. Lateral process of postfrontal large $(0)$, or small or absent (1).

53. Jugal present (0), or absent (1).

54. Parietals paired (0), or fused together (1).

55. Anterolateral corner of parietals projecting anteriorly or forming nearly right angle (0), or corner markedly rounded rendering parietals U-shaped (1).

56. Posteromedian margin of parietals tends to project posteriorly (0), or margin relatively straight (1).

57. Parietals overlap supraoccipital on midline (0), or conspicuous space present between parietals and supra-occipital (1). Some individuals exhibit a narrow space laterally (but not on the midline) and were scored as (0).

58. Posterior-most end of squamosal slender and pointed, gradually curves posterolaterally around quadrate (0), dilated into club-like knob, often encircles end of parietal (1), partially fused to exoccipital (2), or squamosal absent (3).

59. Palatal opening of Jacobson's organ absent (0), distinct from internal choana (1), or palatal opening and internal choana form an undifferentiated long continuous slit (2).

60. Palatine ridges on vomer absent, or very small (0), or large (1).

61. Posteromedial margin of vomer projects posteriorly, occasionally only slightly so (0), or gradually tapers anteriorly (1).

62. Premaxillary-vomer fenestra long and narrow or short and wide (0), long and wide (1), or absent (2).

63. Length of Jacobson's organ portion of vomer approximately one-third total length of vomer $(0)$, slightly less to slightly more than one-half (1), or nearly twice as long (2).

64. Posterolateral margin of vomer small (0), or large, conspicuous wing-like projection present (1).

65. Medial margin of palatines (excluding pterygoids) abruptly converge toward midline (0), parallel or gradually diverge posterolaterally from midline (1), or rounded (2).

66. Posteromedial corner of maxillary shelf tends to be round, or only slightly uneven (0), or a conspicuous process projects from it, which in some species tends to separate palatine from ectopterygoid (1).

67. Anterior portion of ectopterygoid very narrow and gradually tapers to point (0), relatively wide and relatively abruptly tapers to point (1), or very wide throughout most of its length (2). 
68. Epipterygoid contacts both prootic and pterygoid (0), or prootic and/or pterygoid contact absent - epipterygoid may be absent (1).

69. Epipterygoid tends to be round in cross-section (0), or compressed and blade-like (1).

70. Anterior end of trabecula communis slender and round in cross-section and in contact with anterior portion of frontal when ossified inter-orbital septum is present (0), expanded vertically, contributes to partially ossified inter-orbital septum, and in contact with middle one-third of frontal (1), or expanded vertically, contributes to well ossified interorbital septum, and in contact with middle one-third of frontal (2).

71. Anterolateral process of pterygoid longer than anteromedial process of pterygoid (0), processes approximately equal in length (1), or anterolateral process shorter than anteromedial process (2).

72. Base of anteromedial process of pterygoid wider than base of anterolateral process of pterygoid (0), or narrower or approximately equal in width (1).

73. Basitrabecular process of pterygoid large $(0)$, or small or absent (1).

74. Inferior orbital foramen very wide (0), moderately wide (1), narrow (2), or slit-like and nearly absent (3).

75. Pterygoid, immediately anterior to quadrate articulation, does not possess facet for articulation with lower jaw (0), or facet present (1).

76. Thin lateral wall of quadrate large, forming deep and wide posterior depression (0), wall small, depression shallow and narrow (1), or absent (2).

77. Pedicel portion of quadrate forms anterior or medial-most regions (0), or more posterior region (1).

78. Profile of dorsal margin of quadrate sloping posteroventrally (0), gently rounded or horizontal (1), or indented (2).

79. Anterodorsal process of prootic wide and square $(0)$, or narrow and pointed, maybe notched ventrally (1).

80. Anterior prootic notch present (0), or absent (1).

81. Anteromedial process(es) of sphenoid shorter than or as long as basitrabecular process (0), or longer (1).

82. Basitrabecular process of sphenoid approximately as wide as anteromedial process(es) of sphenoid (0), or much narrower (1).

83. Anteroposteriorly orientated sphenoccipital process present $(0)$, or absent (1).

84. Ossified portion of condyles of exoccipitals not or but slightly indented on ventral midline $(0)$, or conspicuously indented which gives appearance of paired occipital condyles (1). 
85. Recessus scala tympani present (0), or absent (1).

86. Parietal process of opisthotic large (0), or small (1).

\section{BASIC DATA MATRIX}

The taxonomic distribution of the 86 characters' states is listed in Table 1, the basic data matrix. Almost all of the twenty-one species available for study were represented by more than one specimen (see MATERIALS, pp. 2-4). Most of the characters were not intraspecifically variable; however, where such variation was observed, the modal character state is listed in Table 1.

\section{ORDER OF EVOLUTIONARY CHANGE}

Once a homologous set of character states is delimited and scored over several taxa, two further hypotheses are required before these data can be used in the inference of phylogeny. The order of evolutionary change must be hypothesized for each set of states and the most primitive state in the set must be selected. The latter issue is discussed under the heading of PRIMITIVE CHARACTER STATE SELECTION (pp. 21-28). The hypothesized order of evolutionary change of each of the 86 characters used herein is presented in Table 2. All of the ordered sets of change are linear, and the six basic patterns [Types 1, 2 (incl. 6), 3 (incl. 7), 4, 5 (incl. 8 and 9) and 10 in Table 2] differ only in the number of staies recognized. The most common pattern (Type 1), exemplified by 56 characters, is the trivial case where only two states are recognized. The sequencing in the other patterns is based on the assumption that the most evenly graded series of changes is the evolutionarily-most-probable hypothesis (Fisher, 1958:41-4).

\section{PRINCIPAL COMPONENT AND NETWORK ANALYSIS}

Principal component analysis was applied to the basic data matrix shown in Table 1. Computation of the principal components was based on the correlation matrix, and the 21 pygopodid species were plotted (Figs. 1-2) according to their projections from those principal axes. The application is particularly revealing in this stud. because it so clearly demonstrates the well-developed structure tha exists in the data (Figs. 1-2) and which characters are reponsible for the separation of the groups (Table 3 ). The 21 species are separated into three well-defined clusters by principal component I (PC I in 


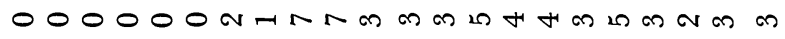
$000000-1-0, N$ N m m N

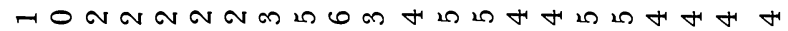

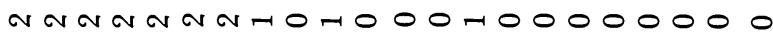

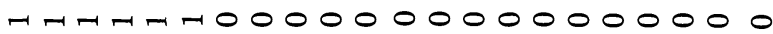

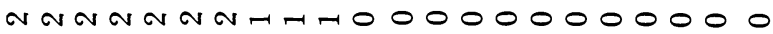

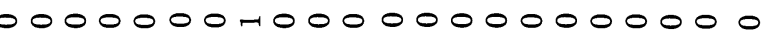

ڤั山 


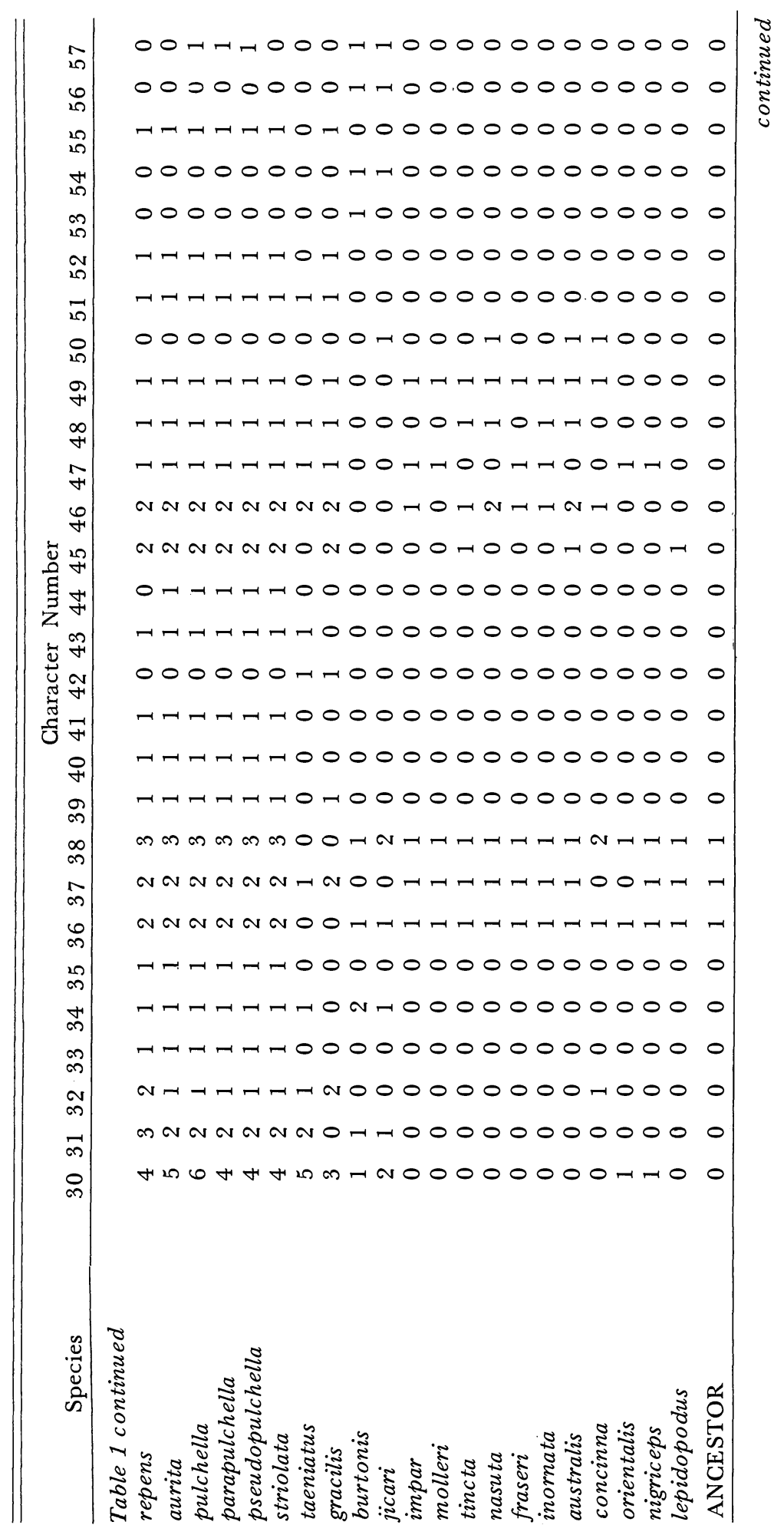


$\infty$

20

$\dot{\infty}$

$\infty$

$\infty$

-

$\stackrel{\circ}{\infty}$

a

$\stackrel{\infty}{\sim}$

N

6

10

齐

है

Z $N$

离

$\frac{\pi^{2}}{4}$

胥

$\infty$

5

6

0

ซ

m

ช

6

8

ก

$\infty$

:

$H-H-H-H-100000000000000$ $h H H-H h-1,00000000000000$ $h H H-H-H 000000000000000$ $h H H-H-10000000000000000$ $h H-H-H-1000000000000000$

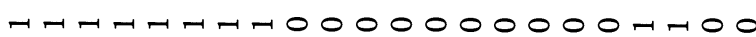
$H H H-H-10000000000000000$ $H-H-H-10000000000000000$ N N N N N N T T 00000000000000 $H \rightarrow H-H-H-100000000000000$ NNWNNNHT000000000000000 $000000007-1000000000000$ $m N T N N T-1000000000000000$ HHH H-HHT0000000000000 $00000000 \pi$ H

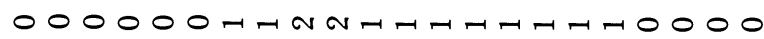
NWNANANOTHO000000000000 $00000000-1000000000000$ -1000000000000000000000

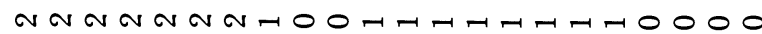

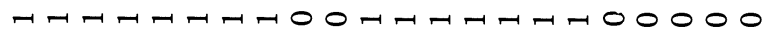

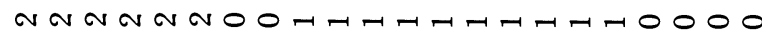
$-1000-100-100000000000000$ N N N N NWNWNWNHTHO000000000000

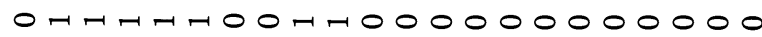

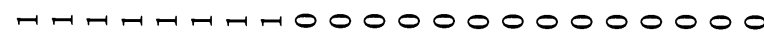

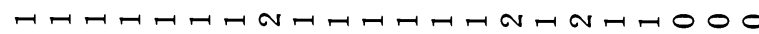

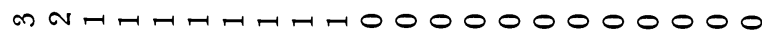



$\stackrel{0}{2}$ $\ddot{凶}$

¿

은 
TABLE 2

CHARACTER STATE TREES AND ADDITIVE BINARY RECODING FOR, OSTEOLOGICAL CHARACTERS ${ }^{1}$

Type 1: $\begin{gathered}0 \rightarrow 1 \\ {[\text { same] }}\end{gathered}$

Characters: $1,2,4,6,8-14,18-21,23-6,33,35,39-44,47-57$, $60,61,64,66,68-9,72-3,75,77,79-86$.

$\begin{array}{rrrr}\text { Type } & 2: & 0 & 0 \\ & \mathrm{a} & {\left[\begin{array}{lll}0 & 0 & 1 \\ 0 & 1 & 1\end{array}\right]} \\ & \mathrm{b} & \text { Characters }\end{array}$

Characters: $3,5,15-7,32,34,45-6,59,62,65,67,70,71$, $76,78$.

Type 3

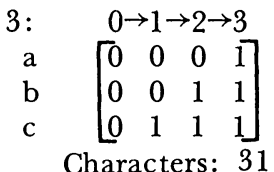

Characters: $31,58,74$.

Type 4

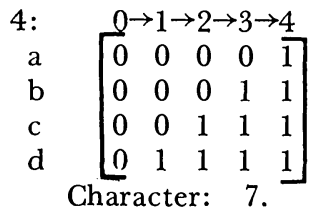

Type 5: $\quad 0 \rightarrow 1 \rightarrow 2 \rightarrow 3 \rightarrow 4 \rightarrow 5 \rightarrow 6$

$\mathrm{a}$
$\mathrm{b}$
$\mathrm{c}$
$\mathrm{d}$
$\mathrm{e}$
$\mathrm{f}$$\left[\begin{array}{lllllll}0 & 0 & 0 & 0 & 0 & 0 & 1 \\ 0 & 0 & 0 & 0 & 0 & 1 & 1 \\ 0 & 0 & 0 & 0 & 1 & 1 & 1 \\ 0 & 0 & 0 & 1 & 1 & 1 & 1 \\ 0 & 0 & 1 & 1 & 1 & 1 & 1 \\ 0 & 1 & 1 & 1 & 1 & 1 & 1\end{array}\right]$

Type 6 :

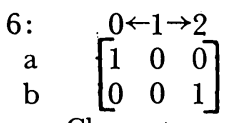

Characters: 22, 36-7, 63.

Type 7: $\quad 0 \leftarrow 1 \rightarrow 2 \rightarrow 3$

$\mathrm{a}$
$\mathrm{b}$
$\mathrm{c}$$\quad\left[\begin{array}{llll}1 & 0 & 0 & 0 \\ 0 & 0 & 1 & 1 \\ 0 & 0 & 0 & 1\end{array}\right]$

Character: 38.

Type 8: $\quad 0 \leftarrow 1 \leftarrow 2 \rightarrow 3 \rightarrow 4 \rightarrow 5 \rightarrow 6$

8:
a
b
c
d
e
f $\quad\left[\begin{array}{lllllllll}1 & 1 & 0 & 0 & 0 & 0 & 0 \\ 1 & 0 & 0 & 0 & 0 & 0 & 0 \\ 0 & 0 & 0 & 1 & 1 & 1 & 1 \\ 0 & 0 & 0 & 0 & 1 & 1 & 1 \\ 0 & 0 & 0 & 0 & 0 & 1 & 1 \\ 0 & 0 & 0 & 0 & 0 & 0 & 1\end{array}\right]$

Character: 28. 
Table 2 continued

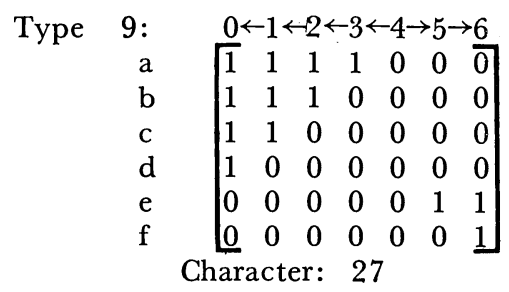

Type: 10 : $\quad 0 \leftarrow 1 \leftarrow 2 \leftarrow 3 \rightarrow 4 \rightarrow 5 \rightarrow 6 \rightarrow 7$

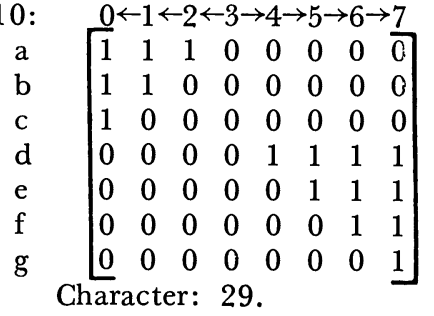

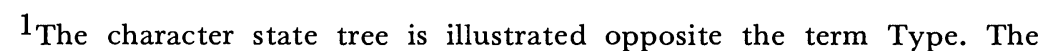
additive binary recoding of the states is enclosed in brackets immediately below, and each binary factor is indexed by the lower case letter placed to the left of the row. The numbers of the characters exhibiting that Type of character state are listed to the right of the term Character. See Table 1 for basic data matrix.

Fig. 1) which accounts for $55.9 \%$ of the variance. All species previously referred to the genus Aprasia (aurita, / parapulchella, pulchella, pseudopulchella, repens and striolata) form a tight cluster at one extreme while another 13 species which have been referred to five genera, Aclys, Delma, Lialis, Paradelma and Pygopus are grouped together at the other extreme. Two monotypic genera, Pletholax gracilis and Ophidiocephalus taeniatus are found between these divergent clusters. Most characters, except 2, 10-12, 19-21, 24, 42-3, $53-4,56,59,69$, and 75 , contribute significantly to the separation of these three groups (Table 3). The two species, burtonis and jicari, previously referred to the genus Lialis, are separated from all others by PC II. An additional $12.6 \%$ of the variance is accounted for by this axis, and four characters 54,56,69, and 75, load the heaviest while $11(12-14,28-9,34,49,53,57,61$ and 71) do so only slightly. less so. PC III separates Pletholax gracilis and Ophidiocephalus taeniatus from all others and PC IV arranges the species into a linear array of four weakly defined groups: 1) Paradelma orientalis, Pygopus 
lepidopodus and $P$. nigriceps. 2) Ophidiocephalus taeniatus. 3) species of the genera Aclys, Aprasia, Delma, and Lialis. 4) Pletholax gracilis. PC V, which together with PC I-IV accounts for an accumulated $89.2 \%$ of the variance, only distinguishes Ophidiocephalus taeniatus from all other species. The two sets of characters that are most highly correlated $( \pm .3$ and \pm .2 ) with PC III (see Table 3 ) are 2, 21, 24 and 42 and 10,11,22, 36, 38 and 64-5. The two that are most highly correlated $( \pm .4$ and \pm .3 ) with PC IV are 19-20 and 49 and 59, and the two with PC V $( \pm .3$ and \pm .2$)$ are 8 and 11 and $2,12,21,24-6,36,39,42,45-6,52,55,64$ and 66-7. The monotypic Aclys and Paradelma do not obviously separate from the Delma and Pygopus clusters of species until PC VII and PC VIII extractions, respectively. Little significance is attached to these axes because they account for so little additional variance, $1.97 \%$ and $1.26 \%$, respectively.

The major groups of taxa delimited by the principal component analysis are not based on a set of characters from one region of the skeleton (e.g., skull, girdles or limbs), characters associated with a particular function (e.g., feeding or locomotion), or characters of a specific kind (e.g., shape or meristic). This can be concluded from the fact that the relative component character correlations with each of the major axes (I-V; see Table 3) do not exhibit obvious patterns of character covariation. The same general observation was made when the 86 characters were clustered into hierarchic groups according to the 21 taxa that they describe (Table 1). The Prim network form of analysis which is described immediately below was used in this additional attempt to discover meaningful covariation among characters. I must conclude that the major groups of pygopodid species are not predicted by any particular kind of character. Furthermore, if these phenetic relationships are good approximations of phylogenetic relationships, as it will become evident that they are later on in this paper, then I must also conclude that the evolutionary history within the family cannot be attributed to any particular set of osteological characters, at least those regionally, functionally or qualitatively defined above. While it seems only reasonable to assert that the evolution of the Pygopodidae from its tetrapod progenitor involved considerable change in limbs and girdles we cannot say that that evolutionary trend predominated in the subsequent history of the family. If modification of limbs and girdles ever predominated it must have occured before the most primitive living species diverged.

Preliminary insight into evolutionary relationships can be obtained from Prim and Wagner networks (Farris, 1970). Network analysis is an excellent way of objectively delimiting graphically connected clusters of taxa, species groups in this case, and discovering their approximate relationships to each other without having to make any statements about which state of a character is the most primitive. Network analysis requires only a basic data matrix, sets of 

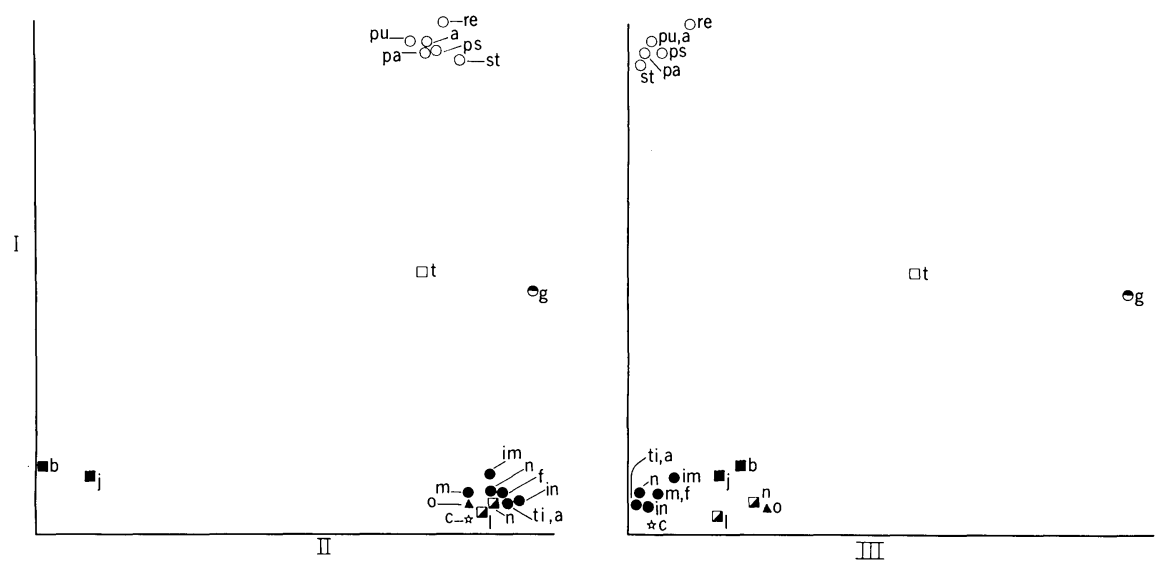

Fig. 1 Principal component I plotted against II and III. The data consist of 21 species of pygopodids and 86 osteological characters (see Table 1). Table 3 lists the eigenvalues and the component correlation coeffieients of this analysis. The taxa whose relationships are illustrated here, and in Figs. 2-4, 7, are defined by the following combination of symbols (genus) and letters (species): (汭) Aclys - (c) concinna; (o) Aprasia - (a) aurita, (pa) parapulchella, (ps) pseudopulchella, (pu) pulchella, (re) repens, (st) striolata; (•) Delma - (a) australis, ' (f) fraseri (im) impar, (in) inornata, (m) molleri, (n) nasuta, (ti) tincta; (-) Lialis - (b) burtonis, (j) jicari; (ㅁ) Ophidiocephalus - (t) taeniatus; (\) Paradelma - (o) orientalis; $(\bullet)$ Pletholax - (g) gracilis; (₫) Pygopus -(1)!lepidopodus,,$(\mathrm{n})$ nigriceps. These definitions are identical to those employed by Kluge (1974).

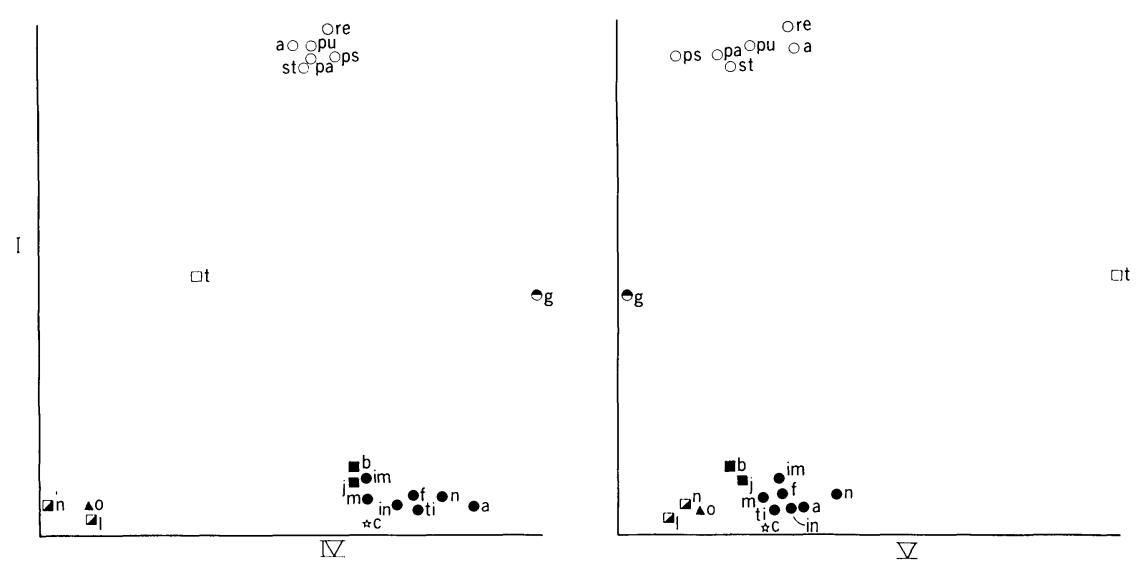

Fig. 2. Principal component I plotted against IV and V. The data consists of 21 species of pygopodids and 86 osteological characters (see Table 1). Table 3 lists the eigenvalues and the component correlation coefficients of this analysis. The symbols and letters in the graphs refer to the taxa defined in the legend of Fig. 1. 
TABLE 3

PRINCIPAL COMPONENT ANALYSIS OF OSTEOLOGICAL CHARACTERS(SEE FIGS. 1-2)

\begin{tabular}{|c|c|c|c|c|c|}
\hline Component & I & II & III & IV & V \\
\hline $\begin{aligned} & \text { Eigenvalue } \\
& \% \text { total variance }\end{aligned}$ & $\begin{array}{l}48.1 \\
55.9\end{array}$ & $\begin{array}{l}10.8 \\
68.5\end{array}$ & $\begin{array}{r}8.7 \\
78.6\end{array}$ & $\begin{array}{r}5.7 \\
85.2\end{array}$ & $\begin{array}{r}3.4 \\
89.2\end{array}$ \\
\hline \multicolumn{6}{|l|}{$\begin{array}{l}\text { Character } \\
\text { Number }\end{array}$} \\
\hline 1 & .1 & .0 & .1 & .0 & .1 \\
\hline 2 & .0 & .1 & .3 & .2 & -.2 \\
\hline 3 & .1 & -.1 & .0 & .0 & .1 \\
\hline 4 & .1 & .0 & -.1 & .0 & -.1 \\
\hline 5 & .1 & .0 & .0 & .0 & .1 \\
\hline 6 & .1 & -.1 & .1 & .0 & .0 \\
\hline 7 & .1 & .0 & .0 & -.1 & .0 \\
\hline 8 & -.1 & .1 & -.1 & .2 & .3 \\
\hline 9 & .1 & .0 & -.1 & .0 & -.1 \\
\hline 10 & .0 & .1 & .2 & -.1 & .1 \\
\hline 11 & .0 & -.1 & -.2 & .2 & .3 \\
\hline 12 & .0 & -.2 & .0 & .0 & .2 \\
\hline 13 & .1 & -.2 & .1 & .0 & .0 \\
\hline 14 & .1 & -.2 & .1 & .0 & .0 \\
\hline 15 & .1 & -.1 & .1 & -.1 & .0 \\
\hline 16 & .1 & -.1 & .1 & -.1 & .0 \\
\hline 17 & .1 & -.1 & .1 & .0 & .0 \\
\hline 18 & .1 & -.1 & .1 & .0 & .0 \\
\hline 19 & .0 & .0 & -.1 & .4 & -.1 \\
\hline 20 & .0 & .0 & -.1 & .4 & -.1 \\
\hline 21 & .0 & .1 & .3 & .2 & -.2 \\
\hline 22 & .1 & .0 & -.2 & -.1 & .0 \\
\hline 23 & .1 & .0 & -.1 & .0 & -.1 \\
\hline 24 & .0 & .1 & .3 & .2 & -.2 \\
\hline 25 & .1 & .0 & .1 & .1 & -.2 \\
\hline 26 & .1 & .0 & .0 & -.1 & .2 \\
\hline 27 & -.1 & -.1 & .0 & .1 & -.1 \\
\hline 28 & -.1 & -.2 & .0 & .1 & .0 \\
\hline 29 & -.1 & -.2 & .0 & .1 & .0 \\
\hline 30 & .1 & .0 & .1 & -.1 & .1 \\
\hline 31 & .1 & -.1 & .0 & .0 & .1 \\
\hline 32 & .1 & .0 & .1 & .1 & .0 \\
\hline 33 & .1 & .0 & -.1 & .0 & -.1 \\
\hline 34 & .1 & -.2 & .0 & .0 & .1 \\
\hline 35 & .1 & .0 & -.1 & .0 & -.1 \\
\hline 36 & .1 & .0 & -.2 & .0 & -.2 \\
\hline 37 & .1 & .1 & .0 & .1 & -.1 \\
\hline 38 & .1 & .0 & -.2 & .0 & -.1 \\
\hline 39 & .1 & .0 & .0 & .1 & -.2 \\
\hline 40 & .1 & .0 & -.1 & .0 & -.1 \\
\hline 41 & .1 & .0 & -.1 & .0 & -.1 \\
\hline
\end{tabular}




\begin{tabular}{|c|c|c|c|c|c|}
\hline Component & I & II & III & IV & $\mathrm{V}$ \\
\hline Eigenvalue & 48.1 & 10.8 & 8.7 & 5.7 & 3.4 \\
\hline$\%$ total variance & 55.9 & 68.5 & 78.6 & 85.2 & 89.2 \\
\hline \multicolumn{6}{|l|}{$\begin{array}{l}\text { Character } \\
\text { Number }\end{array}$} \\
\hline \multicolumn{6}{|l|}{ Table 3 continued } \\
\hline 42 & .0 & .0 & .3 & .1 & .2 \\
\hline 43 & .0 & .0 & .0 & -.1 & .1 \\
\hline 44 & .1 & .0 & -.1 & .0 & -.1 \\
\hline 45 & .1 & .1 & .0 & .1 & -.2 \\
\hline 46 & .1 & .1 & .0 & .2 & .2 \\
\hline 47 & .1 & .1 & .1 & -.1 & .0 \\
\hline 48 & .1 & .1 & .0 & .2 & .1 \\
\hline 49 & .1 & .2 & -.1 & .3 & .0 \\
\hline 50 & -.1 & -.1 & -.1 & .1 & .1 \\
\hline 51 & .1 & .0 & .1 & .0 & .1 \\
\hline 52 & .1 & .0 & .0 & .1 & -.2 \\
\hline 53 & .0 & -.2 & .0 & .0 & .0 \\
\hline 54 & .0 & -.3 & .0 & .0 & -.1 \\
\hline 55 & .1 & .0 & .0 & .1 & -.2 \\
\hline 56 & .0 & -.3 & .0 & .0 & -.1 \\
\hline 57 & .1 & -.2 & .0 & .0 & -.1 \\
\hline 58 & .1 & -.1 & .1 & .0 & .0 \\
\hline 59 & .0 & .0 & .1 & .3 & .0 \\
\hline 60 & .1 & .0 & .1 & .0 & .1 \\
\hline 61 & .1 & -.2 & -.1 & .0 & -.1 \\
\hline 62 & .1 & -.1 & .0 & .0 & .1 \\
\hline 63 & .1 & .1 & -.1 & .0 & .0 \\
\hline 64 & .1 & .0 & .2 & .1 & -.2 \\
\hline 65 & .1 & .0 & -.2 & .1 & .0 \\
\hline 66 & .1 & .1 & .0 & .2 & .2 \\
\hline 67 & .1 & .1 & -.1 & .1 & .2 \\
\hline 68 & .1 & .0 & .0 & .0 & .0 \\
\hline 69 & .0 & -.3 & .0 & .0 & -.1 \\
\hline 70 & .1 & -.1 & .0 & -.1 & .1 \\
\hline 71 & -.1 & -.2 & .1 & .2 & .1 \\
\hline 72 & -.1 & -.1 & -.1 & .1 & .0 \\
\hline 73 & .1 & -.1 & .1 & .0 & .0 \\
\hline 74 & .1 & .0 & -.1 & .0 & .1 \\
\hline 75 & .0 & -.3 & .0 & .0 & -.1 \\
\hline 76 & .1 & .0 & .0 & .0 & .0 \\
\hline 77 & .1 & .0 & .1 & .0 & .1 \\
\hline 78 & .1 & .0 & .0 & .0 & .0 \\
\hline 79 & .1 & .0 & -.1 & .0 & .0 \\
\hline 80 & .1 & .0 & -.1 & .0 & .0 \\
\hline 81 & .1 & .1 & .1 & -.2 & .0 \\
\hline 82 & .1 & .0 & .0 & -.1 & .1 \\
\hline 83 & .1 & .0 & -.1 & .0 & -.1 \\
\hline 84 & .1 & .0 & .0 & -.1 & .1 \\
\hline 85 & .1 & .0 & .1 & .0 & .1 \\
\hline 86 & .1 & .0 & .1 & .0 & .1 \\
\hline
\end{tabular}




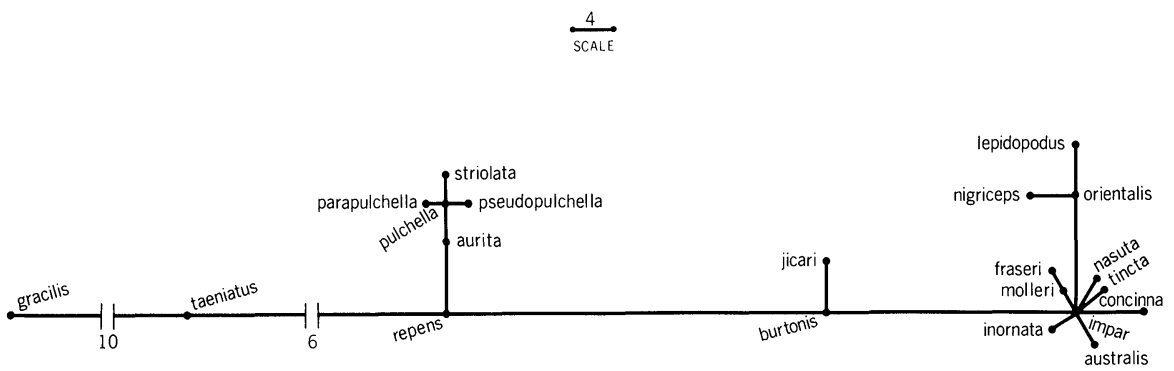

Fig. 3. Prim network cluster analysis of 21 species of pygopodids described by 86 osteological characters (Table 1). All characters were transformed to the same 0 to 1 span. The results of the principal component and Wagner network analyses applied to the same data set are illustrated in Figs. 1-2 and 4, respectively. The symbols and letters in this network refer to the 21 taxa defined in the legend of Fig. 1. The angles of the Prim network are arbitrary, and the interval lengths are proportionate to the sum of the transformed character differences between adjacent species. The scale is four such units of difference.

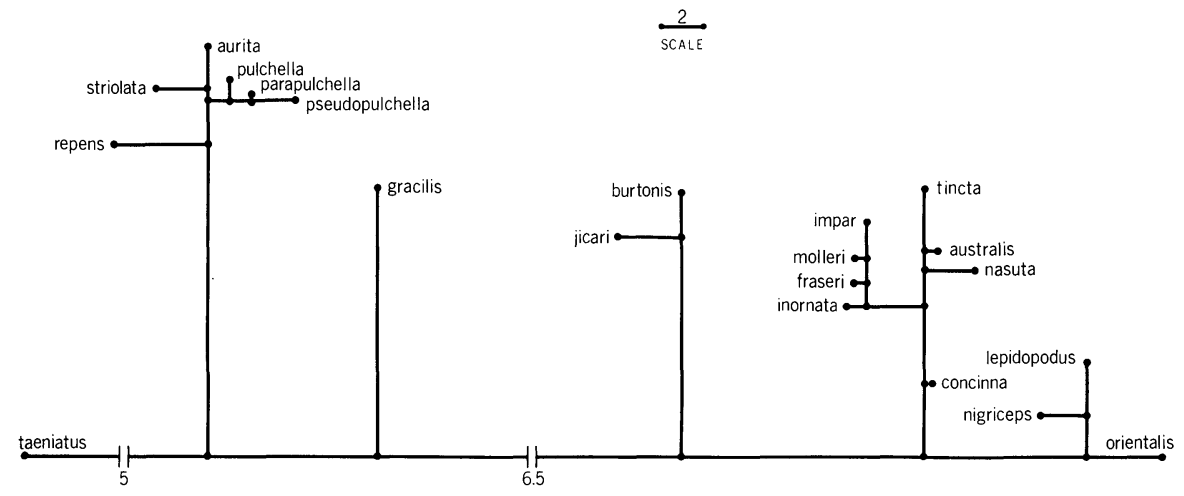

Fig. 4. Wagner network cluster analysis of 21 species of pygopodids described by 86 osteological characters (Table 1). All characters were transformed to the same 0 to 1 span. The results of the principal component and Prim network analyses applied to the same data set are illustrated in Figs. 1-2 and 3, respectively. The symbols and letters in this network refer to the 21 taxa defined in the legend of Fig. 1. The angles of the Wagner network are arbitrary, and the interval lengths are proportionate to the sum of the transformed differences between adjacent species. The scale is two such units of difference. 
homologous states, and that the order of evolutionary change be hypothesized for each character. Prim and Wagner networks are minimum length undirected trees. The Wagner network algorithm generates a hypothetical intermediate taxon at each furcation and thereby minimizes the number of character state changes $(=$ evolutionary steps) that are implied by the final topology. The Prim network does not hypothesize intermediates, and consequently, the total number of character state changes $(=$ total length of the network) will be larger than the Wagner network.

I applied the Prim and Wagner network algorithms to a transformed version of the basic data matrix shown in Tables 1-2. The transformation involved converting all characters to the same span, 0 to 1 . I could not discover a meaningful and objective way to weight differentially the 86 osteological characters, and I have no choice but to give all characters equal weight. Both networks (Figs. 3-4) and the principal component analysis (Figs. 1-2) delimit the same six groups of species (Table 4). These are labled Group I: aurita, parapulchella, pseudopulchella, pulchella, repens and striolata; Group II: taeniatus; Group III: gracilis; Group IV: burtonis and jicari; Group V: australis, concinna, fraseri, impar, inornata, molleri, nasuta and tincta; Group VI: lepidopodus, nigriceps and orientalis. Species of Group I are currently (Kluge, 1974) placed in the genus Aprasia, Group II in Ophidiocephalus, Group III in Pletholax and Group IV in Lialis. Group V consists of one species, concinna, which is placed in the monotypic genus Aclys while the remainder are referred to Delma. Group VI consists of one species, orientalis, which is placed in the monotypic genus Paradelma, while the remaining two species are referred to Pygopus. According to the Wagner network of relationships (Fig. 4) Group I is most similar to II and both are nearly equally similar to all other Groups. Groups V and VI are the most similar and I and VI the least so. Group III is more similar to I and II while IV is more similar to V and VI.

\section{PRIMITIVE CHARACTER STATE SELECTION}

\section{Criteria and Theory}

In 1967, I presented four general rules for estimating the primitive state of a character. The criteria appear to differ very little from the informal procedures that systematists have followed for many years (Wagner, 1961). The four rules were reworded, reduced to three and further qualified by Kluge and Farris (1969: 5-6). They may be stated even more concisely as follows: the primitive state of a character is

1) frequently observed

a) among the groups related to the one being studied and 
TABLE 4

MAJOR CLADISTIC GROUPS (SEE FIG. 4) AND

RELATIVE PRIMITIVENESS OF PYGOPODIDS

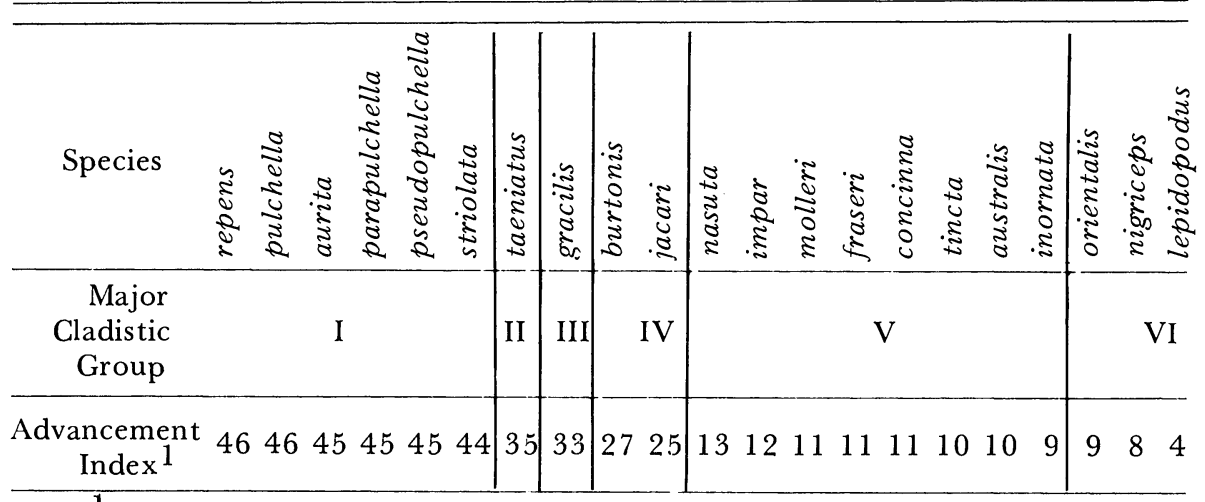

1 The advancement index for a given species was calculated as the sum of the derived states. A derived state is any state other than the most primitive one, and each derived state is given a value of one. Fifty-five characters were employed in the estimation and these are listed under assertions A-C (see pp. 27-28 for further discussion).

b) within the group chosen for study (Fig. 5) and

2) exhibited by that taxon which is estimated to be primitive on the basis of other evidence.

For convenience in the discussion to follow I will refer to the taxomonic assemblage chosen for study as the primary group and the related groups as secondary. It is assumed that the greater the frequency of occurrence of a particular state within a group the greater the likelihood that it is the primitive one in that group, and as the evidence increases that a taxon is primitive so does the likelihood that an otherwise undetermined state exhibited by that taxon is primitive. It must be emphasized that a character state should be considered widespread only when it is exhibited by several taxa that otherwise have little in common. Such an estimation of frequency avoids the bias produced by a much more speciose lineage that is characterized by a derived state that has remained unchanged since its appearance in the common ancestor of that radiation. Logically, fossils can not be considered different from living forms in the rules because they have membership in either the primary or some secondary group, and the limits of all groups and group relationships can be estimated from network analysis (see previous section) that makes no assumptions about primitiveness (Kluge and Farris, 1969; Farris, 1970; Lundberg, 1972).

Recent criticism and apparent misunderstanding of the meaning and use of the above criteria for estimating the primitive state of a character (Mayr, 1969; Lundberg, 1972; Sneath and Sokal, 1973; Moffat, 1973) suggest that further discussion is warranted before they 
are applied in the present study. Even the basic term "primitive character state" continues to be misunderstood by some. The primitive state among an estimated homologous set, is defined as that condition expressed by the most recent common ancestor of the group whose phylogenetic history is to be estimated, i.e. the primary group (Kluge and Farris, 1969). In Figure 5 it is the state that characterizes common ancestor A. In the present study, it becomes a question of which state of each of the 86 recorded characters is most likely to have been present in the most recent common ancestor of the 21 species of pygopodids examined. Doubtless, if this common ancestor could be observed directly it would be more similar to known pygopodids (sensu Kluge, 1974) than to other lizards, and it would be placed in the same family according to cladistic classificatory dogma (Hennig, 1966). The simple notion of genealogical descent is sufficient to conclude that any group of species whose origin was not the result of hybridization has but one most recent common ancestor. Furthermore, given the ideal definition of "primitive character state" set forth above, it follows that primitiveness is not absolute but a relative concept. As illustrated in Figure 5, that state of a homologous set found in common ancestor $\mathrm{A}$ is primitive relative to those observed in the derived species ' $\left(A_{1-5}\right)$, and likewise a different homologous state in common ancestor! $\mathrm{A}-\mathrm{B}$ is primitive relative to that found in $\mathrm{A}$. A different homologous character statel in common ancestor A-B-C is the most primitive of the three groups shown in Figure 5. Take again, for example, the present study that focuses on estimating the phylogenetic history of pygopodids. There is considerable evidence to support the hypothesis that the lizard families Pygopodidae and Gekkonidae had a more recent common ancestor than either has had with any other known family of lizards (Underwood, 1957). Accepting this hypothesis (Fig. 6), there are two temporally successive common ancestors of particular interest to us, that of pygopodids alone as a group and that of the pygopodids plus the gekkonids. The state that characterizes the pygopodid-gekkonid common ancestor is primitive relative to that which characterizes the common ancestor of pygopodids alone. The primitive state may be the same in the temporally successive common ancestors but it does not necessarily have to be! In general, primitiveness must be specified in relation to a particular common ancestor, and an earlier appearing character state is, by definition, primitive relative to those derived from it.

A compelling reason for using the two criteria listed above for estimating the primitive state of a character is that one obtains the best fit to data. In this paper, the best fit to data is that network or tree hypothesis that is of minimum length. The ideal perfect fit is one where the total number of character state changes (evolutionary steps) in the original data matrix equals the total length of the network or tree. If only homologous sets of states, or at least the 


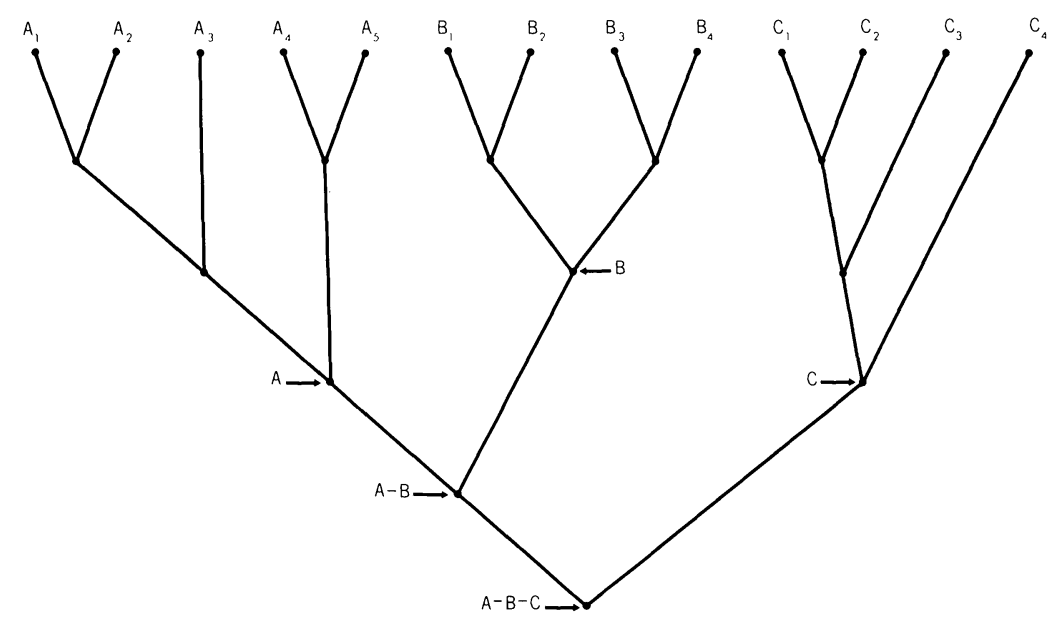

Fig. 5. A hypothetical phylogenetic history of three groups of evolutionary species $A_{1-5}, B_{1-4}$, and $\mathrm{C}_{1-4} . \mathrm{A}, \mathrm{B}$, and $\mathrm{C}$ are the common ancestors of the respective groups, while A-B and A-B-C denote the temporally successive common ancestors of the three groups. Assume that $\mathrm{A}_{1-5}$ is the primary group and $\mathrm{B}_{1-4}$ and $\mathrm{C}_{1-4}$ are the secondary groups.

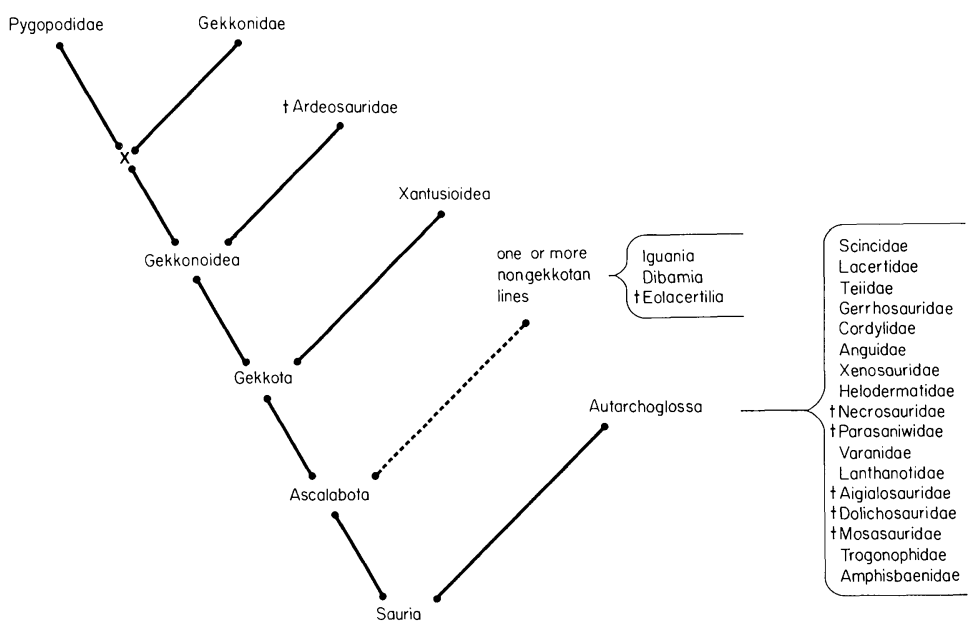

Fig. 6. A hypothesis of the cladistic ancestry of saurians leading to the Pygopodidae. The symbols $\dagger$ denote extinction and $\mathrm{X}$ the most recent common ancestor of the Pygopodidae and Gekkonidae. See text (pp. 25-28) 'for further explanation. 
best possible estimates, are employed in the study of phylogeny, then the two criteria should be followed because they minimize the number of homoplasious events that are eventually generated in the final topological hypothesis of phylogeny. The original conclusions of homology would be contradicted, and this would be counterproductive and illogical, if the best fit to data in this sense were not sought. In general, these criteria help to produce the most parsimonious conclusions, that is the shortest phylogenetic tree, as well as the hypothesis with the minimum number of extra assumptions (= extra evolutionary steps).

In any particular case, the two general criteria listed above are not to be applied uncritically to all characters, that is to say without regard for other data and hypotheses. An investigator may be able to cite more convincing evidence for primitiveness, although probably only very rarely, and in these cases the conclusions may differ from those derived from the application of the general criteria. A word of caution is in order here, however; the usual problem with the "more convincing evidence" is that it tends not to be so compelling on close inspection (i.e., it simply reduces to an assertion), and rarely is it rigorously and objectively applied. Furthermore, it may not lead to the statistical best fit to data, and in these instances we realize a contradiction to our hypothesis of homology which must be resolved. I believe that present study of pygopodids provides a justifiable case for the use of other data and hypotheses for estimating the primitive state of certain characters. The present case is based on my assumption that the snake-like pygopodids evolved from typical tetrapod-like lizards. And, from this assumption it necessarily follows that the more tetrapod-like state observed in pygopodids is primitive (see assertion A below). Only the 15 characters associated with the limbs and girdles and body diameter and length can be interpreted on these grounds (see further discussion below).

\section{Application}

Application of the criteria discussed above for estimating primitiveness requires that the groups of lizards related to pygopodids be identified, and, ideally, that their cladistic relationships be estimated. I have illustrated the most widely accepted hypothesis of the cladistic history leading to the Pygopodidae in Figure 6. This phylogenetic tree is a transcription of Underwood's (1971) generally accepted classification of the lizards. As stated above, the evidence is overwhelming that among the known families of lizards the gekkonids have had the most recent common ancestor with the pygopodids (Underwood, 1957). Underwood's (1971) classification does not contain a formal name for that cladistic event which is designated by the symbol $\mathrm{X}$ in Figure 6 . The evidence that the extinct family Ardeosauridae is more closely 
related to the pygopodids and gekkonids than it is to any other group(s) of lizards is also very convincing (Hoffstetter, 1964). And from this relationship it follows that the Ardeosauridae is cladistically ancestral to the common ancestor of pygopodids and gekkonids. The position of the Xantusioidea within the Gekkota, as outlined in Figure 6, is questioned by some (e.g., Moffat, 1973), and its classification may require revision. Actually, the details of the cladistic history outside the Gekkonoidea is unimportant for the purposes of my application of the criteria. It is sufficient to recognize that there are gekkonoids (whose relationships are as described above) and "other lizards," and that the gekkonoids are not the earliest saurian divergence.

I have used principal components (Figs, 1-2) and Prim and Wagner network analyses (Figs. 3-4) to estimate objectively the major groups of species in the Pygopodidae and their relationships to each other. The same six groups of species are delimited by the three methods (Table 4). I have estimated the degree to which a state is widespread within the family from its frequency of occurrence within and among these groups. The branching pattern of relationships specified by the minimum-length Wagner network (Fig. 4) is used to measure degree of parsimony in the individual characters. Each character had a certain distribution of states on the network and accordingly a countable number of transitions (evolutionary steps). When the number of transitions on the network is equal to the number given in the original data tables (see Tables 1-2) then homoplasy has not been detected in that character. As the network transitions increase beyond the number given in the original data tables so does the predicted degree of homoplasy in that character. There is an inverse relationship between degree of homoplasy and parsimony. The selection of the primitive state of a character can increase the number of transitions, and minimizing the degree of homoplasy is used as a criterion in that selection process (see below).

A preliminary estimation of the relative primitiveness of species is helpful in picking the most likely primitive state of a character when no other obvious basis for selection is available. As I indicated previously, this approach assumes that the more primitive species tend to be more primitive in all regards (rule 2 above). The preliminary evidence of relative species primitiveness in this study is based on 55 characters (Table 4). Prediction of the primitive state of these characters is based on the more robust rule 1; see the assertions and arguments listed opposite A-C below. One species, lepidopodus (Fig. 4), is estimated to be much more primitive than all of the others studied.

The specific assertions, and associated assumptions, on which I base my estimate of the primitive state of each of the 86 osteological characters are described and listed in alphabetical order immediately below. I have placed the assertions in the order that I believe most 
accurately reflects their predictability. Predictability is taken to be some function of the kind and number of associated assumptions, their being true, and the chance of sampling error. Obviously, assertion $\mathrm{G}$ should be the poorest predictor and it must be used only when the evidence for the relative primitiveness of the species is extremely good. I believe the robustness of assertions A-C in this regard justifies its limited use in the present research.

Assertions and assumptions:

A. The character state in pygopodids that is most like the tetrapod condition is primitive. This assertion assumes that the tetrapod habit is primitive relative to the snake-like form of pygopodids.

B. The character state in pygopodids that is the most widespread among other lizard families is primitive. This assertion assumes that other lizard families are secondary groups and that pygopodids are not cladistically ancestral to that assemblage.

C. The character state in pygopodids that is the most widespread among gekkonid and ardeosaurid lizards is primitive. This assertion assumes that gekkonids and ardeosaurid lizards are secondary groups and that one or both of them is cladistically ancestral to pygopodids.

D. The character state in pygopodids that is the most widespread within the family is primitive. A state is widespread when it is invariably present in five of the six groups of species delimited by Figure 4 and listed in Table 4 .

E. The argument and assumption are the same as D except that invariable presence in four of the six groups is used as the measure of frequency.

F. The argument and assumption are the same as D except that the mode, sampled over all species studied without regard for group, is used as the measure of frequency.

G. The character state in pygopodids that is exhibited by the most primitive species is primitive. The most primitive species in this study is lepidopodus (see Table 4) and all of the characters that were evaluated by the A-C assertions were used in that relative ranking.

The estimated primitive state of each character is listed in Table 1 in the row opposite the taxon labled ANCESTOR. The characters are arranged in the following list according to the most robust assertion that was used in the estimation of their primitive state. Other, less robust assertions apply to almost every character; however, they have not been cited for the sake of tabular simplicity. When assertion $\mathrm{G}$ was applied the interval length adjacent to lepidopodus (Fig. 4) was employed as the reference and not lepidopodus itself. 
Assertion A.

Characters $(\mathrm{n}=15): 1,3-7,{ }^{\prime}, 10-18$.

Assertion B.

Characters $(\mathrm{n}=22): 9,19-20,25,29,31-5,39,40,42,44$, 51-3, 68-9, 83, 85-6.

Assertion C.

Characters $(\mathrm{n}=18): 23,28,45-6,54,58-9,66,70,72-7,81-2$, 84.

Assertion D.

Characters $(\mathrm{n}=7): 2,21,24,41,56,79-80$.

Assertion E.

Characters $(\mathrm{n}=10): 8,22,26,43,50,55,57,61,63-4$.

Assertion F.

Characters $(\mathrm{n}=8): 27,30,36-8,60,62,78$.

Assertion G.

Characters $(n=6): 47-9,65,67,71$.

I have relatively little confidence in the selection of the primitive state of the six characters listed under G. In any case, a completely random selection of primitive states in these few characters does not change the cladistics of the phylogentic hypothesis, only the length of a few of the intervals. The modal state (assertion F) is state one in character 47,48 , and 67 and not the primitive state zero. The choice of state one as primitive would have resulted in a longer, less parsimonious, individual character state tree.

\section{ADDITIVE BINARY CODING AND CHARACTER COMPATIBILITY ANALYSIS}

The character compatibility theory and method developed recently by Le Quesne $(1969,1974)$ has excited many students of phylogenetic inference, including myself (Kluge, 1975). The method is simple, applicable to all forms of data, and it identifies incompatible characters in a data set, that is those variables that predict different phylogenies. An unambiguous statement (a unique hypothesis) can be made about phylogenetic history from the remaining compatible characters, and assuming, as many have, that compatible characters are homologous sets of states then a true statement can be made as well. Obviously, this is appealing, and the method is relevant to the present study of pygopodids.

Is the basic assumption that the compatible characters are also homologous a realistic one? Estabrook (1972:441-2) evaluated this relation and succinctly concluded that "All that incompatibility teaches us is that not both of two incompatible characters are true [sensu the parameter phylogeny]." In fact then, the Le Quesne method does not find compatibility or the truth. Additional conceptual and procedural problems with the Le Quesne method become 
apparent when it is applied to a large data set, such as the one employed in this study. These more detailed criticisms are now discussed.

A clique is a set of compatible characters that is not a subset of another clique. To discover the clique(s) in a data set according to the Le Quesne method (Kluge, 1975) all comparable variables must consist of only two states (0 and 1). I have applied additive binary coding (see Farris, Kluge and Eckardt, 1970) to the multistate characters of the basic pygopodid data set (Table 1) to accomplish this transformation. Additive binary coding preserves the exact topology of a multistate character state tree (as specified by Table 2). The completely recoded binary data are presented in Table 5. Lower case alphabetic suffixes have been added to a character's number to indicate that binary recoding is associated with it. The frequency distribution of number cliques is shown in Table 6. There are 1006 cliques for the 86 osteological characters (= 139 binary characters; see Table 5). This number is much larger than any reported previously. Fourteen of the 139 binary characters, 2, 21, 22a, 24, 27d, 27f, 28f, $30 \mathrm{a}, 31 \mathrm{a}, 34 \mathrm{a}, 53,58 \mathrm{a}, 68$ and $74 \mathrm{a}$, cannot be incompatible because only one of the 21 species possesses state 1 . Table 6 clearly demonstrates that more than one clique can have the same number of characters, and the high degree to which this is so in the present study has not been reported previously. In fact, there are four cliques with the same maximum number of binary characters (81). Such a large number of different sets of characters that contain the same maximum number of characters makes it impossible to select one as the best predictor of phylogeny. We must conclude that compatibility analysis does not necessarily provide a unique prediction, and the problem is accentuated when the significance between cliques that differ in only one or a few characters is considered. Suppose that there exist two cliques, one consisting of 81 characters and the other with 80 . Does the clique with the largest number of characters most accurately predict phylogeny? If not, what exactly are significant differences in number of characters?

When additive binary coding is applied to a multistate character one or more of the resultant binary factors may become incompatible with some other variable in the data set. The probability of this occurring is related to the number of characters in the set, and in the present study at least one binary factor of each multistate character is incompatible in the 18 largest cliques (Table 7). Should the entire multistate character not be used in predicting phylogeny when one or more of its binary factors are found to be incompatible? Logically, complete elimination would follow when all of the factors of a multistate character are found to be incompatible. One might conclude that the entire multistate character must be eliminated when any of its binary factors are found to be incompatible because of the affect that an instance of convergence (incl. parallelism) has on 


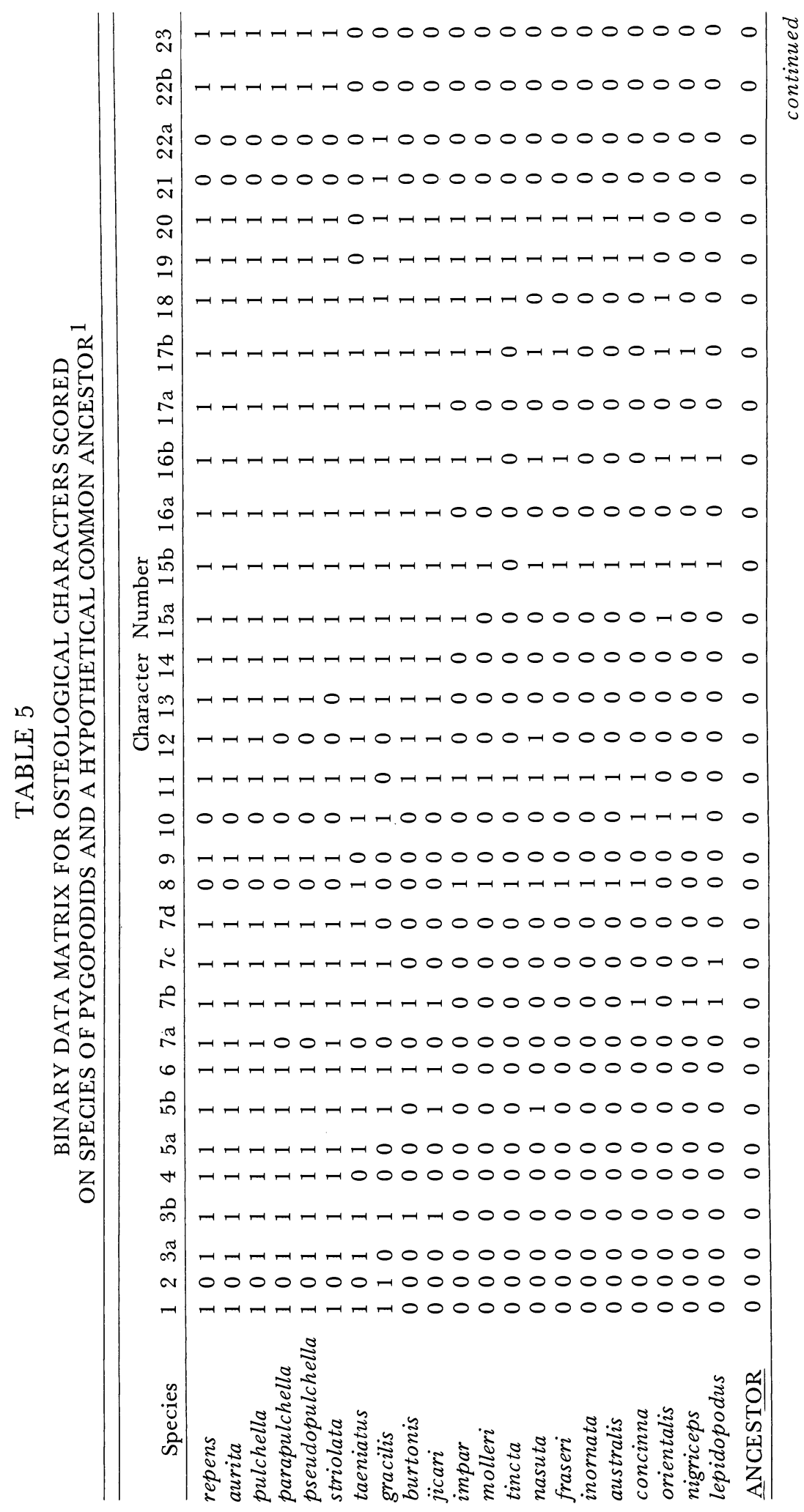




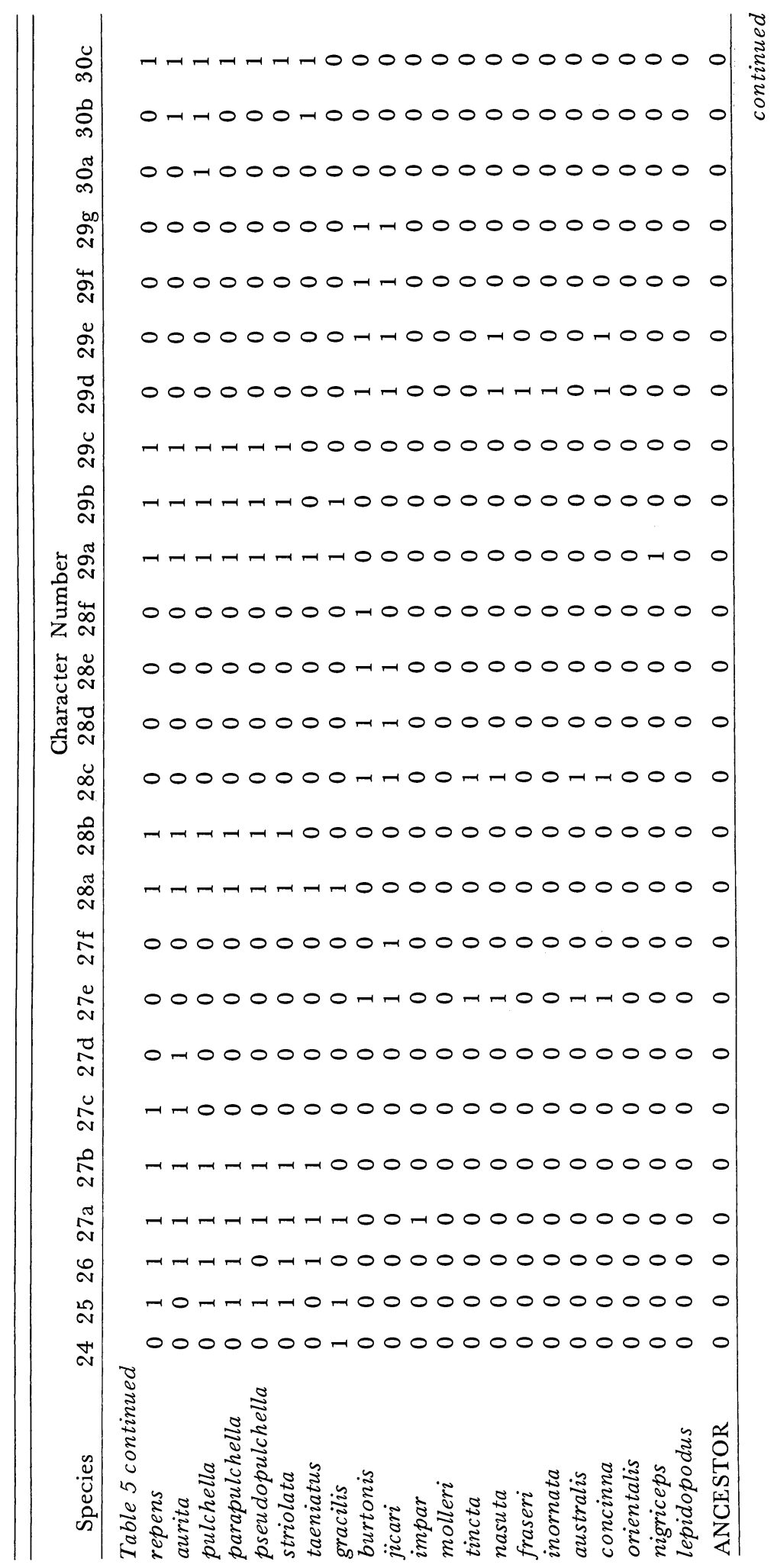


HAHAH0 000000000000000 $0 \pi H A-0000000000000000$ $H \pi-4 \pi-1000000000000000$ $000000-700000000000000$ $H H-H-14000000000000000$ $H H H-H 0000000000000000$ $H \pi-H-10-100000000000000$ $4 H-H-10000000000000000$ $4 H-4 H-100040000000-10000$ $0000007-00000000000000$ $H A H A H 0000000000000000$ $000000-100000000000000$ $H A H A-0700000000000000$ $00000000-10000000-1000$ $H-H H-1-000000000000000$

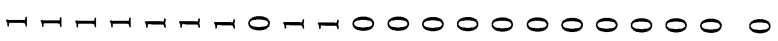
$00000000-0000000000000$ H-H-H0000000000000000 $H 4 h H H 4 h-100000000070000$ $-1000000-00000000000000$

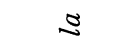

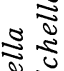

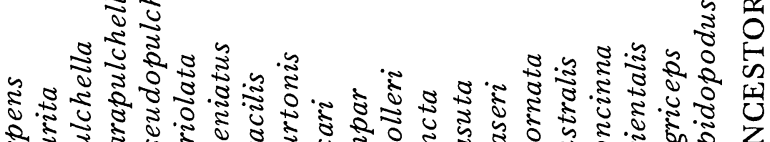




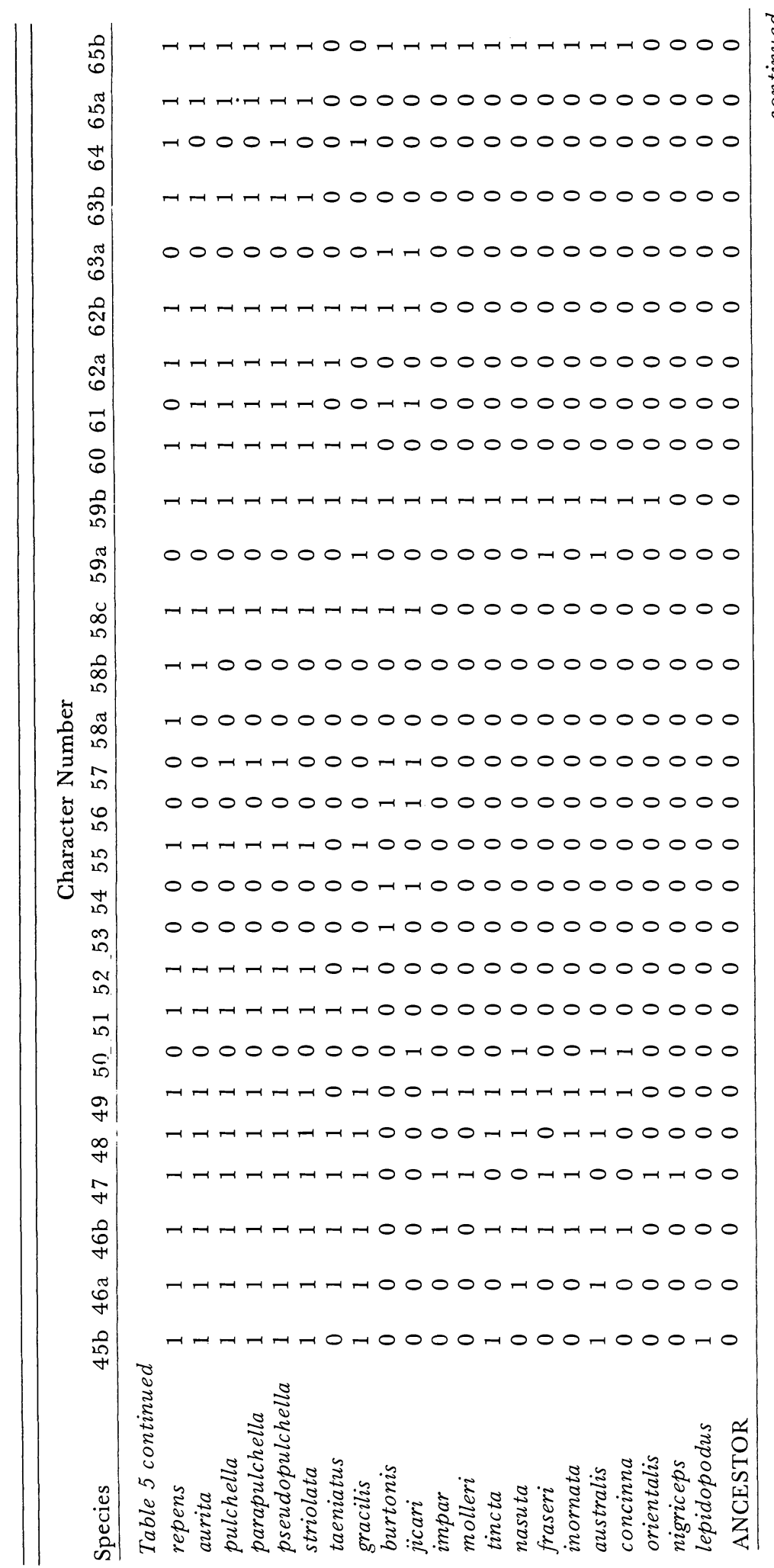




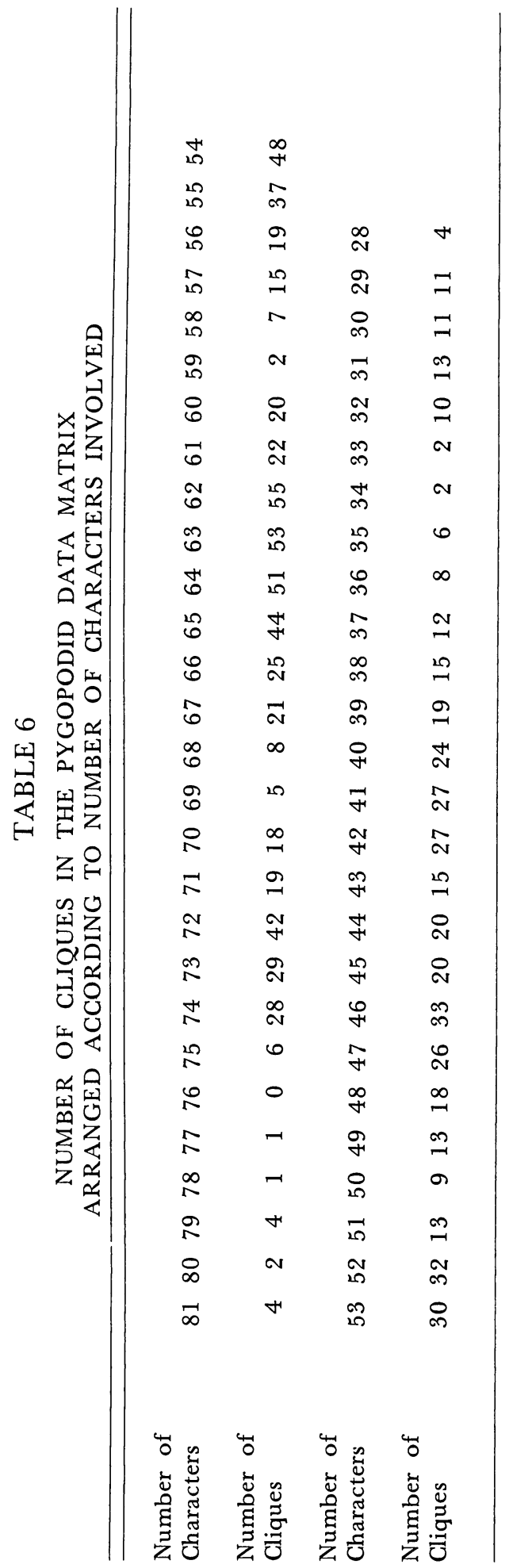




\section{TABLE 7}

\section{CHARACTERS OF THE EIGHTEEN LARGEST CLIQUES, EXTRACTED FROM THE DATA MATRIX}

\section{Clique A. 81 binary characters}

$1,2,3 \mathrm{a}, 3 \mathrm{~b}, 4,5 \mathrm{a}, 6,7 \mathrm{a}, 7 \mathrm{~d}, 9,14,15 \mathrm{a}, 15 \mathrm{~b}, 16 \mathrm{a}, 16 \mathrm{~b}, 17 \mathrm{a}, 17 \mathrm{~b}, 21,22 \mathrm{a}, 22 \mathrm{~b}$, $23,24,27 \mathrm{~b}, 27 \mathrm{c}, 27 \mathrm{~d}, 27 \mathrm{f}, 28 \mathrm{a}, 28 \mathrm{~b}, 28 \mathrm{~d}, 28 \mathrm{e}, 28 \mathrm{f}, 29 \mathrm{c}, 29 \mathrm{f}, 29 \mathrm{~g}, 30 \mathrm{a}, 30 \mathrm{c}$, $30 \mathrm{~d}, 31 \mathrm{a}, 31 \mathrm{~b}, 33,34 \mathrm{a}, 35,37 \mathrm{~b}, 38 \mathrm{c}, 40,41,43,44,53,54,56,58 \mathrm{a}, 58 \mathrm{~b}, 58 \mathrm{c}$, 60, 62a, 62b, 63a, 63b, 65a, 67a, 68, 69, 70a, 71a, 73, 74a, 74c, 75, 76a, 76b, 77,78 a, 78 b, $79,80,82,83,84,85,86$.

Clique B. 81 binary characters

1, 2, 3a, 3b, 4, 5a, 6, 7a, 7d, 9, 14, 15b, 16a, 16b, 17a, 17b, 21, 22a, 22b, 23, 24, 27b, 27c, 27d, 27f, 28a, 28b, 28d, 28e, 28f, 29c, 29f, 29g, 30a, 30c, 30d, $30 \mathrm{f}, 31 \mathrm{a}, 31 \mathrm{~b}, 33,34 \mathrm{a}, 35,37 \mathrm{~b}, 38 \mathrm{c}, 40,41,43,51,53,54,56,58 \mathrm{a}, 58 \mathrm{~b}, 58 \mathrm{c}$, $60,62 \mathrm{a}, 62 \mathrm{~b}, 63 \mathrm{a}, 63 \mathrm{~b}, 65 \mathrm{a}, 67 \mathrm{a}, 68,69,70 \mathrm{a}, 71 \mathrm{a}, 73,74 \mathrm{a}, 74 \mathrm{c}, 75,76 \mathrm{a}, 76 \mathrm{~b}$, 77,78 a, 78 b, 79, 80, 82, 83, 84, 85, 86 .

\section{Clique C. 81 binary characters}

1, 2, 3a, 3b, 4, 5a, 6, 7d, 9, 14, 15a, 15b, 16a, 16b, 17a, 17b, 21, 22a, 22b, 23, 24, 27b, 27c, 27d, 27f, 28a, 28b, 28d, 28e, 28f, 29c, 29f, 29g, 30a, 30c, 30d, $31 \mathrm{a}, 31 \mathrm{~b}, 33,34 \mathrm{a}, 35,37 \mathrm{~b}, 38 \mathrm{c}, 40,41,43,51,53,54,56,58 \mathrm{a}, 58 \mathrm{~b}, 58 \mathrm{c}, 60$, 62a, 62b, 63a, 63b, 65a, 67a, 68, 69, 70a, 71a, 73, 74a, 74b, 74c, 75, 76a, 76b, $77,78 \mathrm{a}, 78 \mathrm{~b}, 79,80,82,83,84,85,86$.

\section{Clique D. 81 binary characters}

1, 2, 3a, 3b, 4, 5a, 6, 7d, 9, 14, 15b, 16a, 16b, 17a, 17b, 21, 22a, 22b, 23, 24, $27 \mathrm{~b}, 27 \mathrm{c}, 27 \mathrm{~d}, 27 \mathrm{f}, 28 \mathrm{a}, 28 \mathrm{~b}, 28 \mathrm{~d}, 28 \mathrm{e}, 28 \mathrm{f}, 29 \mathrm{c}, 29 \mathrm{f}, 29 \mathrm{~g}, 30 \mathrm{a}, 30 \mathrm{c}, 30 \mathrm{~d}, 30 \mathrm{f}$, $31 \mathrm{a}, 31 \mathrm{~b}, 33,34 \mathrm{a}, 35,37 \mathrm{~b}, 38 \mathrm{c}, 40,41,43,51,53,54,56,58 \mathrm{a}, 58 \mathrm{~b}, 58 \mathrm{c}, 60$, 62a, 62b, 63a, 63b, 65a, 67a, 68, 69, 70a, 71a, 73, 74a, 74b, 74c, 75, 76a, 76b, $77,78 \mathrm{a}, 78 \mathrm{~b}, 79,80,82,83,84,85,86$.

\section{Clique E. 80 binary characters}

1, 2, 3a, 3b, 4, 5a, 6, 7a, 7d, 9, 14, 15a, 16a, 17a, 18, 21, 22a, 22b, 23, 24, $27 \mathrm{~b}, 27 \mathrm{c}, 27 \mathrm{~d}, 27 \mathrm{f}, 28 \mathrm{a}, 28 \mathrm{~b}, 28 \mathrm{~d}, 28 \mathrm{e}, 28 \mathrm{f}, 29 \mathrm{c}, 29 \mathrm{f}, 29 \mathrm{~g}, 30 \mathrm{a}, 30 \mathrm{c}, 30 \mathrm{~d}, 31 \mathrm{a}$, $31 \mathrm{~b}, 33,34 \mathrm{a}, 35,37 \mathrm{~b}, 38 \mathrm{c}, 40,41,43,51,53,54,56,58 \mathrm{a}, 58 \mathrm{~b}, 58 \mathrm{c}, 59 \mathrm{~b}, 60$, 62a, 62b, 63a, 63b, 65a, 67a, 68, 69, 70a, 71a, 73, 74a, 74c, 75, 76a, 76b, 77, $78 \mathrm{a}, 78 \mathrm{~b}, 79,80,82,83,84,85,86$.

\section{Clique F. 80 binary characters}

1, 2, 3a, 3b, 4, 5a, 6, 7d, 9, 14, 15a, 16a, 17a, 18, 21, 22a, 22b, 23, 24, 27b, 27 c, 27d, 27f, 28a, 28b, 28d, 28e, 28f, 29c, 29f, 29g, 30a, 30c, 30d, 31a, 31b, $33,34 \mathrm{a}, 35,37 \mathrm{~b}, 38 \mathrm{c}, 40,41,43,51,53,54,56,58 \mathrm{a}, 58 \mathrm{~b}, 58 \mathrm{c}, 59 \mathrm{~b}, 60,62 \mathrm{a}$, 62b, 63a, 63b, 65a, 67a, 68, 69, 70a, 71a, 73, 74a, 74b, 74c, 75, 76a, 76b, 77, 78a, $78 \mathrm{~b}, 79,80,82,83,84,85,86$. 
Table 7 continued

Clique G. 79 binary characters

1, 2, 3a, 3b, 4, 5a, 6, 7a, 7b, 7d, 9, 14, 15b, 16a, 17a, 21, 22a, 22b, 23, 24, $27 \mathrm{~b}, 27 \mathrm{c}, 27 \mathrm{~d}, 27 \mathrm{f}, 28 \mathrm{a}, 28 \mathrm{~b}, 28 \mathrm{~d}, 28 \mathrm{e}, 28 \mathrm{f}, 29 \mathrm{c}, 29 \mathrm{f}, 29 \mathrm{~g}, 30 \mathrm{a}, 30 \mathrm{c}, 30 \mathrm{~d}, 31 \mathrm{a}$, $31 \mathrm{~b}, 33,34 \mathrm{a}, 35,37 \mathrm{~b}, 38 \mathrm{c}, 40,41,43,51,53,54,56,58 \mathrm{a}, 58 \mathrm{~b}, 58 \mathrm{c}, 60,62 \mathrm{a}$, $62 \mathrm{~b}, 63 \mathrm{a}, 63 \mathrm{~b}, 65 \mathrm{a}, 67 \mathrm{a}, 68,69,70 \mathrm{a}, 71 \mathrm{a}, 73,74 \mathrm{a}, 74 \mathrm{c}, 75,76 \mathrm{a}, 76 \mathrm{~b}, 77,78 \mathrm{a}$, $78 \mathrm{~b}, 79,80,82,83,84,85,86$.

\section{Clique H. 79 binary characters}

$1,2,3 \mathrm{a}, 3 \mathrm{~b}, 4,5 \mathrm{a}, 6,7 \mathrm{~d}, 9,14,15 \mathrm{a}, 15 \mathrm{~b}, 16 \mathrm{a}, 16 \mathrm{~b}, 17 \mathrm{a}, 17 \mathrm{~b}, 21,22 \mathrm{a}, 22 \mathrm{~b}, 23$, $24,27 \mathrm{~b}, 27 \mathrm{~d}, 27 \mathrm{f}, 28 \mathrm{a}, 28 \mathrm{~b}, 28 \mathrm{~d}, 28 \mathrm{e}, 28 \mathrm{f}, 29 \mathrm{c}, 29 \mathrm{f}, 29 \mathrm{~g}, 30 \mathrm{a}, 30 \mathrm{c}, 30 \mathrm{~d}, 31 \mathrm{a}$, $31 \mathrm{~b}, 33,34 \mathrm{a}, 35,37 \mathrm{~b}, 38 \mathrm{c}, 40,41,43,44,51,53,54,56,58 \mathrm{a}, 58 \mathrm{c}, 60,62 \mathrm{a}$, $62 \mathrm{~b}, 63 \mathrm{a}, 63 \mathrm{~b}, 65 \mathrm{a}, 67 \mathrm{a}, 68,69,70 \mathrm{a}, 71 \mathrm{a}, 73,74 \mathrm{a}, 74 \mathrm{c}, 75,76 \mathrm{a}, 76 \mathrm{~b}, 77,78 \mathrm{a}$, $78 \mathrm{~b}, 79,80,82,83,84,85,86$.

\section{Clique I. 79 binary characters}

1, 2, 3a, 3b, 4, 5a, 6, 7d, 9, 14, 15b, 16a, 16b, 17a, 17b, 21, 22a, 22b, 23, 24, $27 \mathrm{~b}, 27 \mathrm{~d}, 27 \mathrm{f}, 28 \mathrm{a}, 28 \mathrm{~b}, 28 \mathrm{~d}, 28 \mathrm{e}, 28 \mathrm{f}, 29 \mathrm{c}, 29 \mathrm{f}, 29 \mathrm{~g}, 30 \mathrm{a}, 30 \mathrm{c}, 30 \mathrm{~d}, 30 \mathrm{f}, 31 \mathrm{a}$, $31 \mathrm{~b}, 33,34 \mathrm{a}, 35,37 \mathrm{~b}, 38 \mathrm{c}, 40,41,43,44,51,53,54,56,58 \mathrm{a}, 58 \mathrm{c}, 60,62 \mathrm{a}$, $62 \mathrm{~b}, 63 \mathrm{a}, 63 \mathrm{~b}, 65 \mathrm{a}, 67 \mathrm{a}, 68,69,70 \mathrm{a}, 71 \mathrm{a}, 73,74 \mathrm{a}, 74 \mathrm{c}, 75,76 \mathrm{a}, 76 \mathrm{~b}, 77,78 \mathrm{a}$, $78 \mathrm{~b}, 79,80,82,83,84,85,86$.

\section{Clique J. 79 binary characters}

1, 2, 3a, 3b, 4, 5a, 6, 7b, 7d, 9, 14, 15b, 16a, 17a, 21, 22a, 22b, 23, 24, 27b, $27 \mathrm{c}, 27 \mathrm{~d}, 27 \mathrm{f}, 28 \mathrm{a}, 28 \mathrm{~b}, 28 \mathrm{~d}, 28 \mathrm{e}, 28 \mathrm{f}, 29 \mathrm{c}, 29 \mathrm{f}, 29 \mathrm{~g}, 30 \mathrm{a}, 30 \mathrm{c}, 30 \mathrm{~d}, 31 \mathrm{a}, 31 \mathrm{~b}$, $33,34 \mathrm{a}, 35,37 \mathrm{~b}, 38 \mathrm{c}, 40,41,43,51,53,54,56,58 \mathrm{a}, 58 \mathrm{~b}, 58 \mathrm{c}, 60,62 \mathrm{a}, 62 \mathrm{~b}$, $63 \mathrm{a}, 63 \mathrm{~b}, 65 \mathrm{a}, 67 \mathrm{a}, 68,69,70 \mathrm{a}, 71 \mathrm{a}, 73,74 \mathrm{a}, 74 \mathrm{~b}, 74 \mathrm{c}, 75,76 \mathrm{a}, 76 \mathrm{~b}, 77,78 \mathrm{a}$, $78 \mathrm{~b}, 79,80,82,83,84,85,86$.

\section{Clique K. 78 binary characters}

1, 2, 3a, 3b, 4, 5a, 6, 7d, 9, 14, 15a, 16a, 17a, 18, 21, 22a, 22b, 23, 24, 27b, $27 \mathrm{~d}, 27 \mathrm{f}, 28 \mathrm{a}, 28 \mathrm{~b}, 28 \mathrm{~d}, 28 \mathrm{e}, 28 \mathrm{f}, 29 \mathrm{c}, 29 \mathrm{f}, 29 \mathrm{~g}, 30 \mathrm{a}, 30 \mathrm{c}, 30 \mathrm{~d}, 31 \mathrm{a}, 31 \mathrm{~b}, 33$, $34 \mathrm{a}, 35,37 \mathrm{~b}, 38 \mathrm{c}, 40,41,43,44,51,53,54,56,58 \mathrm{a}, 58 \mathrm{c}, 59 \mathrm{~b}, 60,62 \mathrm{a}, 62 \mathrm{~b}$, $63 \mathrm{a}, 63 \mathrm{~b}, 65 \mathrm{a}, 67 \mathrm{a}, 68,69,70 \mathrm{a}, 71 \mathrm{a}, 73,74 \mathrm{a}, 74 \mathrm{c}, 75,76 \mathrm{a}, 76 \mathrm{~b}, 77,78 \mathrm{a}, 78 \mathrm{l}$ $79,80,82,83,84,85,86$.

\section{Clique L. 77 binary characters}

$1,2,3 \mathrm{a}, 3 \mathrm{~b}, 4,5 \mathrm{a}, 6,7 \mathrm{~b}, 7 \mathrm{~d}, 9,14,15 \mathrm{~b}, 16 \mathrm{a}, 17 \mathrm{a}, 21,22 \mathrm{a}, 22 \mathrm{~b}, 23,24,27 \mathrm{~b}$, $27 \mathrm{~d}, 27 \mathrm{f}, 28 \mathrm{a}, 28 \mathrm{~b}, 28 \mathrm{~d}, 28 \mathrm{e}, 28 \mathrm{f}, 29 \mathrm{c}, 29 \mathrm{f}, 29 \mathrm{~g}, 30 \mathrm{a}, 30 \mathrm{c}, 30 \mathrm{~d}, 31 \mathrm{a}, 31 \mathrm{~b}, 33$, $34 \mathrm{a}, 35,37 \mathrm{~b}, 38 \mathrm{c}, 40,41,43,44,51,53,54,56,58 \mathrm{a}, 58 \mathrm{c}, 60,62 \mathrm{a}, 62 \mathrm{~b}, 63 \mathrm{a}$, $63 \mathrm{~b}, 65 \mathrm{a}, 67 \mathrm{a}, 68,69,70 \mathrm{a}, 71 \mathrm{a}, 73,74 \mathrm{a}, 74 \mathrm{c}, 75,76 \mathrm{a}, 76 \mathrm{~b}, 77,78 \mathrm{a}, 78 \mathrm{~b}, 79$, $80,82,83,84,85,86$. 
Table 7 continued

Clique M. 75 binary characters

1, 2, 3a, 4, 5a, 7a, 7d, 9, 21, 22a, 22b, 23, 24, 27a, 27b, 27c, 27d, 27e, 27f, 28a, 28b, 28c, 28d, 28e, 28f, 29c, 29e, 29f, 29g, 30a, 30c, 30d, 31a, 31b, 33, $34 \mathrm{a}, 35,37 \mathrm{~b}, 38 \mathrm{c}, 40,41,43,51,53,54,56,58 \mathrm{a}, 58 \mathrm{~b}, 59 \mathrm{~b}, 60,62 \mathrm{a}, 63 \mathrm{a}, 63 \mathrm{~b}$, 65a, 67a, 68, 69, 70a, 71a, 72, 74a, 74c, 75, 76a, 76b, 77, 78a, 78b, 79, 80, 82, $83,84,85,86$.

\section{Clique N. 75 binary characters}

1, 2, 3a, 4, 5a, 7d, 9, 21, 22a, 22b, 23, 24, 27a, 27b, 27c, 27d, 27e, 27f, 28a, $28 \mathrm{~b}, 28 \mathrm{c}, 28 \mathrm{~d}, 28 \mathrm{e}, 28 \mathrm{f}, 29 \mathrm{c}, 29 \mathrm{e}, 29 \mathrm{f}, 29 \mathrm{~g}, 30 \mathrm{a}, 30 \mathrm{c}, 30 \mathrm{~d}, 31 \mathrm{a}, 31 \mathrm{~b}, 33,34 \mathrm{a}$, $35,37 \mathrm{~b}, 38 \mathrm{c}, 40,41,43,51,53,54,56,58 \mathrm{a}, 58 \mathrm{~b}, 59 \mathrm{~b}, 60,62 \mathrm{a}, 63 \mathrm{a}, 63 \mathrm{~b}, 65 \mathrm{a}$, $67 \mathrm{a}, 68,69,70 \mathrm{a}, 71 \mathrm{a}, 72,74 \mathrm{a}, 74 \mathrm{~b}, 74 \mathrm{c}, 75,76 \mathrm{a}, 76 \mathrm{~b}, 77,78 \mathrm{a}, 78 \mathrm{~b}, 79,80,82$, $83,84,85,86$.

\section{Clique O. 75 binary characters}

1, 2, 3a, 4, 5a, 7a, 7d, 9, 21, 22a, 22b, 23, 24, 27b, 27c, 27d, 27e, 27f, 28a, 28b, 28c, 28d, 28e, 28f, 29a, 29c, 29e, 29f, 29g, 30a, 30c, 30d, 31a, 31b, 33, $34 \mathrm{a}, 35,37 \mathrm{~b}, 38 \mathrm{c}, 40,41,43,47,51,53,54,56,58 \mathrm{a}, 58 \mathrm{~b}, 60,62 \mathrm{a}, 63 \mathrm{a}, 63 \mathrm{~b}$, $65 \mathrm{a}, 67 \mathrm{a}, 68,69,70 \mathrm{a}, 71 \mathrm{a}, 74 \mathrm{a}, 74 \mathrm{c}, 75,76 \mathrm{a}, 76 \mathrm{~b}, 77,78 \mathrm{a}, 78 \mathrm{~b}, 79,80,81,82$, $83,84,85,86$.

\section{Clique P. 75 binary characters}

1, 2, 3a, 4, 5a, 7d, 9, 21, 22a, 22b, 23, 24, 27b, 27c, 27d, 27e, 27f, 28a, 28b, 28c, 28d, 28e, 28f, 29a, 29c, 29e, 29f, 29g, 30a, 30c, 30d, 31a, 31b, 33, 34a, $35,37 \mathrm{~b}, 38 \mathrm{c}, 40,41,43,47,51,53,54,56,58 \mathrm{a}, 58 \mathrm{~b}, 60,62 \mathrm{a}, 63 \mathrm{a}, 63 \mathrm{~b}, 65 \mathrm{a}$, $67 \mathrm{a}, 68,69,70 \mathrm{a}, 71 \mathrm{a}, 74 \mathrm{a}, 74 \mathrm{~b}, 74 \mathrm{c}, 75,76 \mathrm{a}, 76 \mathrm{~b}, 77,78 \mathrm{a}, 78 \mathrm{~b}, 79,80,81,82$, $83,84,85,86$.

\section{Clique Q. 75 binary characters}

1, 2, 3a, 4, 5a, 7a, 7d, 9, 15b, 16b, 17b, 21, 22a, 22b, 23, 24, 27b, 27c, 27d, 27f, 28a, 28b, 28d, 28e, 28f, 29a, 29c, 29f, 29g, 30a, 30c, 30d, 30f, 31a, 31b, $33,34 \mathrm{a}, 35,37 \mathrm{~b}, 38 \mathrm{c}, 40,41,43,51,53,54,56,58 \mathrm{a}, 58 \mathrm{~b}, 60,62 \mathrm{a}, 63 \mathrm{a}, 63 \mathrm{~b}$, $65 \mathrm{a}, 67 \mathrm{a}, 68,69,70 \mathrm{a}, 71 \mathrm{a}, 74 \mathrm{a}, 74 \mathrm{c}, 75,76 \mathrm{a}, 76 \mathrm{~b}, 77,78 \mathrm{a}, 78 \mathrm{~b}, 79,80,81,82$, $83,84,85,86$.

\section{Clique R. 75 binary characters}

$1,2,3 \mathrm{a}, 4,5 \mathrm{a}, 7 \mathrm{~d}, 9,15 \mathrm{~b}, 16 \mathrm{~b}, 17 \mathrm{~b}, 21,22 \mathrm{a}, 22 \mathrm{~b}, 23,24,27 \mathrm{~b}, 27 \mathrm{c}, 27 \mathrm{~d}, 27 \mathrm{f}, 28 \mathrm{a}$, 28b, 28d, 28e, 28f, 29a, 29c, 29f, 29g, 30a, 30c, 30d, 30f, 31a, 31b, 33, 34a, 35, $37 \mathrm{~b}, 38 \mathrm{c}, 40,41,43,51,53,54,56,58 \mathrm{a}, 58 \mathrm{~b}, 60,62 \mathrm{a}, 63 \mathrm{a}, 63 \mathrm{~b}, 65 \mathrm{a}, 67 \mathrm{a}, 68$, $69,70 \mathrm{a}, 71 \mathrm{a}, 74 \mathrm{a}, 74 \mathrm{~b}, 74 \mathrm{c}, 75,76 \mathrm{a}, 76 \mathrm{~b}, 77,78 \mathrm{a}, 78 \mathrm{~b}, 79,80,81,82,83,84$, 85,86 .

the meaning of the evolutionary history of the whole character of which it is a part. The argument for this action seems to rest on the assumption that the convergence implied by the incompatibility of the single transition of a binary factor affects the likelihood of 
incompatibility of the other character state transitions that make up the rest of the multistate character. I can visualize no theoretical or mechanistic reason how convergence would have such an affect. A compelling reason for retaining all compatible binary factors is that any compatibility is predicted to contain useful information on divergence in some part of the evolutionary history being studied, and to overlook useful information is illogical. I have retained all compatible binary factors in the following reconstruction(s) of phylogeny.

In order to reconstruct phylogeny from a clique one need only specify the primitive state of each character (as determined above; see Table 1), and then cluster the taxa together on the basis of the largest number of shared derived character states (Farris, Kluge and Eckardt, 1970). The tree so constructed will be of minimum length (i.e., most parsimonious). A phylogenetic tree was constructed according to this algorithm for each of the 18 largest cliques (Fig. 7). The characters making up each clique are listed in Table 7 . The affect of fourteen characters, 2, 21, 22a, 24, 27d, 27f, 28f, 30a, 31a, 34a, $53,58 \mathrm{a}, 68$, and $74 \mathrm{a}$, on the clustering is nil because the derived state (1) of each is characteristic of only one species, i.e., it cannot be shared. Each of the 18 trees is a different phylogenetic hypothesis and each is a perfect fit to its data. Which tree is the most probable hypothesis? Note that the gross hierarchic structure (the Group relationships) suggested by the principal component and network analyses is not obviously produced by the compatible characters alone. Of course, one can attribute this difference to the presence of both compatible and incompatible characters in the principal component and network analyses. Still, other unaccounted for differences may exist. For example, a phylogenetic hypothesis based on any set of compatible characters, even the largest in a study, does not necessarily sample those characters for which the best evidence for primitiveness is available. This is illustrated in the present study by the fact that tincta is almost always the most primitive species in the trees produced from the 18 largest cliques. However, that cladistic position of tincta is not predicted by the 55 characters where primitiveness appears to be best documented (see Table 4). I view this example as an illustration of how a character sampling bias can markedly affect one's phylogenetic prediction. Except by a priori weighting, I do not see how compatibility analysis can be freed from such sampling problems.

\section{A PHYLOGENETIC HYPOTHESIS}

The estimable phylogenetic parameters are direction of change (polarity), relative amount of change (patristic) and relative recency of common ancestry (cladistic); see Kluge (1971). In the present study of pygopodids polarity has been discussed under the headings 


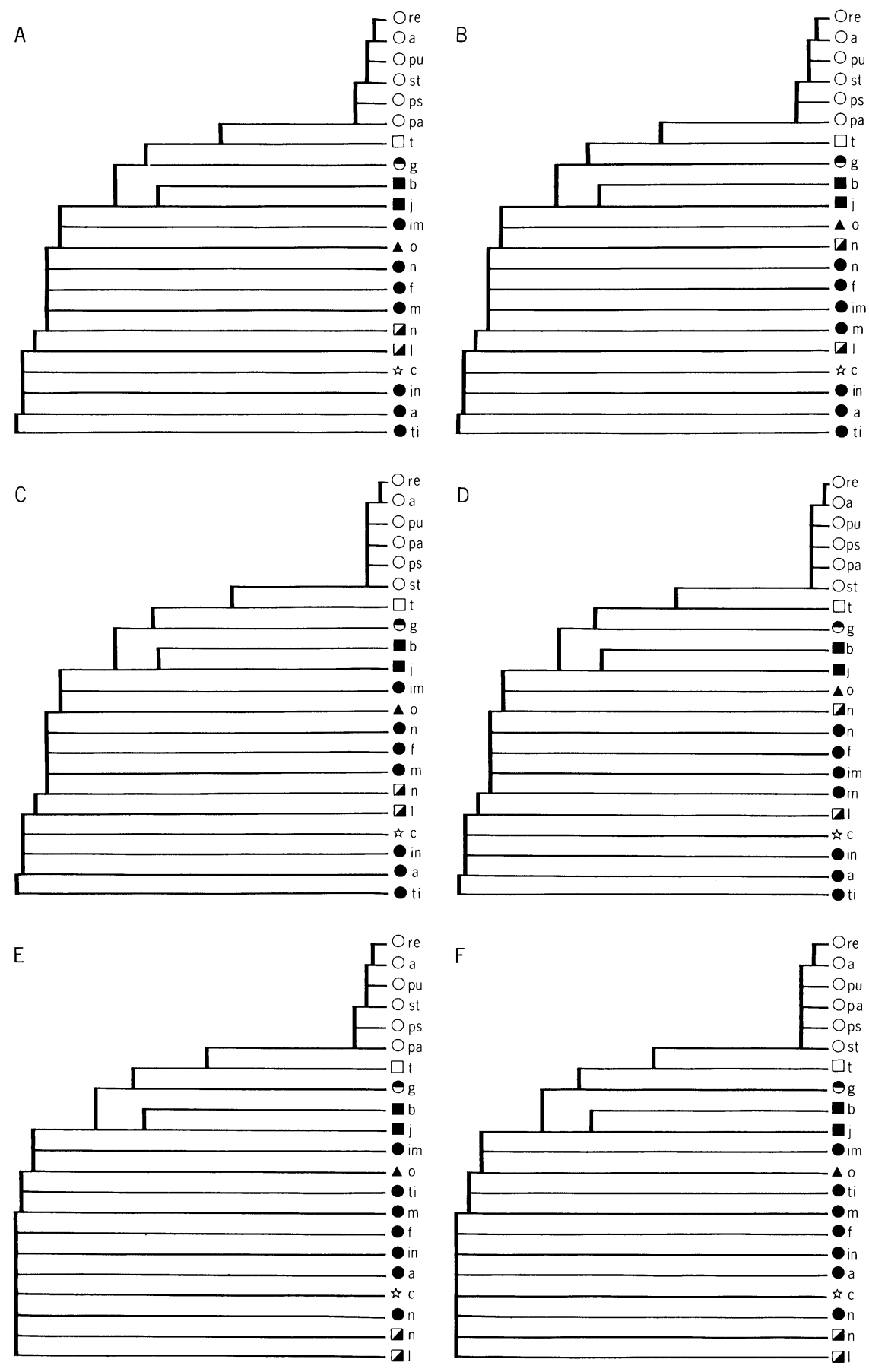

Fig. 7. Minimum length trees based on the largest cliques found in the pygopodid data matrix summarized in Table 5. Table 7 lists the binary characters that form these cliques. Trees A-R refer to cliques A-R in Table 7. Tree A is based on a clique of 81 characters, B on $81, \mathrm{D}$ on $81, \mathrm{E}$ on 80 and $\mathrm{F}$ on 80 . 

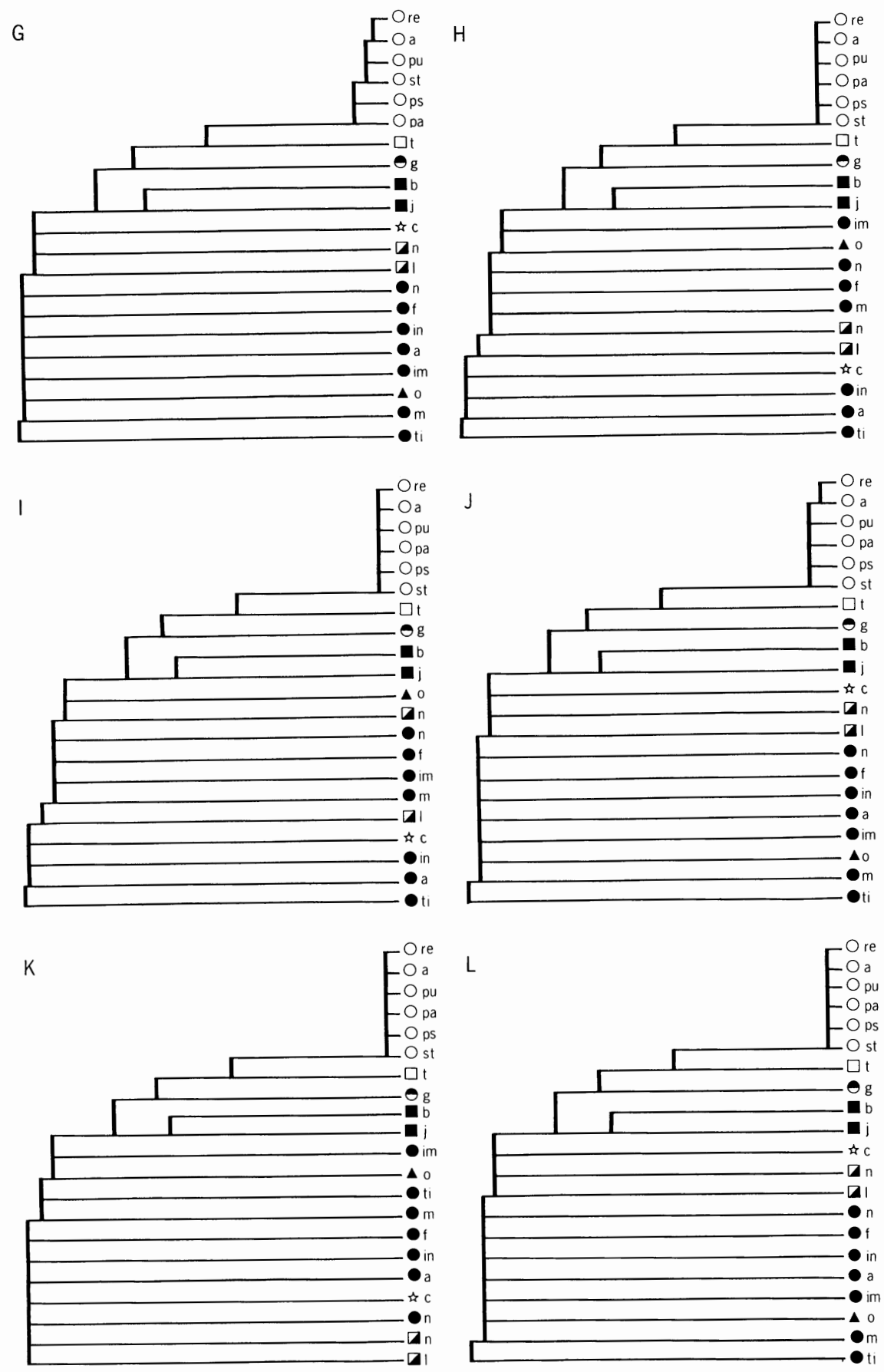

Fig. 7 (cont.). Tree $\mathrm{G}$ is based on a clique of 79 characters, $\mathrm{H}$ on 79 , I on $79, \mathrm{~J}$ on $79, \mathrm{~K}$ on 78 , and $\mathrm{L}$ on 77 . 

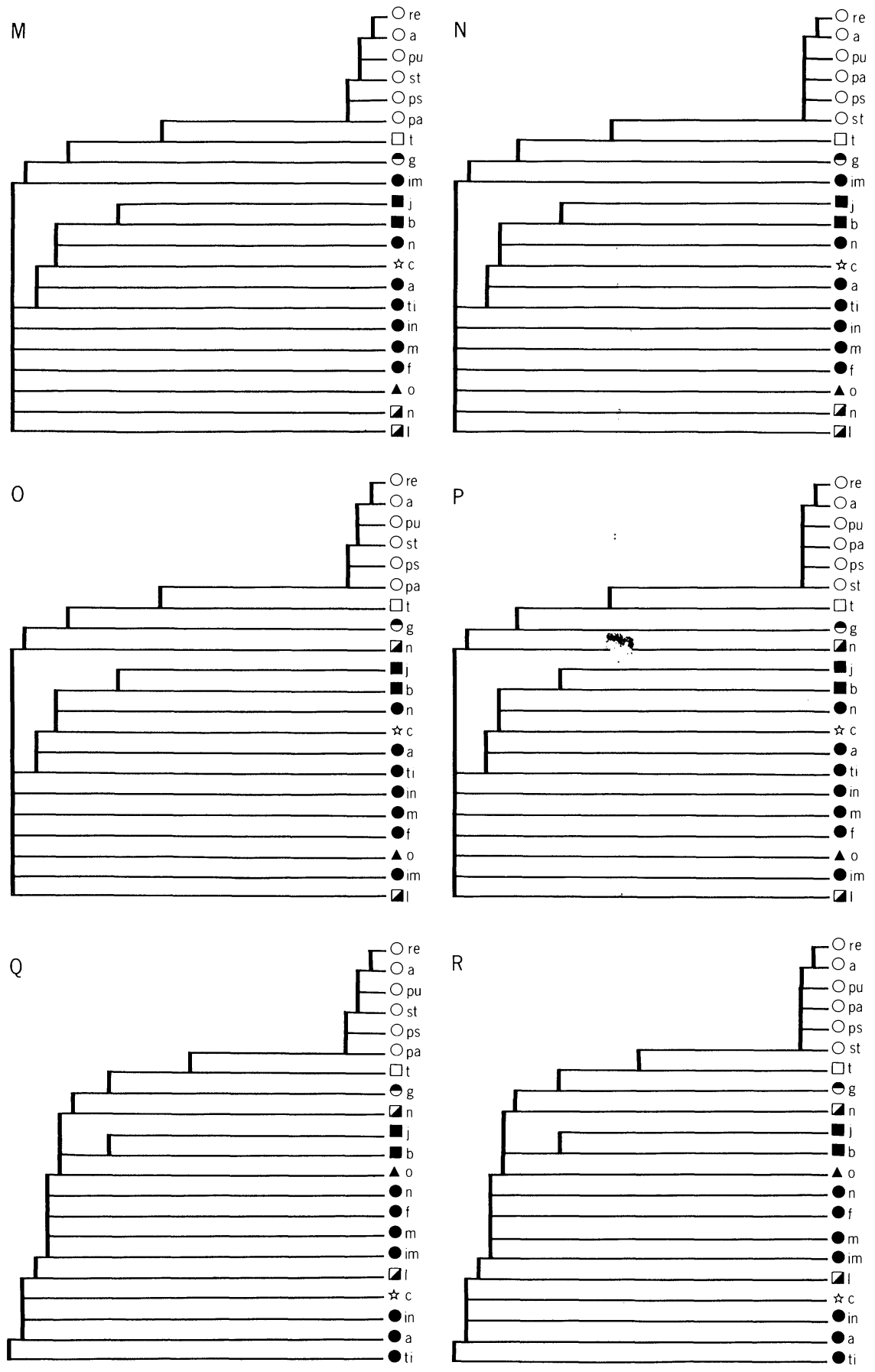

Fig. 7 (cont.). Tree $\mathrm{M}$ is based on a clique of 75 characters, $\mathrm{N}$ on $75, \mathrm{O}$ on $75, \mathrm{P}$ on 75 , $\mathrm{Q}$ on 75 and $\mathrm{R}$ on 75 . 
of ORDER OF EVOLUTIONARY CHANGE and PRIMITIVE CHARACTER STATE SELECTION (pp. 10, 21-28), and the estimate of polarity for each character is summarized in Table 1; also see the section entitled BASIC DATA MATRIX (p. 10).

Numerous similarity coefficients and clustering algorithms have been proposed and applied to data like those in Table 1. The relationships among taxa that are predicted by these applications are usually expressed graphically by continous diverging lines of varying lengths and they have been interpreted as estimates of the patristic and cladistic parameters of phylogeny. Phylogenetic Systematics, often referred to as cladistics (Farris, Kluge and Eckardt, 1970), and Quantitative Phyletics (Kluge and Farris, 1969) are prominent among the many sets of " methods which purport to provide the best phylogenetic inference possible. Needless to say, inferences may change with addition and/or deletion of characters and taxa. The details of the Phylogenetic Systematic and Quantitative Phyletic methods are described elsewhere (Kluge and Farris, 1969; Farris, Kluge and Eckardt, 1970) and their assumptions and limitations have received considerable review and debate (Estabrook, 1972; Sneath and Sokal, 1973). me most significant difference between the two approaches concerns the fact that Phylogenetic Systematics estimates only the cladistic parameter and in doing so it uses only derived states. Quantitative Phyletics estimates both cladistics and patristics and it uses all states, derived and primitive, in those estimations. The proponents of Phylogenetic Systematics assert that the primitive state cannot be used to infer relative recency of common ancestry because no evolutionary change is implied by the primitive state. The logic of their philosophy is unassailable; however, I do not believe that it necessarily has to be applied in practice. Moreover, as I will argue below, to ignore similarity based on shared primitive states can lead to significantly different phylogenetic hypotheses.

I have already pointed out that primitiveness must be viewed as a relative concept (pp. 21-25). Further, the states that characterize the most recent common ancestor of a set of taxa are by definition the most primitive ones in that study. For example, in Fig. 5, taxa $\mathrm{A}_{1-5}$ have a most recent common ancestor $\mathrm{A}$, and the state of each character that describes $\mathrm{A}$ is the most primitive one. The state that describes $\mathrm{A}$ is only primitive relative to those that evolve from it! According to the Phylogenetic Systematic philosophy, for the study of a given set of taxa, say $A_{1-5}$, only the derived states, those differing from the most recent common ancestor, A, are acceptable for analysis. I contend that the taxonomic limits of any study, say $\mathrm{A}_{1-5}$, are purely arbitrary, in the sense that they are set by the availability of material and the extent of the investigator's time and interest. And, it necessarily follows in relaxing the arbitrary taxonomic limit of a study and including other more diverse taxa (eg., $\mathrm{B}_{1-4}$ and 
$\mathrm{C}_{1-4}$ of Fig. 5) that the most primitive set of states will become derived eventually. I am not suggesting that the actual taxonomic limits of a study be relaxed and extended ad infinitum, but only that we recognize primitiveness as a relative concept and that the states of all characters are derived from some preexisting condition. For the purposes of phylogenetic theory, preexistence can be said to stop with the common ancestor of all life.

Exclusion of primitive states from one's inference of phylogeny necessarily means that the patristic parameter cannot be estimated. This follows from the fact that estimated most primitive states, like estimated derived states, may be convergent. The fact that the estimate of the cladistic parameter can vary according to the number of convergent states is another reason why both derived and primitive (see below) states should be included in the analysis.

I have applied the Wagner tree algorithm (Farris, 1970) of Quantitative Phyletics to the pygopodid data set summarized in Table 1. Differential weighting was not employed because I could not identify any evolutionarily sound basis for determining the coefficients peculiar to each character. In one important sense I have weighted the data set to begin with. This follows from the fact that I sampled only the conservative skeletal system and not other more variable parts of the pygopodid phenotype. All characters were scaled to the same 0 to 1 span. The phylogenetic hypothesis that results from the analysis of these data is graphically illustrated in Figure 8. Once again, like the Prim and Wagner networks and principal component analysis, six groups of species are conspicuously set apart from each other on both patristic and cladistic grounds (see Fig. 1-4). Group I consists of aurita, parapulchella, pseudopulchella, pulchella, repens, and striolata. Groups II and III consist of one species each, taeniatus and gracilis, respectively, and Group IV consists of burtonis and jicari. Group $\mathrm{V}$ is made up of australis, concinna, fraseri, impar, inornata, molleri, nasuta and tincta. And, lepidopodis, nigriceps and orientalis make up Group VI. I pointed out on pp. 10-16 that Group I species are currently placed in the genus Aprasia, Group II in Ophidiocephalus, Group III in Pletholax, Group IV in Lialis, Group V in Aclys (concinna only) and Delma, and Group VI in Paradelma (orientalis only) and Pygopus (Kluge, 1974). Further, the phylogenetic hypothesis in Figure 8 predicts that these groups form a linear series of historical relationships. The most primitive group is VI and the most derived is I. Groups II-V are arranged between these extremes in the order that their Group numbers imply. The patristic distances between the most recent common ancestor of adjacent groups indicates that VI and V are the least different patristically and IV and III the most different. Differences between V and IV, III and II, and II and I are approximately the same and intermediate between the two extreme differences. The difference between IV and III is approximately five times greater than that between VI and V, the 


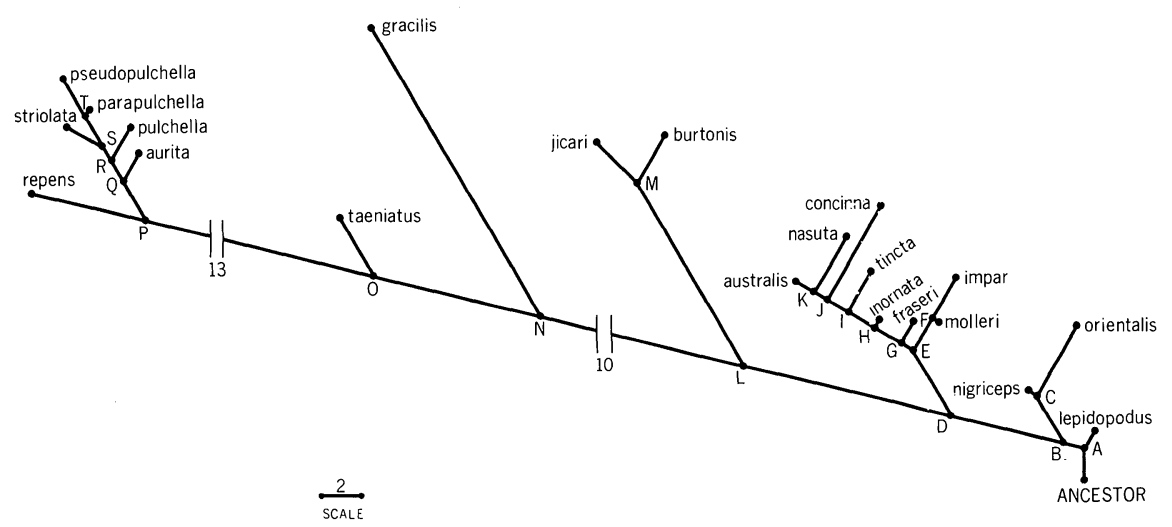

Fig. 8. A phylogenetic hypothesis of 21 species of pygopodids based on the Wagner tree algorithm. The raw data for this analysis are presented in Tables 1 and 2. All characters were rescaled to the same 0 to 1 span of states. The capital letters at the points of divergences denote the successively nested monophyletic groups. The interval lengths are proportionate to the patristic distances calculated from the rescaled data in Table 1 . The amount of patristic distance removed from intervals L,N and O,P for purposes of compacting the illustrations is indicated by the numbers located below the broken portion of the interval.

intermediate differences are between 2.5 and 2.9 times greater than $\mathrm{VI}$ and $\mathrm{V}$.

The consistency index (c) for the phylogenetic prediction illustrated in Figure 8 is .572. Such a large value indicates that the hierarchic hypothesis is a very good 2-dimensional representation of the data set (Tables 1-2). Thirty-seven of the 86 characters analyzed $(43 \%)$ are represented in the hypothesis exactly as they are described in Tables 1-2, i.e., no convergent states are observed (Table 8). In fact, 243 character state changes are observed in the phylogenetic hypothesis compared to the total predicted number of 139 (viz., one less than the number of states in a character, summed over all characters); see Tables 1-2 and 8. According to the Wagner tree algorithm, 243 is the fewest number of changes (transitions or steps of other authors) that can be found when the data set of Table 1 is converted to a 2-dimensional hierarchic structure (see correction on p. 57). The difference between the predicted and observed numbers of changes, 104, is the number of extra evolutionary events (convergences, parallelisms, or reversals). The predicted total number of evolutionary changes, 139 in the present example, has been called the size of the data set (R) and the observed total number of evolutionary changes, 243 , the length of the tree $(\mathrm{L})$. The consistency index, $\mathrm{c}$, is calculated by dividing $\mathrm{R}$ by $\mathrm{L}$.

An individual character consistency index $\left(c_{i}\right)$ is found by dividing $r_{i}$ by $l_{i}$, where $r_{i}$ is the predicted patristic length or predicted number of evolutionary changes, as set forth in Tables 1 and 2, 
TABLE 8

CHARACTER ANALYSIS BASED ON THE HYPOTHETICAL PHYLOGENY OF PYGOPODIDS (SEE FIG. 8)

\begin{tabular}{|c|c|c|c|}
\hline \multirow[b]{2}{*}{ Character (i) } & \multicolumn{2}{|c|}{$\begin{array}{c}\text { Number of Character } \\
\text { State Changes }\end{array}$} & \multirow{2}{*}{$\begin{array}{r}\text { Consistency } \\
\text { Index }\left(c_{i}\right)\end{array}$} \\
\hline & Predicted $\left(\mathrm{r}_{\mathrm{i}}\right)$ & Observed $\left(\mathrm{l}_{\mathbf{i}}\right)$ & \\
\hline 1 & 1 & 1 & 1.00 \\
\hline 2 & 1 & 1 & 1.00 \\
\hline 3 & 2 & 2 & 1.00 \\
\hline 4 & 1 & 1 & 1.00 \\
\hline 5 & 2 & 4 & 0.50 \\
\hline 6 & 1 & 1 & 1.00 \\
\hline 7 & 4 & 11 & 0.36 \\
\hline 8 & 1 & 2 & 0.50 \\
\hline 9 & 1 & 1 & 1.00 \\
\hline 10 & 1 & 4 & 0.25 \\
\hline 11 & 1 & 2 & 0.50 \\
\hline 12 & 1 & 4 & 0.25 \\
\hline 13 & 1 & 2 & 0.50 \\
\hline 14 & 1 & 1 & 1.00 \\
\hline 15 & 2 & 5 & 0.40 \\
\hline 16 & 2 & 4 & 0.50 \\
\hline 17 & 2 & 6 & 0.33 \\
\hline 18 & 1 & 4 & 0.25 \\
\hline 19 & 1 & 2 & 0.50 \\
\hline 20 & 1 & 2 & 0.50 \\
\hline 21 & 1 & 1 & 1.00 \\
\hline $22^{1}$ & 2 & 2 & 1.00 \\
\hline 23 & 1 & 1 & 1.00 \\
\hline 24 & 1 & 1 & 1.00 \\
\hline 25 & 1 & 3 & 0.33 \\
\hline 26 & 1 & 2 & 0.50 \\
\hline $27^{1}$ & 6 & 9 & 0.67 \\
\hline $28^{1}$ & 6 & 7 & 0.86 \\
\hline $29^{1}$ & 7 & 15 & 0.47 \\
\hline 30 & 6 & 10 & 0.61 \\
\hline 31 & 3 & 4 & 0.75 \\
\hline 32 & 2 & 4 & 0.50 \\
\hline 33 & 1 & 1 & 1.00 \\
\hline 34 & 2 & 3 & 0.67 \\
\hline 35 & 1 & 1 & 1.00 \\
\hline $36^{1}$ & 2 & 3 & 0.67 \\
\hline $37^{1}$ & 2 & 5 & 0.40 \\
\hline $38^{1}$ & 3 & 6 & 0.50 \\
\hline 39 & 1 & 2 & 0.50 \\
\hline 40 & 1 & 1 & 1.00 \\
\hline 41 & 1 & 1 & 1.00 \\
\hline 42 & 1 & 2 & 0.50 \\
\hline 43 & 1 & 1 & 1.00 \\
\hline 44 & 1 & 1 & 1.00 \\
\hline 45 & 2 & 7 & 0.29 \\
\hline 46 & 2 & 5 & 0.40 \\
\hline
\end{tabular}




\begin{tabular}{|c|c|c|c|}
\hline \multirow[b]{2}{*}{ Character (i) } & \multicolumn{2}{|c|}{$\begin{array}{l}\text { Number of Character } \\
\text { State Changes }\end{array}$} & \multirow{2}{*}{$\begin{array}{r}\text { Consistency } \\
\text { Index }\left(c_{i}\right)\end{array}$} \\
\hline & Predicted $\left(r_{i}\right)$ & Observed $\left(l_{i}\right)$ & \\
\hline \multicolumn{4}{|l|}{ Table 8 continued } \\
\hline 47 & 1 & 3 & 0.33 \\
\hline 48 & 1 & 3 & 0.33 \\
\hline 49 & 1 & 3 & 0.33 \\
\hline 50 & 1 & 2 & 0.50 \\
\hline 51 & 1 & 1 & 1.00 \\
\hline 52 & 1 & 2 & 0.50 \\
\hline 53 & 1 & 1 & 1.00 \\
\hline 54 & 1 & 1 & 1.00 \\
\hline 55 & 1 & 2 & 0.50 \\
\hline 56 & 1 & 1 & 1.00 \\
\hline 57 & 1 & 3 & 0.33 \\
\hline 58 & 3 & 4 & 0.75 \\
\hline 59 & 2 & 5 & 0.40 \\
\hline 60 & 1 & 1 & 1.00 \\
\hline 61 & 1 & 2 & 0.50 \\
\hline 62 & 2 & 2 & 1.00 \\
\hline $63^{1}$ & 2 & 2 & 1.00 \\
\hline 64 & 1 & 3 & 0.33 \\
\hline 65 & 2 & 4 & 0.50 \\
\hline 66 & 1 & 3 & 0.33 \\
\hline 67 & 2 & 3 & 0.67 \\
\hline 68 & 1 & 1 & 1.00 \\
\hline 69 & 1 & 1 & 1.00 \\
\hline 70 & 2 & 3 & 0.67 \\
\hline 71 & 2 & 3 & 0.67 \\
\hline 72 & 1 & 4 & 0.25 \\
\hline 73 & 1 & 2 & 0.50 \\
\hline 74 & 3 & 5 & 0.60 \\
\hline 75 & 1 & 1 & 1.00 \\
\hline 76 & 2 & 2 & 1.00 \\
\hline 77 & 1 & 1 & 1.00 \\
\hline 78 & 2 & 2 & 1.00 \\
\hline 79 & 1 & 1 & 1.00 \\
\hline 80 & 1 & 1 & 1.00 \\
\hline 81 & 1 & 2 & 0.50 \\
\hline 82 & 1 & 1 & 1.00 \\
\hline 83 & 1 & 1 & 1.00 \\
\hline 84 & 1 & 1 & 1.00 \\
\hline 85 & 1 & 1 & 1.00 \\
\hline 86 & 1 & 1 & 1.00 \\
\hline
\end{tabular}

${ }^{1} \mathrm{~A}$ state other than zero is primitive.

and $\mathrm{l}_{\mathrm{i}}$ is the patristic length or number of evolutionary changes observed on the 2-dimensional hierarchic hypothesis (see Table 8). The individual character consistency indexes are tabulated in Table 8. Table 9 ranks the characters according to their consistency index. The indices vary between 1.00 and 0.25 . The lower the value the 
larger the number of nondivergent phenomena that are observed in the hypothesis.

The predicted character state changes and where they occur in the evolutionary transitions between taxa for the hypothesis illustrated in Figure 8 are summarized in Table 10. Twenty-six of the 104 nondivergent events $(25 \%)$ predicted by the hypothesis are reversals to the primitive state.

Monophyletic groups of taxa, the cladistic part of a phylogenetic hypothesis, can be specified unequivocally only by unique evolutionary changes. These are the conditions that have evolved but once and are the only ones that unambiguously determine taxonomic membership in a group (Hennig, 1966). I know of no one who has found a way to detect and prove the existence of a unique evolutionary event (see previous discussion of CHARACTER COMPATIBILITY, pp. 28-39, and Estabrook, 1972), and therefore, the argument is usually made that the larger the number of hypothesized changes characteristic of a monophyletic group the more evidence there is for the group's existence (Farris, 1971). In the pygopodid phylogenetic hypothesis illustrated in Figure 8, there are 20 monophyletic groups. The common ancestor of each group is designated by a upper case letter, A-T and it is used in the following discussion to refer to that group. Only nine of the 20 groups are characterized by unique evolutionary events. They are A, B, D, L, M, N, O, P and Q. All evolutionary changes in Figure 8, unique and independently evolved, are listed in Table 11 opposite the interval where the event occurs. The interval immediately ancestral to a monophyletic group provides the information for that group's definition. For example, the monophyletic group designated L in Figure 8 is characterized by those events that describe the interval $\mathrm{D}, \mathrm{L}$ in Table 11 . The $\mathrm{D}, \mathrm{L}$ interval is based on state changes in 15 characters. The characters are $3,6,12-18,30,31,34$, 58,62 , and 70 (see pp. 55-67). Which of these changes are unique can be determined by inspecting Table 10. For example, character 3 is predicted to contain only unique evolutionary events, viz., states 0,1 and 2 are derived but once in the two intervals $(\mathrm{D}, \mathrm{L}$ and $\mathrm{N}, \mathrm{O})$ where change in this character occurs. Character 12, in contrast to 3, exhibits no unique character states. Character 12 is binary and both states are predicted to have evolved more than once independently. In fact, character 12 contains examples of two reversals to the primitive state and two convergences. Character 58 provides another interesting example (see Table 10). While state 1 is derived but once, and that unique event describes the D,L interval, state 2 appears in two intervals. State 2 is implied by the transition 1-3 in the interval designated "P, repens" and it appears again in the "Q, aurita" interval. This example emphasizes the fact that multistate characters can contain both uniquely derived states and those that appear more than once. Stated another way, a multistate character may unequivocally specify one monophyletic group but not another in a given phylogenetic hypothesis. Elimination of an entire multistate 
TABLE 9

CONSISTENCY INDEX OF CHARACTERS USED IN HYPOTHETICAL PHYLOGENY OF PYGOPODIDS (SEE FIG. 8) ${ }^{1}$

$$
\begin{aligned}
& \mathrm{c}_{\mathrm{i}}=1.00 \\
& 1-4,6,9,14,21-4,33,35,40-1,43-4,51,53-4,56,60,62-3 \text {, } \\
& 68-9,75-80,82-6 \quad \mathrm{n}=37 \\
& \mathrm{c}_{\mathrm{i}}=\begin{array}{l}
0.85 \\
28
\end{array} \\
& \mathrm{n}=1 \\
& \mathrm{c}_{\mathrm{i}}=0.75 \\
& 31,58 \quad \mathrm{n}=2 \\
& \mathrm{c}_{\mathrm{i}}=0.67 \\
& 27,34,36,67,70-1 \quad \mathrm{n}=6 \\
& c_{\mathrm{i}}=\begin{array}{l}
0.61 \\
30
\end{array} \\
& \mathrm{n}=1 \\
& c_{i}=0.60 \\
& \mathrm{n}=1 \\
& 74 \\
& \mathrm{c}_{\mathrm{i}}=0.50 \\
& 5,8,11,13,16,19,20,26,32,38-9,42,50,52,55,61,65 \text {, } \\
& 73,81 \\
& \mathrm{n}=19 \\
& c_{i}=0.47 \\
& 29 \\
& \mathrm{n}=1 \\
& c_{i}=0.40 \\
& 15,37,46,59 \quad \mathrm{n}=4 \\
& \mathrm{c}_{\mathrm{i}}=\begin{array}{l}
0.36 \\
7
\end{array} \\
& \mathrm{n}=1 \\
& \mathrm{c}_{\mathrm{i}}=0.33 \\
& 17,25,47-9,57,64,66 \quad \mathrm{n}=8 \\
& c_{i}=0.29 \\
& 45 \quad n=1 \\
& \mathrm{c}_{\mathrm{i}}=0.25 \\
& 10,12,18,72 \quad \mathrm{n}=4
\end{aligned}
$$

${ }^{1}$ The consistency index is listed in Table $8 . c_{i}=$ consistency index; $\mathrm{n}=$ number of characters. 


\section{TABLE 10}

PREDICTED CHARACTER STATE CHANGES AND INTERVALS IN HYPOTHETICAL PHYLOGENY OF PYGOPODIDS (SEE FIG. 8)

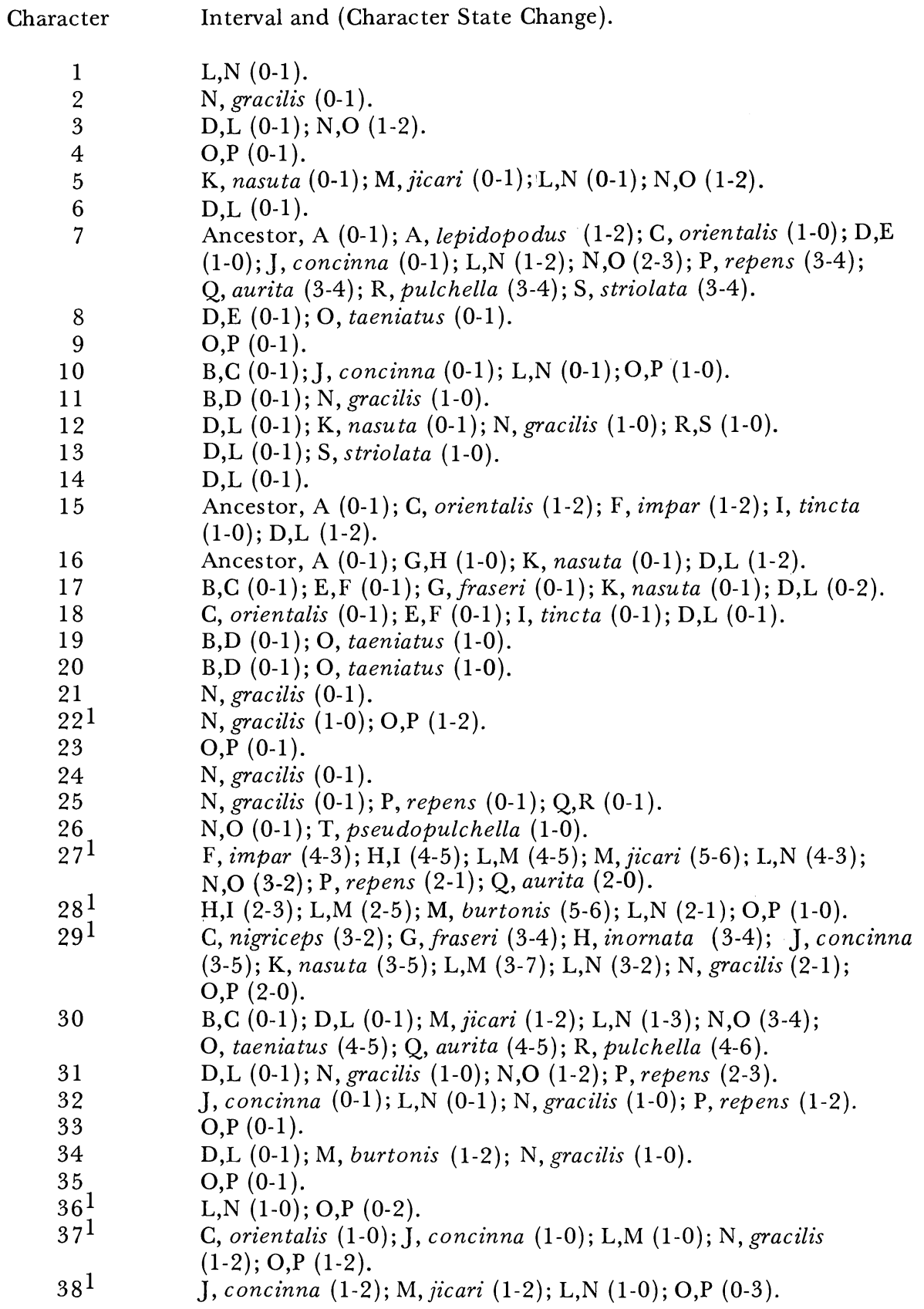


Table 10 continued

Character Interval and (Character State Change).

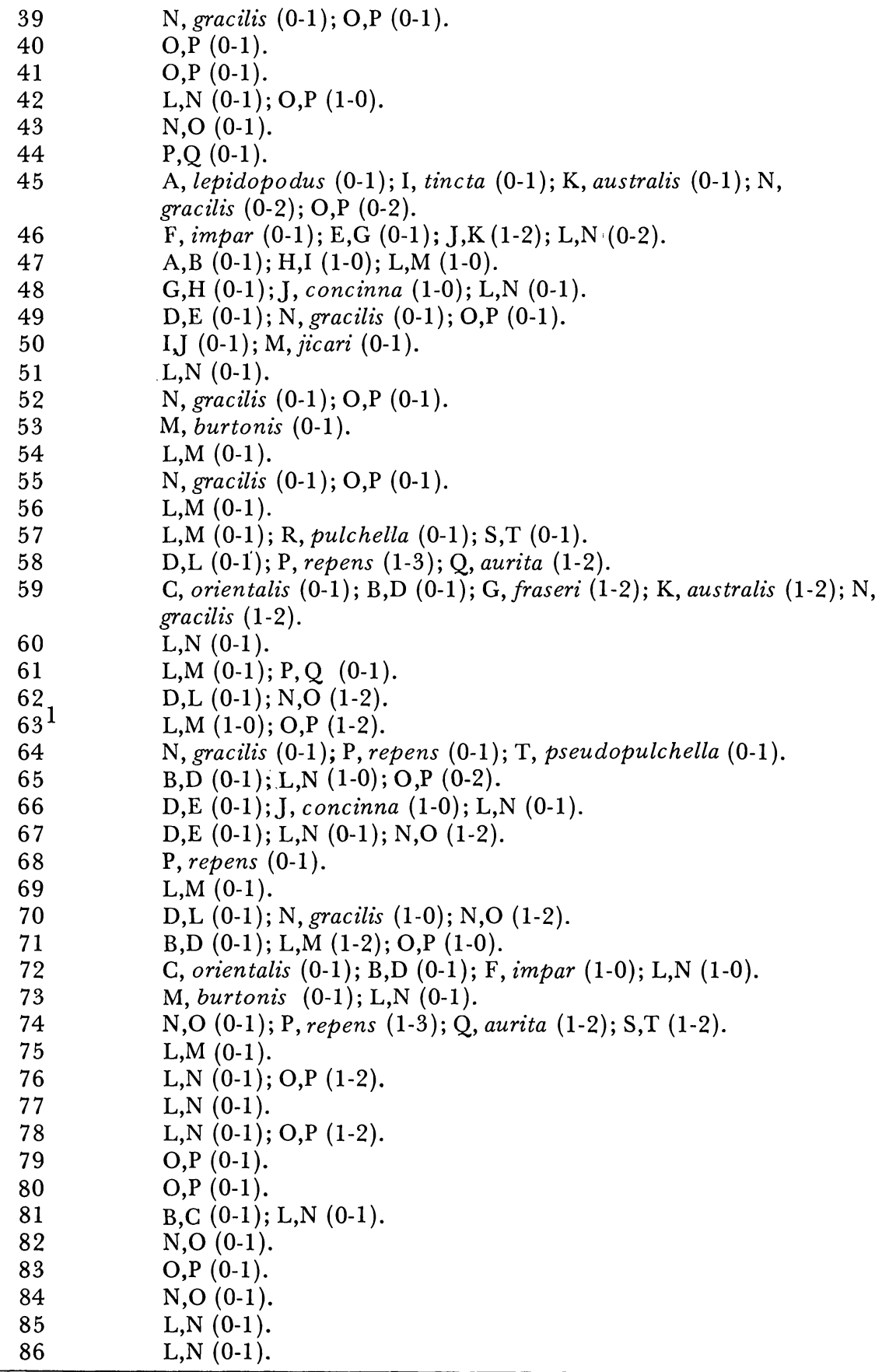

${ }^{1} \mathrm{~A}$ state other than zero is primitive. 
TABLE 11

PREDICTED CHARACTER STATE CHANGES LISTED BY INTERVAL OF THE HYPOTHETICAL PHYLOGENY (SEE FIG. 8) ${ }^{1}$

\begin{tabular}{|c|c|}
\hline Interval & Character and (Character State Change) \\
\hline Ancestor, A & $7(0-1) ; 15(0-1) ; 16(0-1)$ \\
\hline A, lepidopodus & $7(1-2) ; 45(0-1)$ \\
\hline $\mathrm{A}, \mathrm{B}$ & $47(0-1)$ \\
\hline $\mathrm{B}, \mathrm{C}$ & $10(0-1) ; 17(0-1) ; 30(0-1) ; 81(0-1)$ \\
\hline $\mathrm{C}$, nigriceps & $29(3-2)$ \\
\hline $\mathrm{C}$, orientalis & $7(1-0) ; 15(1-2) ; 18(0-1) ; 37(1-0) ; 59(0-1) ; 72(0-1)$ \\
\hline $\mathrm{B}, \mathrm{D}$ & $\begin{array}{l}11(0-1) ; 19(0-1) ; 20(0-1) ; 59(0-1) ; 65(0-1) ; 71(0-1) \text {; } \\
72(0-1)\end{array}$ \\
\hline $\mathrm{D}, \mathrm{E}$ & $7(1-0) ; 8(0-1) ; 49(0-1) ; 66(0-1) ; 67(0-1)$ \\
\hline $\mathrm{E}, \mathrm{F}$ & $17(0-1) ; 18(0-1)$ \\
\hline $\mathrm{F}$, molleri & No character state changes are predicted. \\
\hline $\mathrm{F}$, impar & $15(1-2) ; 27(4-3) ; 46(0-1) ; 22(1-0)$ \\
\hline $\mathrm{E}, \mathrm{G}$ & $46(0-1)$ \\
\hline $\mathrm{G}$, fraseri & $17(0-1) ; 29(3-4) ; 59(1-2)$ \\
\hline $\mathrm{G}, \mathrm{H}$ & $16(1-0) ; 48(0-1)$ \\
\hline $\mathrm{H}$, inornata & $29(3-4)$ \\
\hline $\mathrm{H}, \mathrm{I}$ & $27(4-5) ; 28(2-3) ; 47(1-0)$ \\
\hline I, tincta & $15(1-0) ; 18(0-1) ; 45(0-1)$ \\
\hline $\mathrm{I}, \mathrm{J}$ & $50(0-1)$ \\
\hline $\mathrm{J}$, concinna & $\begin{array}{l}7(0-1) ; 10(0-1) ; 29(3-[4]-5) ; 32(0-1) ; 37(1-0) ; 38(1-2) \\
48(1-0) ; 66(1-0)\end{array}$ \\
\hline $\mathrm{J}, \mathrm{K}$ & $46(1-2)$ \\
\hline $\mathrm{K}$, australis & $45(0-1) ; 59(1-2)$ \\
\hline $\mathrm{K}$, nasuta & $5(0-1) ; 12(0-1) ; 16(0-1) ; 17(0-1) ; 29(3-[4]-5)$ \\
\hline $\mathrm{D}, \mathrm{L}$ & $\begin{array}{l}3(0-1) ; 6(0-1) ; 12(0-1) ; 13(0-1) ; 14(0-1) ; 15(1-2) ; \\
16(1-2) ; 17(0-[1]-2) ; 18(0-1) ; 30(0-1) ; 31(0-1) ; 34(0-1) ; 5 \\
(0-1) ; 62(0-1) ; 70(0-1)\end{array}$ \\
\hline $\mathrm{L}, \mathrm{M}$ & $\begin{array}{l}27(4-5) ; 28(2-[3-4]-5) ; 29(3-[4-5-6]-7) ; 37(1-0) ; \\
47(1-0) ; 54(0-1) ; 56(0-1) ; 57(0-1) ; 61(0-1) ; 63(1-0) \\
69(0-1) ; 71(1-2) ; 75(0-1)\end{array}$ \\
\hline $\mathrm{M}$, burtonis & $28(5-6) ; 34(1-2) ; 53(0-1) ; 73(0-1)$ \\
\hline M, jicari & $5(0-1) ; 27(5-6) ; 30(1-2) ; 38(1-2) ; 50(0-1)$ \\
\hline $\mathrm{L}, \mathrm{N}$ & $\begin{array}{l}1(0-1) ; 5(0-1) ; 7(1-2) ; 10(0-1) ; 27(4-3) ; 28(2-1) ; 29 \\
(3-2) ; 30(1-[2]-3) ; 32(0-1) ; 36(1-0) ; 38(1-0) ; 42(0-1) \text {; } \\
46(0-[1]-2) ; 48(0-1) ; 51(0-1) ; 60(0-1) ; 65(1-0) ; 66 \\
(0-1) ; 67(0-1) ; 72(1-0) ; 73(0-1) ; 76(0-1) ; 77(0-1) ; 78 \\
(0-1) ; 81(0-1) ; 85(0-1) ; 86(0-1)\end{array}$ \\
\hline $\mathrm{N}$, gracilis & $\begin{array}{l}2(0-1) ; 11(1-0) ; 12(1-0) ; 21(0-1) ; 22(1-0) ; 24(0-1) ; \\
25(0-1) ; 29(2-1) ; 31(1-0) ; 32(1-2) ; 34(1-0) ; 37(1-2) ; \\
39(0-1) ; 45(0-[1]-2) ; 49(0-1) ; 52(0-1) ; 55(0-1) ; 59 \\
(1-2) ; 64(0-1) ; 70(1-0)\end{array}$ \\
\hline $\mathrm{N}, \mathrm{O}$ & $\begin{array}{l}3(1-2) ; 5(1-2) ; 7(2-3) ; 26(0-1) ; 27(3-2) ; 30(3-4) ; 31 \\
(1-2) ; 43(0-1) ; 62(1-2) ; 67(1-2) ; 70(1-2) ; 74(0-1) ; 82 \\
(0-1) ; 84(0-1)\end{array}$ \\
\hline O, taeniatus & $8(0-1) ; 19(1-0) ; 20(1-0) ; 30(4-5)$ \\
\hline $\mathrm{O}, \mathrm{P}$ & $\begin{array}{l}4(0-1) ; 9(0-1) ; 10(1-0) ; 20(1-2) ; 23(0-1) ; 28(1-0) ; 29 \\
(2-[1]-0) ; 33(0-1) ; 35(0-1) ; 36(0-[1]-2) ; 37(1-2) ; 38\end{array}$ \\
\hline
\end{tabular}




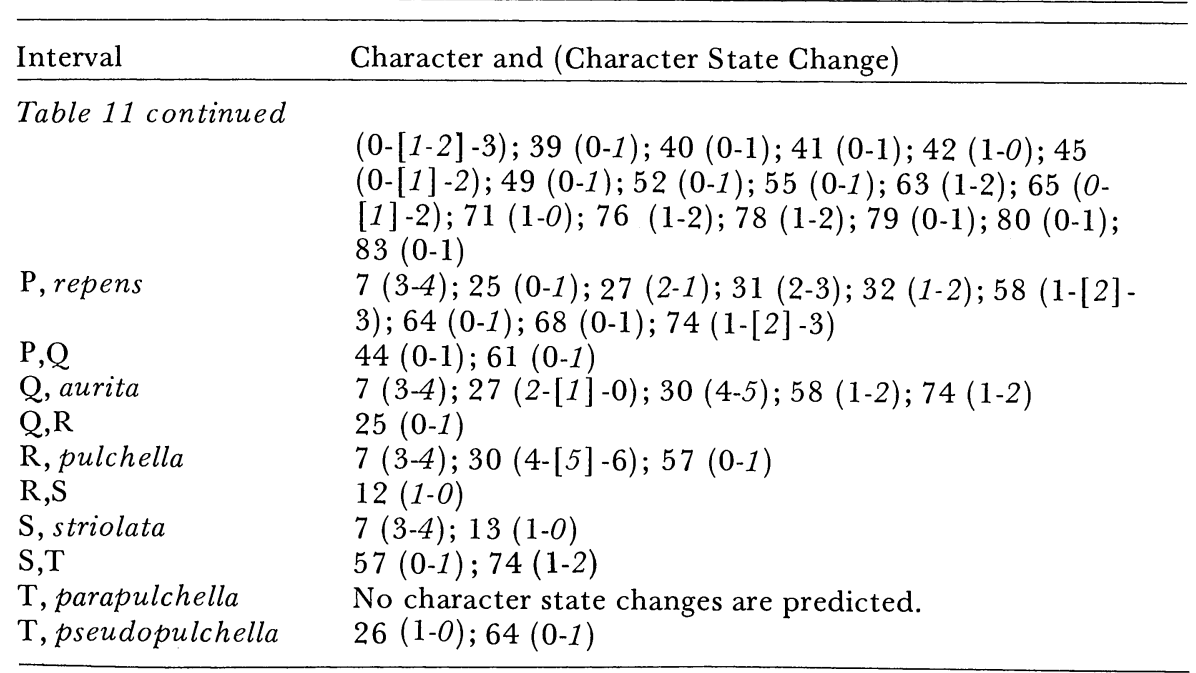

${ }^{1}$ States that are not uniquely derived are in italics. Brackets enclose states implied by the corresponding transition listed in Table 2 .

character from a study because some of its states are independently evolved (see discussion on page 29) will distort the evidence for monophyletic groups.

The number of uniquely derived states that characterizes each of the monophyletic groups recognized in a phylogenetic hypothesis varies considerably. In the present study of pygopodids (Fig. 8), the number ranges from 0 to 19 (see Table 12). It is particularly noteworthy that the most conspicuously differentiated species and clusters of species in Figure 8, referred to previously as Groups I-VI, belong to or are themselves monophyletic groups diagnosed by the largest number of uniquely derived states. Group I (monophyletic group P) is diagnosed by 19 such states. Group II, consisting of only taeniatus, and Group I belong to monophyletic group 0 and it is diagnosed by 13 uniquely derived states. Group III consisting of only gracilis, and II and I belong to monophyletic group $\mathrm{N}$ and it is diagnosed by 13 uniquely derived states. Group IV (monophyletic group M) is diagnosed by 8 uniquely derived states and its membership in the monophyletic group L, which includes Groups I, II, and III, is diagnosed by 11 uniquely derived states. Groups I-V are included in monophyletic group $\mathrm{D}$ and it is characterized by 4 uniquely derived states. The three species of Group VI are distributed between monophyletic groups $\bar{B}$ and $A$ and each is diagnosed by one uniquely derived state. The monophyletic clusters of species within the largest Groups, I and $\mathrm{V}$ have one or no uniquely derived states. Only the $\mathrm{Q}$ monophyletic set, which includes all species of Group I but repens, is diagnosed by one uniquely derived state. The remainder of these cladistic relationships are based on conditions that are hypothesized 
TABLE 12

NUMBER OF CHARACTER STATE CHANGES DESCRIBING INTERVALS AND CORRESPONDING MONOPHYLETIC GROUPS OF THE HYPOTHETICAL PHYLOGENY (SEE FIG. 8$)^{1}$

\begin{tabular}{|c|c|c|c|}
\hline Interval & $\begin{array}{c}\text { Monophyletic } \\
\text { Group }\end{array}$ & $\begin{array}{c}\text { Total Number } \\
\text { of Changes }\end{array}$ & $\begin{array}{c}\text { Number of } \\
\text { Unique Changes }\end{array}$ \\
\hline Ancestor, A & A & 3 & 1 \\
\hline $\mathrm{A}, \mathrm{B}$ & B & 1 & 1 \\
\hline $\mathrm{B}, \mathrm{C}$ & $\mathrm{C}$ & 4 & 0 \\
\hline $\mathrm{B}, \mathrm{D}$ & $\mathrm{D}$ & 7 & 4 \\
\hline $\mathrm{D}, \mathrm{E}$ & $\mathrm{E}$ & 5 & 0 \\
\hline $\mathrm{E}, \mathrm{F}$ & $\mathrm{F}$ & 2 & 0 \\
\hline $\mathrm{E}, \mathrm{G}$ & $\mathrm{G}$ & 1 & 0 \\
\hline $\mathrm{G}, \mathrm{H}$ & $\mathrm{H}$ & 2 & 0 \\
\hline $\mathrm{H}, \mathrm{I}$ & I & 3 & 0 \\
\hline $\mathrm{I}, \mathrm{J}$ & $\mathrm{J}$ & 1 & 0 \\
\hline $\mathrm{J}, \mathrm{K}$ & $\mathrm{K}$ & 1 & 0 \\
\hline $\mathrm{D}, \mathrm{L}$ & $\mathrm{L}$ & 16 & 11 \\
\hline $\mathrm{L}, \mathrm{M}$ & $\mathrm{M}$ & 18 & 8 \\
\hline $\mathrm{L}, \mathrm{N}$ & $\mathrm{N}$ & 29 & 13 \\
\hline $\mathrm{N}, \mathrm{O}$ & $\mathrm{O}$ & 14 & 13 \\
\hline $\mathrm{O}, \mathrm{P}$ & $\mathrm{P}$ & 34 & 19 \\
\hline$P, Q$ & $Q$ & 2 & 1 \\
\hline $\mathrm{Q}, \mathrm{R}$ & $\mathrm{R}$ & 1 & 0 \\
\hline $\mathrm{R}, \mathrm{S}$ & $\mathrm{s}$ & 1 & 0 \\
\hline $\mathrm{S}, \mathrm{T}$ & $\mathrm{T}$ & 2 & 0 \\
\hline A, lepidopodus & -1 & 2 & 0 \\
\hline C, nigriceps & & 1 & 0 \\
\hline $\mathrm{C}$, orientalis & & 6 & 0 \\
\hline $\mathrm{F}$, molleri & & 0 & 0 \\
\hline $\mathrm{F}$, impar & & 4 & 0 \\
\hline $\mathrm{G}$, fraseri & & 3 & 0 \\
\hline $\mathrm{H}$, inornata & & 1 & 0 \\
\hline $\mathrm{I}$, tincta & & 3 & 0 \\
\hline $\mathrm{J}$, concinna & & 9 & 0 \\
\hline $\mathrm{K}$, australis & & 2 & 0 \\
\hline $\mathrm{K}$, nasuta & & 6 & 0 \\
\hline $\mathrm{M}$, burtonis & & 4 & 3 \\
\hline $\mathrm{M}$, jicari & & 5 & 1 \\
\hline $\mathrm{N}$, gracilis & & 21 & 4 \\
\hline $\mathrm{O}$, taeniatus & & 4 & 0 \\
\hline $\mathrm{P}$, repens & & 11 & 4 \\
\hline $\mathrm{Q}$, aurita & & 6 & 1 \\
\hline$\widetilde{\mathrm{R}}$, pulchella & & 4 & 1 \\
\hline $\mathrm{S}$, striolata & & 2 & 0 \\
\hline $\mathrm{T}$, parapulchella & & 0 & 0 \\
\hline $\mathrm{T}$, pseudopulchella & & 2 & 0 \\
\hline
\end{tabular}

$\mathrm{T}$, pseudopulchella

1The category "Monophyletic Group" does not logically apply to the species considered alone. 
to have evolved independently, and I must conclude that there is relatively less unambiguous evidence for these relationships. Table 11 also indicates that only six of the 21 species are themselves diagnosed by uniquely derived states. These species and the number of their unique states, in parentheses, are as follows: burtonis (3), jicari (1), gracilis (4), repens (4), aurita (1), and pulchella (1).

\section{A REEXAMINATION OF THE CHARACTERS}

A phylogenetic tree, such as the most parsimonious one illustrated in Figure 8, is a hypothesis of historical relationships among taxa. To a limited degree, a phylogenetic tree also serves as a test of the hypothesis that the states of each character are homologous. Earlier in this paper (pp. 48-55), I argued that an unambiguous phylogenetic hypothesis contains no homoplastic states, and that the phylogenist's primary goal is to detect and eliminate all cases of homoplasy from the original data matrix before a tree is derived from it. However, some cases of homoplasy persist in phylogenetic hypotheses derived from all but the most trivial studies because of the 1) imprecise way in which the concept of homology is operationalized, and because of the absence of adequate rules with which to 2) discover the course of character state evolution (the character state tree) and 3) determine the most primitive state of a character. The fact that an organism's phenotype is extremely complicated and difficult to observe and sample must not be overlooked as another major source of the homoplasy in a data set. In the absence of the true tree, the most parsimonious phylogenetic hypothesis serves as the best topology with which to test for these residual homoplasious events because of the wellfounded logical-philosophical bases associated with that particular treeforming algorithm (Kluge and Farris, 1969:7). While even the most parsimonious phylogenetic hypothesis cannot be used to prove that a character's states are homologous, it does call attention to specific instances where original observations and interpretation of homology might be in error, that is homoplasy is predicted.

When homoplasy is predicted, either a genuine case of independent evolution has been discovered or one that is due to some form of error on the part of the investigator: While a true case of independent evolution cannot be established with certainty in the absence of the real phylogeny, actual investigator error of ten becomes more readily apparent when we are forced to focus on a relatively few predicted homoplasious events.

Investigator errors are of three general kinds, observational, clerical and of judgement. By observational, I mean that the scientist's initial perception may be incorrect; that is, a "mental typographical" error exists. It often happens that we think we see something correctly the first time but when forced to focus on it we realize that 
a mistake has been made. Just as a scientist tries to find and correct written typographical errors ( $=$ the clerical class cited above) he should also try to find and correct these mental mistakes. However, by observational error, I do not mean an error in judgement about states being more or less similar and therefore homologous or not. If we allow ourselves to correct the so-called errors of judgement then we cannot be sure that our personal, and perhaps completely subconsciously hidden, biases have not played a significant part in shaping our phylogenetic hypothesis. This kind of reexamination of characters for observational and clerical errors must be done openly, carefully and with complete honesty. The remainder of this section of my paper is devoted to identifying and correcting those kinds of errors, as well as to describing alternative equally parsimonious character state trees and different character state codings. This section will conclude with a discussion of some of the more probable cases of independent evolution. I believe that exceptional cases of evolution such as these will help us to better understand what adaptations are in general and how they are produced by natural selection or arise by chance.

There appear to be quite a few characters in the present study where investigator error, as defined above, is the likely explanation for the predicted homoplasy. The specific reasons for these errors are several, and more than one may apply to a character. For example, I strongly suspect that imprecisely defined character states are responsible for at least some of the predicted homoplasy in characters 5, $10,12,25,34,36,45,50,57,59,64-5,70$, and 74 . The qualitative terms used to describe size and shape in these characters (e.g., large and small, wide and narrow, long and short, pointed and round, shallow and deep, etc.) are particularly suspect. Even the often used qualifiers (e.g., gently, abruptly, greatly, moderately, slightly, strongly, weakly, inconspicuously, markedly, nearly, gradually, etc.) do not add sufficient precision to the size and shape terms to remove the suspicion because they are themselves lacking a precise definition. Precision can be added to the definition of character states by describing them in terms of some other aspect of the individual's phenotype which is taken as a "standard." For example, in character 11, "Ischium wider than pubis $(0)$, or equal to or narrower than pubis (1)," the condition of the pubis is used as the standard. I believe that the predicted homoplasy for some characters used in this study (e.g., 11 and 72) can be attributed to the fact that the "standard" is homoplasious and not a "true standard." I believe that precise redefinition and remeasurement of the states of the above cited characters will remove much of their predicted homoplasy. Wherever time will allow, continous phenotypic variation should be described in metric units rather than arbitrary, discontinuous and hard to define qualitative states (see further discussion on p. 5).

Some instances of homoplasy are almost certainly artifacts of 
the extremely small sample sizes and my comparison of species of different sexes and ages; see Materials on pp. 2-4. Five species, aurita, australis, jicari, pulchella and tincta, were represented by single skeletons, and three others, concinna, orientalis and taeniatus, were studied by means of low voltage X-rays only. I believe it is particularly significant that much of the predicted homoplasy in the data set involves taeniatus, which is known from but a single male and which I studied from only four, difficult to read, monoscopic X-rays. Naturally, the values that I used to characterize all of the above species are particularly prone to sampling error. I believe that poor sampling, rather than genuine independent evolution, is likely to be the explanation for all or some of the homoplasy predicted in characters $19,20,27-30,32,36-8,49,52$, and 55. There are several characters in the data set which exhibit sexual dimorphism and marked ontogenetic variation. The homoplasy predicted for those characters in species represented by only one sex and subadults are almost certainly due to that form of biased sampling. The sexually dimorphic and ontogenetically varying characters in question are 15-8, and $8,12-3,15-8,28-30$, and 45 , respectively.

The phylogenetic hypothesis illustrated in Figure 8 predicts that in character 58, the condition of the posterior-most end of the squamosal, the "partially fused to the exoccipital" character state (2) evolved independently in the $\mathrm{P}$, repens and $\mathrm{Q}$, aurita intervals (Table 10). This predicted homplasy of state 2 forced me to reexamine the character more closely, and I now believe there exists an equally probable alternative character state tree. The alternative character state tree has the form $0 \rightarrow 1 \rightarrow 2$ and with that form character 58 does

not exhibit any homoplasy when mapped onto the phylogenetic hypothesis illustrated in Figure 8 . The character state tree for this character was originally hypothesized to be linear, $0 \rightarrow 1 \rightarrow 2 \rightarrow 3$ (Table 2; Type 3), and it assumed that the absence of the squamosal (state 3) came about through fusion to the exoccipital. The alternative proposed here assumes that the absence of the squamosal came about through that bone's continued reduction in size. Reexamination of the available skeletal material does not provide support for one or the other of the two character state tree hypotheses. Perhaps, the future study of rostrata and smithi, the species most closely related to repens (Kluge, 1974), will provide that support.

Another way of coding the states of character 36 is as follows: Viewed dorsally, posteromedial process of surangular moderately large and pointed (0), posteromedial process of surangular large and round (1), or absent (2). A type 2 character state tree $(0 \rightarrow 1 \rightarrow 2)$ appears to be the more probable hypothesis for this coding. I believe these alterations of character 36 more accurately describe what I observe because the structural changes implied by the character state transi- 
tions now form a more gradual series of modifications. I consider my initial treatment of this character (p. 7 and Table 2) to be an example of an observational error, and accepting my proposed changes removes all of the homoplasy previously predicted for it (according to Fig. 8).

There are 10 characters $(31,39,45,49,52,55,57,65,67$, and 73$)$ for which alternative, equally parsimonious character state trees can be formulated according to the phylogenetic hypothesis illustrated in Figure 8. The alternatives are described in Table 13, and they differ from the original trees listed in Table 10 in the number of predicted convergences and reversals to the primitive state. The alternative hypothesis for character 31 includes a convergence instead of a reversal, while the alternative hypotheses for characters $39,52,55,67$, and 73 include a reversal instead of a convergence. The alternative hypotheses for characters 49 and 57 contain a reversal and a convergence instead of two convergences, while the alternative hypothesis for character 65 involves two reversals instead of one reversal and one convergence. The alternative hypotheses for character 45 includes four convergences and one reversal instead of five convergences.

I favor the alternative hypothesis for character 31 , the condition of the first visceral arch. It hypothesizes the independent evolution of a discontinuity in the arch (state 1) in the L,M and N,O intervals of the phylogenetic hypothesis (Fig. 8). According to the original hypothesis for character 31 , the first visceral arch is predicted to have become reunited in the $\mathrm{N}$, gracilis interval. I can find no structural evidence in the first visceral arch of gracilis that this has actually happened. The very thin and tenuous form of the first visceral arch and the apparent lack of muscle attachment might be used to argue that the first arch has little or no important function and under those circumstances independent separation is to be expected. I know of no one who has demonstrated the absence of function, and in any case under such a random model of evolution it seems that reunion of a discontinuous arch and separation of a continuous arch should be equally probable events (see further discussion on p. 64).

Character 39 (subnareal region of premaxilla toothed [state 0] or toothless [state 1]) is hypothesized in Table 10 to have independently evolved the edentulous state (1). This convergence occurs in the intervals leading to Groups I, the Aprasia species, and III, gracilis (Fig. 8). The alternative, equally parsimonious character state tree listed in Table 13 hypothesizes a reversal, that is the independent acquisition of teeth, in Group II, taeniatus. I doubt if investigator error is responsible for this predicted homoplasy. While I favor the former independent loss hypothesis (Table 10), the reappearance of teeth in the subnareal region of taeniatus might be an accepted interpretation if tooth primordia can be found in gracilis.

Character 45 , the degree of nasal-maxilla contact, is predicted to 
exhibit a relatively large number of homoplasious events (Table 9). The degree of contact between these bones probably varies ontogenetically in pygopodids, as it does in gekkonids (Kluge, 1962), and the fact that I have no evidence that all of the specimens that I compared in the present research are of the same age I conclude that some of the predicted homoplasy is probably due to that sampling problem. I suspect that the recording of the different qualitatively defined character states may be a source of investigator error because of the continuous nature of the variation and lack of an exact measure of "degree of contact." However, the independent evolution of the loss of contact between the nasal and maxilla (state 2) in Groups I, Aprasia species, and III, gracilis, is probably a real case of convergent evolution. There can be no doubt that the individuals examined are adults and that the contact between nasal and maxillary bones is absent. One might expect considerable independent evolution in the snout region of pygopodids given that there has been so much change associated with that region (Kluge, 1974; also see further discussion on p. 63). I know of no evidence that would allow me to conclude which one of the alternative, equally parsimonious character state trees of character 45 is the more probable.

Character 49, the condition of the posterolateral process of the frontal, exhibits three cases of homoplasy of state 1 according to the phylogenetic hypothesis illustrated in Figure 8 (Table 10). State 1, a large and projecting posterolateral process of the frontal is predicted to have evolved de novo in Groups I, III and V. The alternative, equally parsimonious character state tree (Table 13) hypothesizes that the derived state of Groups I and III is homologous, that is it was present in the L,N interval, and that there has been an evolutionary reversal in Group II, taeniatus. I know of no reason to favor one of these alternative hypotheses over the other. However, as emphasized above, the condition recorded for taeniatus may be a sampling error.

Character 52, the size of the lateral process of the postfrontal, and character 55, the shape of the anterolateral corner of the parietal, exhibit evolutionary reversals in Group II, taeniatus, according to the phylogenetic hypothesis illustrated in Fig. 8 (Table 10). The alternative, equally parsimonious hypothesis for each of these characters is listed in Table 13, and it predicts the independent evolution of the derived state (1) in Groups I and III. The x-ray of taeniatus is not very clear in the region of the postfrontal and parietal, and it is likely that that species will upon further study be found to exhibit state 1 rather than 0 in characters 52 and 55. Such corrected observations would remove all of the homoplasy in the two characters given the same phylogenetic hypothesis illustrated in Figure 8.

Character 57, the degree to which the parietals overlap the supraoccipital on the midline, is predicted to contain three instances of homoplasy according to the phylogenetic hypothesis illustrated in 
TABLE 13

LIST OF THE ALTERNATIVE, EQUALLY OR MORE PARSIMONIOUS CHARACTER STATE TREES. ${ }^{1}$

\begin{tabular}{|c|c|}
\hline Character & Interval and (Character State Change). \\
\hline 7 & $\begin{array}{l}\text { Ancestor, A }(0-1) ; \mathrm{A}, \text { lepidopodus }(1-2) \text {; } \\
\mathrm{C} \text {, orientalis }(1-0) ; \mathrm{D}, \mathrm{E}(1-0) ; \mathrm{J}, \text { concinna } \\
(0-1) ; \mathrm{L}, \mathrm{N}(1-2) ; \mathrm{N}, \mathrm{O}(2-3) ; \mathrm{O}, \mathrm{P}(3-4) ; \\
\mathrm{S}, \mathrm{T}(4-3) \text {. }\end{array}$ \\
\hline 31 & $\mathrm{~L}, \mathrm{M}(0-1) ; \mathrm{N}, \mathrm{O}(0-2) ; \mathrm{P}$, repens $(2-3)$ \\
\hline 39 & $\mathrm{~L}, \mathrm{~N} \quad(0-1) ; \mathrm{O}$, taeniatus (1-0). \\
\hline 45 & $\begin{array}{l}\mathrm{A} \text {, lepidopodus }(0-1) ; \mathrm{I} \text {, tincta }(0-1) \text {; } \\
\mathrm{K} \text {, australis }(0-1) ; \mathrm{L}, \mathrm{N}(0-1) ; \mathrm{N} \text {, gracilis }(1-2) \text {; } \\
\mathrm{O} \text {, taeniatus }(1-0) ; \mathrm{O}, \mathrm{P}(1-2)\end{array}$ \\
\hline 49 & $\mathrm{D}, \mathrm{E}(0-1) ; \mathrm{L}, \mathrm{N}(0-1) ; \mathrm{O}$, taeniatus (1-0). \\
\hline 52 & $\mathrm{~L}, \mathrm{~N}(0-1) ; \mathrm{O}$, taeniatus $(1-0)$ \\
\hline 55 & L,N (0-1); O, taeniatus (1-0). \\
\hline 57 & $\mathrm{~L}, \mathrm{M} \quad(0-1) ; \mathrm{Q}, \mathrm{R} \quad(0-1) ; \mathrm{S}$, striolata $(1-0)$ \\
\hline 65 & $\begin{array}{l}\text { B,D }(0-1) ; N \text {, gracilis }(1-0) ; O \text {, taeniatus }(1-0) \text {; } \\
\text { O,P }(1-2) \text {. }\end{array}$ \\
\hline 67 & $\mathrm{~B}, \mathrm{D}(0-1) ; \mathrm{L}, \mathrm{M} \quad(1-0) ; \mathrm{N}, \mathrm{O}(1-2)$. \\
\hline 73 & $\mathrm{D}, \mathrm{L}(0-1) ; \mathrm{M}$, jicari $(1-0)$. \\
\hline
\end{tabular}

${ }^{1}$ These are alternatives to those given in Table 10 , and they are equally or more parsimonious according to the cladistic topology of pygopodid lizards illustrated in Fig. 8.

Figure 8. These are listed in Table 10 and they involve the independent evolution of the derived state in the intervals $L, M, R$, pulchella and S,T. The alternative, equally parsimonious hypothesis for this character's evolution is described in Table 13. The differences between the alternatives involve the evolution of the derived state in both pulchella and parapulchella and pseudopulchella (the original hypothesis) and the reappearance of the 0 state in striolata. I know of no reason to favor one of these hypotheses over the other. As I discussed above; the imprecise coding of the states of this character may be the basis for the predicted homoplasy.

The shape of the median margin of the palatines, character 65 , has a relatively low consistency index $\left(c_{65}=0.5\right.$, Tables 8-9). 
According to Table 10 and the phylogenetic hypothesis illustrated in Figure 8 , the derived state is convergent in the intervals $B, D$ and $O, P$ and the primitive state reappears in the $\mathrm{L}, \mathrm{N}$ interval. The alternative equally parsimonious character state tree is listed in Table 13; it predicts the independent reversal to the primitive state in the $\mathrm{N}$, gracilis and $\mathrm{O}$, taeniatus intervals. I know of no evidence that would favor one of these hypotheses over the other, and in any case, as discussed above, it seems likely that the character's states have been miscoded.

Character 67 concerns the shape of the anterior portion of the ectopterygoid (p. 8). According to the phylogenetic hypothesis illustrated in Figure 8, state 1 (a relatively wide and pointed ectopterygoid) is predicted to have evolved independently in the $\mathrm{D}, \mathrm{E}$ and L,N intervals (Table 10). The former interval is immediately ancestral to Group V and the latter to Groups I, II and III. The alternative, equally parsimonious character state tree hypothesis (Table 13) predicts a reversal to the most primitive state, a very narrow and slightly pointed ectopterygoid, in the interval $(\mathrm{L}, \mathrm{M})$ immediately ancestral to Group IV. A reexamination of this character in the material now available to me does not provide support for one or the other of these two hypotheses. My imprecise definition of the states may have produced a spurious homoplasious event in this character.

The main difference in the alternative, equally parsimonious character state trees of character 73 involves the predicted history of the size of the basitrabecular process of the pterygoid in the two Group IV species, burtonis and jïcari. In one of the character state tree hypotheses (Table 10), the derived state (1), a small or absent basitrabecular process, is predicted to have appeared independently in burtonis, while in the other hypothesis (Table 13), jicari is predicted to have reevolved the primitive state $(0)$, a large basitrabecular process. The possibility of sampling error in jicari is quite high (as discussed above). Should that be the case with character 73, homoplasy and the alternative character state tree would disappear.

The numbers of scleral ossicles (character 27) and mandibular (character 28), maxillary (character 29) and premaxillary teeth (character 30) are predicted to be homoplastic in the Pygopodidae. Investigator error is a very likely explanation for some of that homoplasy. To begin with, tooth number (Kluge, 1962), but probably not ossicle number, varies ontogenetically. Furthermore, the few data available on Group I suggest that tooth number is sexually dimorphic. Some of the predicted tooth homoplasy is, therefore, expected to be due to my inadequate age and sex sampling of pygopodids. Both the ossicles and teeth are difficult to count. The overlapping nature of the ossicles, their small size and the fact that an ossicle can split lengthwise during eyeball extraction must all contribute to investigator error. The nature of the loss and replace- 
ment of reptile teeth (Edmund, 1969) probably contributes most significantly to the observational error. Also, the asymmetrical differences that exist in an individual pygopodid forces me to conclude that at least some of the observed phenotypic variation is enviromental and not heritable.

There are two general trends in scleral ossicle number that do not appear to involve homoplasy or investigator error (p. 55). Ossicle number increases in Group IV and it decreases in Groups I-III. I hypothesize that both of these sets of changes are real and due to natural selection. These two trends are most obviously correlated with the exceptional diurnal activity of Group IV species and the subterranean habits of the species in Groups I-III (Kluge, 1974). The anatomical relationships between the ossicles and the eyeball and the suspected importance of the ossicles in accommodation (Walls, 1942; Kluge, 1967) suggest functional bases on which natural selection might have acted in forming these trends in the Pygopodidae. Larger numbers of ossicles may improve accommodation in the highly active and diurnal Group IV species, burtonis and jicari, the lower numbers of wider elements may be more effective in maintaining the shape of the eyeball when the sand and soil presses on the side of the head in the fossorial species of Groups I-III.

There are two general patterns of interspecific variation in tooth number in the Pygopodidae that do not appear to involve homoplasy and investigator error (p. 55). There is a decrease in the number of premaxillary teeth; large numbers (12-13) are typical of Groups V and VI and few or none are found in I and II (0-5). Intermediate numbers of premaxillary teeth are characteristic of the phylogenetic intermediate Groups III and IV (Fig. 8). As might be expected from functional considerations the general patterns of mandibular and maxillary too $h$ variation are concordant. Maxillary and mandibular tooth number is predicted to decline in the Pygopodidae; the trend begins with Group VI and culminates in I. Groups V, III and II possess intermediate numbers between these extremes. Group IV species, burtonis and jicari, markedly deviate from this trend in that they possess large numbers of mandibular and maxillary teeth. The different food habits of pygopodids (Kluge, 1974) are correlated with the major differences in tooth numbers. Group I species are exceptional in that they are largely, if not exclusively, myrmecophagous, while Group IV species are unique within the family in that they only eat other lizards, particularly skinks. I suggest that the reduced numbers of teeth in pygopodids is related to capturing and processing small numerous food items like ants, and that the large numbers of teeth are advantageous in capturing, holding and manipulating attenuate struggling prey like skinks. The unexpected small numbers of premaxillary teeth in the Group IV species are correlated with the relatively narrowest snouts found in the family. Presumably, as the narrower snout evolved the possession of smaller numbers of large 
premaxillary teeth was selected for over the condition of larger numbers of small teeth.

Twenty-one $(37-48,53,59-64,66-7)$ of the 86 characters used in my study of pygopodid relationships describe variation in some part of the snout. Many of those characters, 13 of 21 (37-9, 42, $45-8,59,61,64,66-7)$, exhibit one or more homoplasious events (Table 8) according to the phylogentic hypothesis illustrated in Figure 8. I believe that some, and perhaps most, of this predicted homoplasy is the product of natural selection and not chance evolution or investigator error. It is quite evident that the snout region of pygopodids, like most snake-like lizards, has undergone considerable divergence and accordingly it has probably been under strong natural selection. The interspecific differences are not only reflected in the skeleton (Stephenson, 1962) but in numerous scale and morphometric characters as well (Kluge, 1974). The conspicuous interspecific differences in food preferences and microhabitat related to locomotion (Kluge, 1974) are the most obvious functional corollaries of the structural variation seen in the snout region.

Character 38 provides a clear example of one of the major trends in the evolution of the snout of pygopodids, and it seems reasonably certain that at least some of its predicted homoplasy is real independent evolution. Character 38 concerns the varying length of the nasal process of the premaxilla; I believe the predicted homoplasy of its states 1 and 2, which involve the shortening of the nasal process in the O,P interval (Table 10), to be due to natural selection. The little intraspecific variation and the ease with which the states can be discerned are the prime reasons for my ruling out chance and investigator error. The relatively short snouts of the species derived from the O,P interval, all of which have been previously referred to the genus Aprasia (Kluge, 1974), are strikingly different from the relatively much longer snouts of the species with which they are considered to be convergent. It is not clear what the adaptive basis for the convergent evolution in character 38 is but I doubt it if has anything to do with changes in the overall length of the snout.

I interpreted the presence of a bone in the midclavicle region of gracilis as a derived condition (Character 2), that is as a uniquely evolved neomorph. Previously, Stephenson (1962) referred to that element in gracilis as the interclavicle and in doing so he implied that it is homologous with the interclavicle found in gekkonids and most other lizards. I believe my interpretation to be more likely than Stephenson's; at least it is a much more parsimonious conclusion. To hypothesize that the interclavicle is present in gracilis assumes that that bone has been lost at least five times independently in the Pygopodidae (e.g., at the nodes A, B, D, L, and O of the tree illustrated in Fig. 8). It also supposes that there has been strong selection for its retention in but only one of the surviving pygopodid 
lineages. While the midclavicle bone of gracilis is in the correct position, with respect to the other pectoral girdle elements, to be considered the interclavicle it appears to be much too variable in shape, size and attachment to adjacent bones to be considered so without question. Studies of the embryology and function of the midclavicle bone in gracilis are certain to provide insight into this interesting issue.

There are quite a few predicted homoplasious events in the data set for which investigator error may not be responsible. In the absence of strong evidence to the contrary, I conclude that there probably exists some genuine examples of independent evolution in characters 7,13 , $15-8,26,38-9,42,45-8,59,61,66,70-1$, and 81 .

Character 7, the size and shape of the clavicles, is one of the most interesting in the pygopodid data set. It is very homoplastic (Table $\left.9 ; c_{7}=0.36\right)$, much more so than I initially thought it would be and there exists an alternative and more parsimonious character state tree than the one listed in Table 10. The more parsimonious tree hypothesis (Table 13) suggests that the small clavicles found in parapulchella and pseudopulchella reevolved in their most recent common ancestor ( $\mathrm{T}$ in Fig. 8). The original tree hypothesis for this character (Table 10) describes the clavicles as being lost independently in aurita, pulchella, repens and striolata. All of the aforementioned species belong to Group I (Table 4, Fig. 8) which is taxonomically equivalent to the genus Aprasia (Kluge, 1974). Basically, in choosing between the two trees one is concerned with the probability of independent loss versus independent gain of a bone. In this instance, I favor the less parsimonious independent loss hypothesis listed in Table 10 because it fits what I believe to be the most probable model for the evolution of small and presumably vestigal structures. My reexamination of the clavicles in the specimens available not only reaffirms that the bone is extremely small but it forces me to note that there is considerable variation in shape and number of separate centers of ossification per side in an individual. In particular, there are size and shape differences between the two clavicles of a parapulchella and a pseudopulchella (see Fig. 10), and furthermore, I cannot locate the clavicle in one specimen of pseudopulchella. The kind and degree of variation in these species, only some of which is illustrated in Figure 9, leads me to conclude that the clavicle of Group I species is under weak or no natural selection. I propose that once a clavicle is reduced to some small size, and perhaps loses its contact with the other bones of the pectoral girdle, it becomes functionless. I hypothesize that there exists some small size for all bony elements where further reduction, even complete loss, no longer effects an individual's fitness. At or beyond that threshold of size the complete disappearance of the element is random. If this explanation holds for character 7 then the independent loss is not due to predictable evolutionary factors, such as natural selection, but to chance. Under this model I would expect to find considerable clavicle 


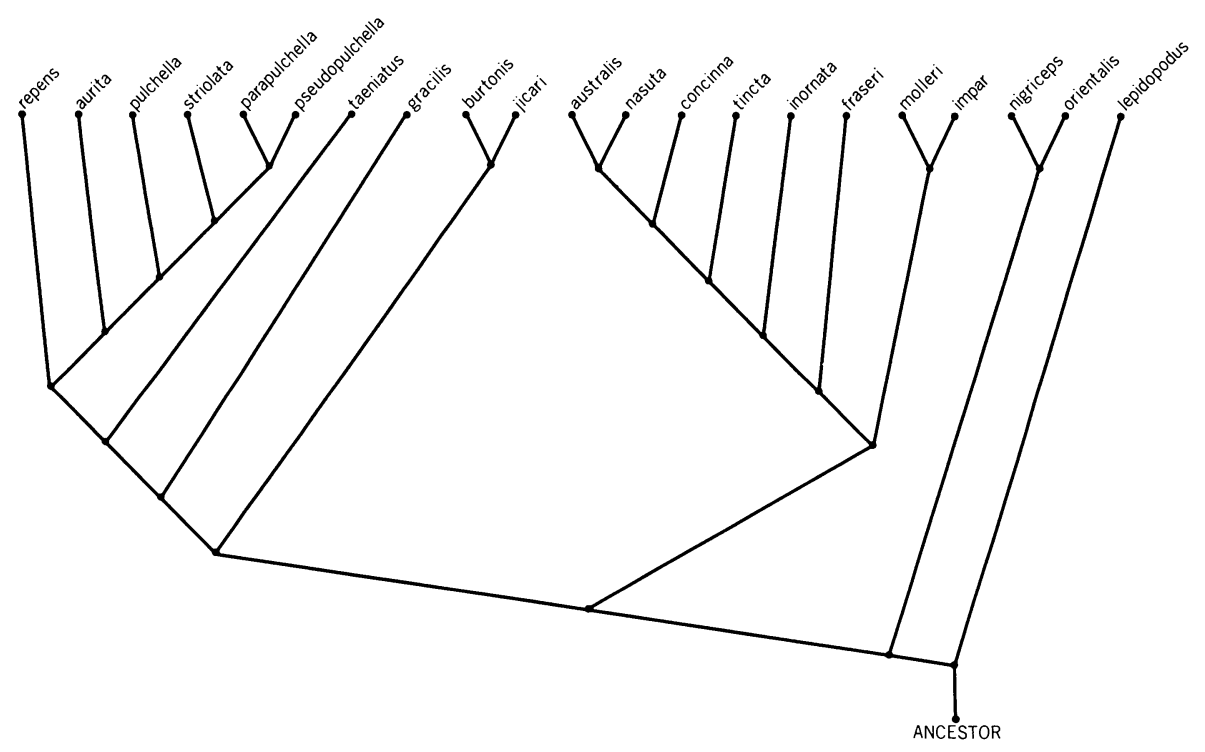

Fig. 9. A phylogenetic hypothesis of 21 species of pygopodids. It is identical to Fig. 8 except it distorts the patristic estimate. It retains the cladistic aspect without modification although all of the species are placed on the same horizontal level to emphasize their contemporaneity.

variation within and among local populations of parapulchella and pseudopulchella.

The hindleg and foot of pygopodids together form a structurally simple paddle-like flap that is usually tightly adpressed to the side of the body. Separate toes cannot be distinguished externally nor can the limits of the foot and lower and upper sections of the leg. Extension of the paddle is rarely observed in living individuals and usually only then in the species with the longest appendage (e.g., lepidopodus and nigriceps). Extension of the paddle involves the hip joint and little if any bending can be detected at the level of the knee and ankle. Characters 13 through 18 (Table 1-2) describe the reduction in size and ultimate loss of most of the bones in the paddle. Except for 14, the condition of the cuboid and tibiofibulare, these characters are predicted to be quite homoplastic (Table 8), and almost all of that independent evolution occurs among the species of Groups V and VI (Tables 4, 10-11; Fig. 8). Given that most of the changes in the bones involve shortening I would predict the overall length of the limbs to be similarly homoplastic. This can be confirmed when the average number of hind limb scales (HLS) listed for each species in Kluge (1974) is used to estimate paddle length and when those values are mapped onto Figure 8. The Group II and III species, taeniatus and gracilis, are the only obvious exceptions to this generalization in that their limbs are longer than 
A
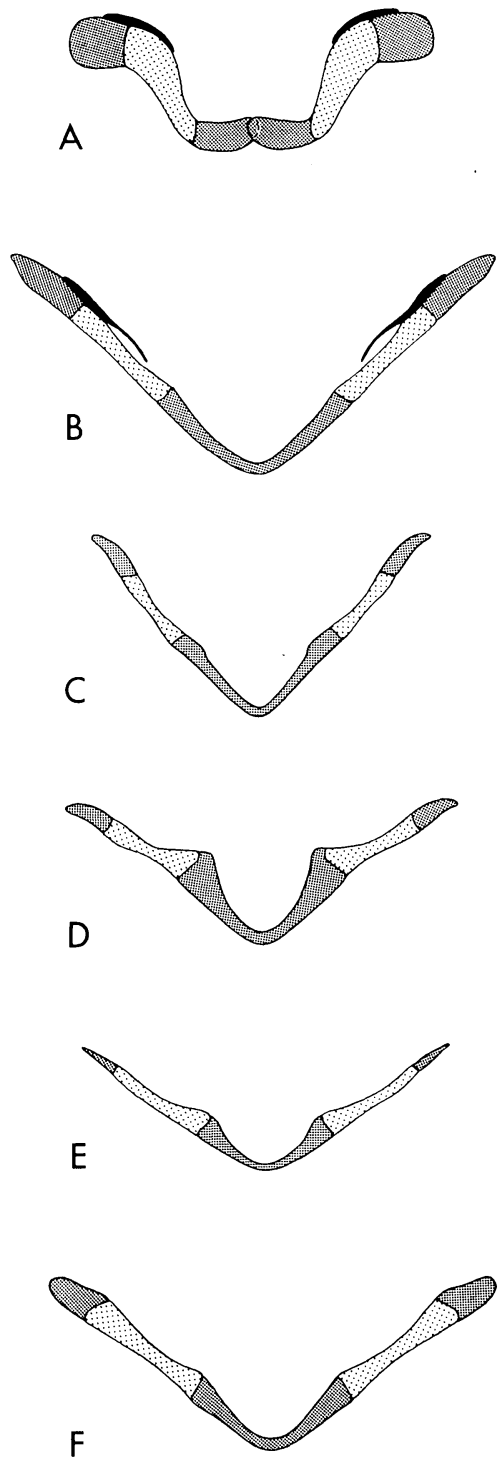
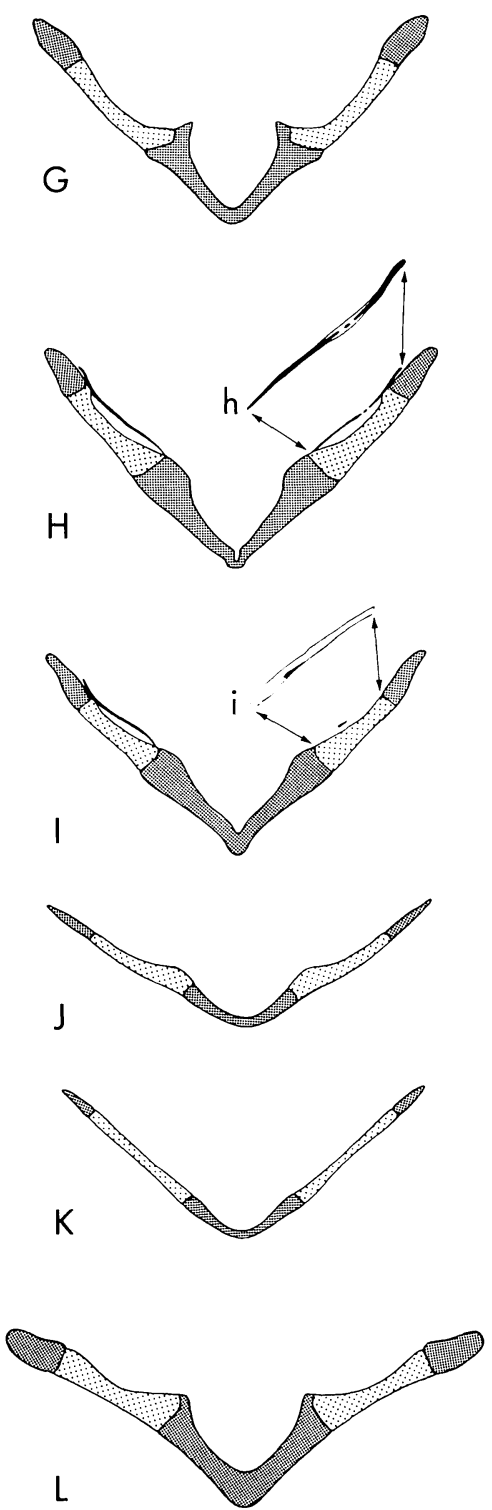

$1 \mathrm{~mm}$

Fig. 10. A ventral view of the pectoral girdle of selected pygopodid lizards. The clavicle is solid black; the $\mathrm{h}$ and $\mathrm{i}$ magnify that bone and emphasize individual variation. The finely stippled bone on the midline is believed to be fused epicoracoids; in Ophidiocephalus taeniatus (A) they overlap but do not fuse. The distal most finely stippled bones are suprascapulae. The scapulocoracoid is the coarsely stippled bone between the suprascapula and epicoracoid. A. Ophidiocephalus taeniatus; NMV D11761. B. Aprasia 'pseudopulchella; UMMZ 131210. C. Aprasia pseudopulchella; UMMZ 131208. D. Aprasia pulchella; UMMZ 131235. E. Aprasia repens; UMMZ 129979. F. Aprasia striolata; UMMZ 131180. G. Aprasia aurita; UMMZ 131224. H. Aprasia parapulchella; UMMZ 131193. I. Aprasia parapulchella; UMMZ 131157. J. Aprasia repens; UMMZ 137573. K. Aprasia repens; UMMZ 129978. L. Aprasia striolata; ' UMMZ 131176. 
expected. How does one explain the origin of the homoplasy in the skeletal characters of the paddle, most of which involves the phalanges? Hind limb size (HLS) differs between males and females in but one species, lepidopodus (Kluge, 1974), and paddle length does not appear to vary ontogenetically. Thus, poor specimen sampling of the sexes and sizes are not likely explanations. I believe any attempt to answer this question must recognize the good correlation between the predicted order of loss of the digits and the degree of homoplasy (Table 8). I concur with Gans (1975) who described toe loss in lizards with reduced limbs, such as pygopodids, as usually occuring centripetally; the order of reduction and loss first involves digit I, then $\mathrm{V}$, then II, then IV and lastly III. I would expect such a correlation as I have found to exist under circumstances of natural selection (Kluge and Kerfoot, 1973) but not chance. I must, therefore, conclude that numerous genuine cases of independent evolution due to natural selection is the most likely interpretation and that the random model used to explain the independent loss of the clavicles does not apply here.

\section{INTRAFAMILIAL CLASSIFICATION}

Six Groups of pygopodid species are clearly differentiated by the principal component anaylsis (Figs. 1-2) and the Prim and Wagner networks (Figs. 3-4). The most parsimonious phylogenetic hypothesis illustrated in Figure 8 also delimits these same clusters. The Group membership and their relationship to previous generic taxonomy were described on pp. 10-16 (Table 4). Group I consists of aurita, parapulchella, pseudopulchella, pulchella, repens and striolata, and they have all been referred to the genus Aprasia. Groups II and III are monotypic; Ophidiocephalus is the generic name applied to the Group II species taeniatus and Pletholax to the Group III species gracilis. Group IV consists of burtonis and jicari, which are the only members of the genus Lialis. Group V consists of a relatively tight cluster of species, australis, concinna, fraseri, impar, inornata, molleri, nasuta and tincta, that have been referred to the genera Aclys (concinna only) and Delma. Group VI consists of lepidopodus, nigriceps and orientalis; the former two species have been referred to Pygopus and the latter is the only member of the genus Paradelma. These six Groups of species are defined by a relatively large number of uniquely evolved character states. All other monophyletic clusters in the phylogenetic hypothesis (Fig. 8) are not so unambiguously defined. The most parsimonious phylogenetic hypothesis (Fig. 8) orders the six Groups in a nearly linear cladistic array from the most primitive VI to the most modified I. V and VI are the least different patristically (8.3) and III and IV differ the most (62.5). The patristic differences separating IV and V (42.3), II and III (25), and I and III 
A
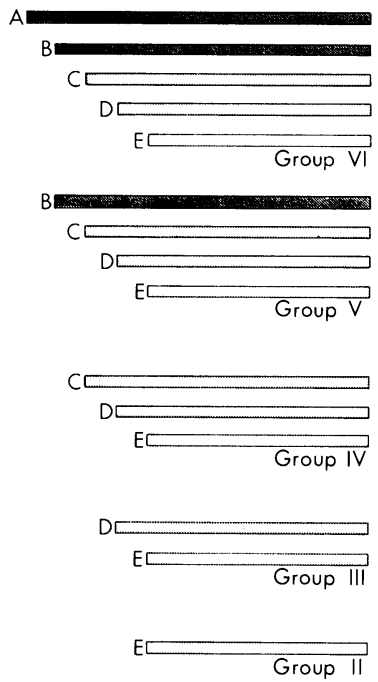

Group 1
B
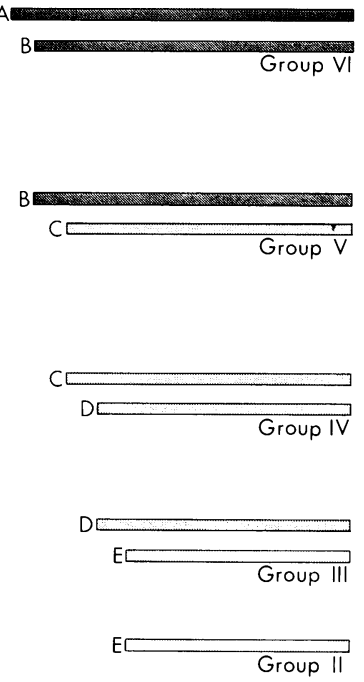

Group I
C

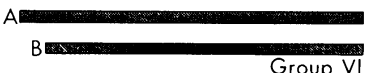

Group VI

Group V
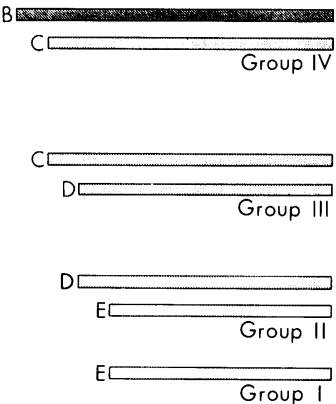

Fig. 11. Three of the possible hierarchic classifications of pygopodid lizards. In the text (p. 69), inclusive category $\mathrm{A}$ is interpreted as the family taxon, B the subfamily, C the tribe, D the subtribe, E the supergenus and the Group as the genus. The Roman numerals refer to the groups of species defined in Table 4 .

(26) are intermediate between these patristic extremes. The questions are: Do any or all of these robust cladistic and patristic conclusions demand changes at the present generic level of classification? Do they provide a basis for a formal classification between the generic and family taxonomic levels?

According to the most parsimonious phylogenetic hypothesis (Fig. 8), the only species that might require new generic reclassifications are concinna and orientalis. While the skeletal characters studied herein clearly place these two within clusters of species referred to other genera, I believe it is advisable to continue to refer them to their own monotypic taxa above the species level. I base my position on the several unique scalational characters that distinguish each of them from all other pygopodids (see Kluge, 1974). Referring concinna to the subgenus Aclys within the genus Delma, and orientalis to the subgenus Paradelma within the genus Pygopus appears to offer the best solution for the reclassification of the species within Groups V and VI.

In my opinion there are only two reasonable alternative classifications of pygopodid lizards above the level of genus, and these are illustrated in Fig. 11. The cladistic parameter illustrated in Figs. 8-9 is faithfully represented in Fig. 11A and 11B. Fig. 11A is nomenclaturally complete, while Fig. $11 \mathrm{~B}$ is simplified to a minimum of categories. 
Fig. 11C does not faithfully reproduce the cladistic relationship of Group V, but it does better reflect how relatively little patristically different it is from VI. There appears to be no overwhelming argument for choosing one of the two alternatives (Fig. 11A and $11 \mathrm{~B}$ versus $11 \mathrm{C}$ ). I tend to favor Fig. $11 \mathrm{C}$, and the following classification of the family Pygopodidae reflects that preference. Each of the taxonomic categories can be diagnosed by referring to Table 11. The species in the classification that are followed by an asterisk have not been studied in this paper; their taxonomic position is inferred from Kluge (1974).

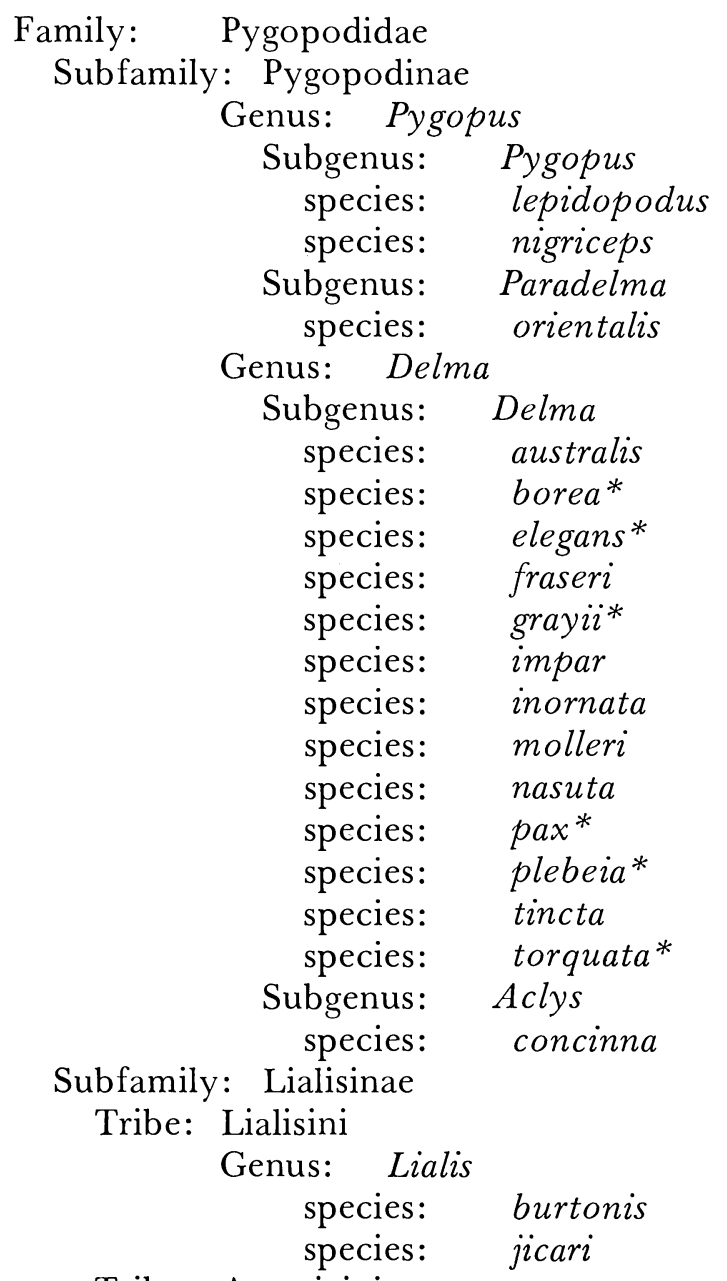

species: burtonis

Tribe: Aprasiaini

Subtribe: Pletholaxini

Genus: Pletholax

species: gracilis 


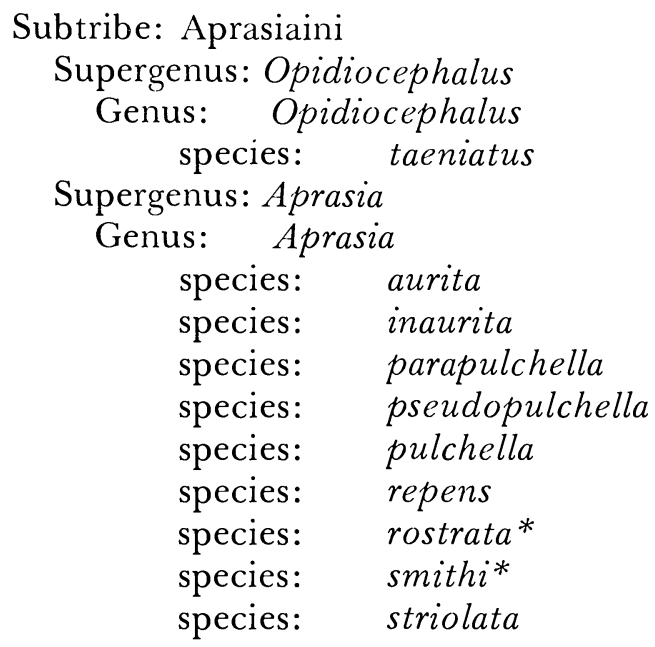

\section{SUMMARY}

Eighty-six binary and multistate skeletal characters were employed in the estimation of the phylogenetic relationships among 21 species of pygopodids. The principal component statistic and Prim and Wagner networks and Wagner tree algorithms were applied to these data. The same well defined six groups of species were delimited in all applications. The most primitive group, consisting of lepidopodus, nigriceps and orientalis, is cladistically ancestral to the assemblage made up of australis, concinna, fraseri, impar, inornata, molleri, nasuta and tincta. The third group consisting of burtonis and jicari is distantly related to and derived from the australis, et al. cluster. Gracilis is cladistically intermediate between the burtonis and jicari assemblage and the monotypic group that is represented by taeniatus. The most highly modified group of species consists of aurita, inaurita, parapulchella, pseudopulchella, pulchella, repens and striolata, and it has its most recent common ancestor with the taeniatus group. These consistently observed clusters are not predicted by any particular subset of characters. The concept of primitiveness is reviewed. The relative nature of the most primitive state is emphasized, and the widely used rules, based on relative frequency of state occurrence, for estimating the most primitive state of a character are stated and defended. These rules were employed in the estimation of the primitive state of each of the 86 characters in the pygopodid data set and the specific assertions and assumptions associated with each prediction are listed. Each character was reexamined in light of the phylogenetic hypothesis generated by the Wagner tree algorithm. Each monophyletic group in the hypothesis is defined by numerous uniquely evolved character states. Some of the pre- 
dicted homoplasious character states in the data set are believed to be due to observational and clerical errors. The small numbers of specimens of a few species and the sexually dimorphic and ontogenetically varing nature of certain characters probably contribute to sampling biases that can explain other cases of homoplasy. Alternative, equally parsimonious character state trees are evaluated on biological grounds and predictions are made for their further study. Some of the independent evolution predicted by the Wagner tree can be explained as the chance loss or gain of a vestigial state, while others appear to be due to natural selection. The adaptive significance of some of the predicted character state trees are discussed. A classification of pygopodids is presented that combines the more obvious cladistic and patristic features of the Wagner tree phylogenetic hypothesis.

Le Quesne's method of determining character incompatibility was applied to the pygopodid data set. There are 1006 unique sets of cladistically compatible characters; four of these sets have the same maximum number of characters. The estimates of the cladistic parameter of pygopodid phylogeny using the largest sets of compatible characters are different in many ways from the Wagner tree hypothesis. At least some of these differences are probably due to sampling biases. Le Quesne's method does not appear to be as useful a tool in phylogenetic inference as previously thought.

\section{LITERATURE GITED}

Edmund, A.G. 1969. Dentition. pp. 117-200. In C. Gans, A. d'A Bellairs and T. Parsons (eds.). Biology of the Reptilia. vol. 1 Academic Press, New York.

Estabrook, G.F. 1972. Cladistic methodology: a discussion of the theoretical basis for the induction of evolutionary history. Ann. Rev. Ecol. Syst., $3: 427-56$.

Farris, J.S. 1970. Methods for computing Wagner Trees. Syst. Zool., 19:83-92.

1971. The hypothesis of nonspecificity and taxonomic congruence. Ann. Rev. Ecol. Syst., 2:277-302.

Farris, J.S., A.G. Kluge and M.J. Eckardt. 1970. A numerical approach to phylogenetic systematics. Syst. Zool., 19:172-89.

Fisher, R.A. 1958. The genetical theory of natural selection. 2nd revised edition. Dover Publ., New York.

Gans, C. 1975. Tetrapod limblessness: evolution and functional corollaries. Amer. Zool., 15:455-67.

Hennig, W. 1966. Phylogenetic systematics. Univ. Illinois Press, Chicago.

Hoffstetter, R. 1964. Les Sauria du Jurassique supérieur et spécialement les Gekkota de Baviére et de Mandchourie. Senck. Biol., 45:281-324.

Kluge, A.G. 1962. Comparative osteology of the eublepharid lizard genus Coleonyx Gray. J. Morph., 110:299-332.

1967. Higher taxonomic categories of gekkonid lizards and their evolution. Bull. Amer. Mus. Nat. Hist., 135:1-60.

1971. Concepts and principles of morphologic and functional studies. pp. 3-41. In A.J. Waterman et al. Chordate structure and function. Macmillan Co., New York. 
1974. A taxonomic revision of the lizard family Pygopodidae. Misc. Publ. Mus. Zool., Univ. Mich., 147:1-221.

1975. Phylogenetic relationships and evolutionary trends in the eublepharine lizard genus Coleonyx. Copeia, 1:24-35.

Kluge, A.G. and J.S. Farris. 1969. Quantitative phyletics and the evolution of anurans. Syst. Zool., 18:1-32.

Kluge, A.G. and W.C. Kerfoot. 1973. The predictability and regularity of character divergence. Am. Nat., 107:426-42.

Le Quesne, W.J. 1969. A method of selection of characters in numerical taxonomy. Syst. Zool., 18:201-5.

1974. The uniquely evolved character concept and its cladistic application. Syst. Zool., 23:513-7.

Lundberg, J.G. 1972. Wagner networks and ancestors. Syst. Zool., 21:398-413.

Mayr, E. 1969. Principles of systematic zoology. McGraw-Hill, New York.

Moffat, L.A. 1973. The concept of primitiveness and its bearing on the phylogenetic classification of the Gekkota. Proc. Linn. Soc. N.S.W., 97:275-301.

Savage, J.M. 1973. The geographic distribution of frogs; patterns and predictions. pp. 351-445. In J.L. Vial, Evolutionary biology of the anurans; contemporary research on major problems. Univ. Missouri Press, Columbia, Missouri.

Sneath, P.H.A. and R.R. Sokal. 1973. Numerical taxonomy. W.H. Freeman, San Francisco.

Sokal, O. 1975. The phylogeny of anuran larvae: a new look. Copeia, 1:1-23.

Stephenson, N.G. 1962. The comparative morphology of the head skeleton, girdles and hind limbs in the Pygopodidae. J. Linn. Soc., Zool., 44:62 7-44.

Underwood, G. 1957. On lizards of the family Pygopodidae. A contribution to the morphology and phylogeny of the Squamata. J. Morph., 100:207-68. 1971. A modern appreciation of Camp's "Classification of the lizards." pp. vii-xvii. In Camp's Classification of Lizards. Soc. Stud. Amphibians Reptiles.

Wagner, W.H., Jr; 1961. Problems in the classification of ferns. pp. 841-4. Recent Advances in Botany. Univ. Toronto Press, Toronto.

Walls, G.L. 1942. The vertebrate eye and its adaptive radiation. Cranbrook Inst. Sci. Bull., 19:1-785. 

